Linköping Studies in Science and Technology

Dissertation No. 2115

\title{
On the other side of change:
}

Exploring the role that design can play in retaining sustainable doings

Wanjun Chu
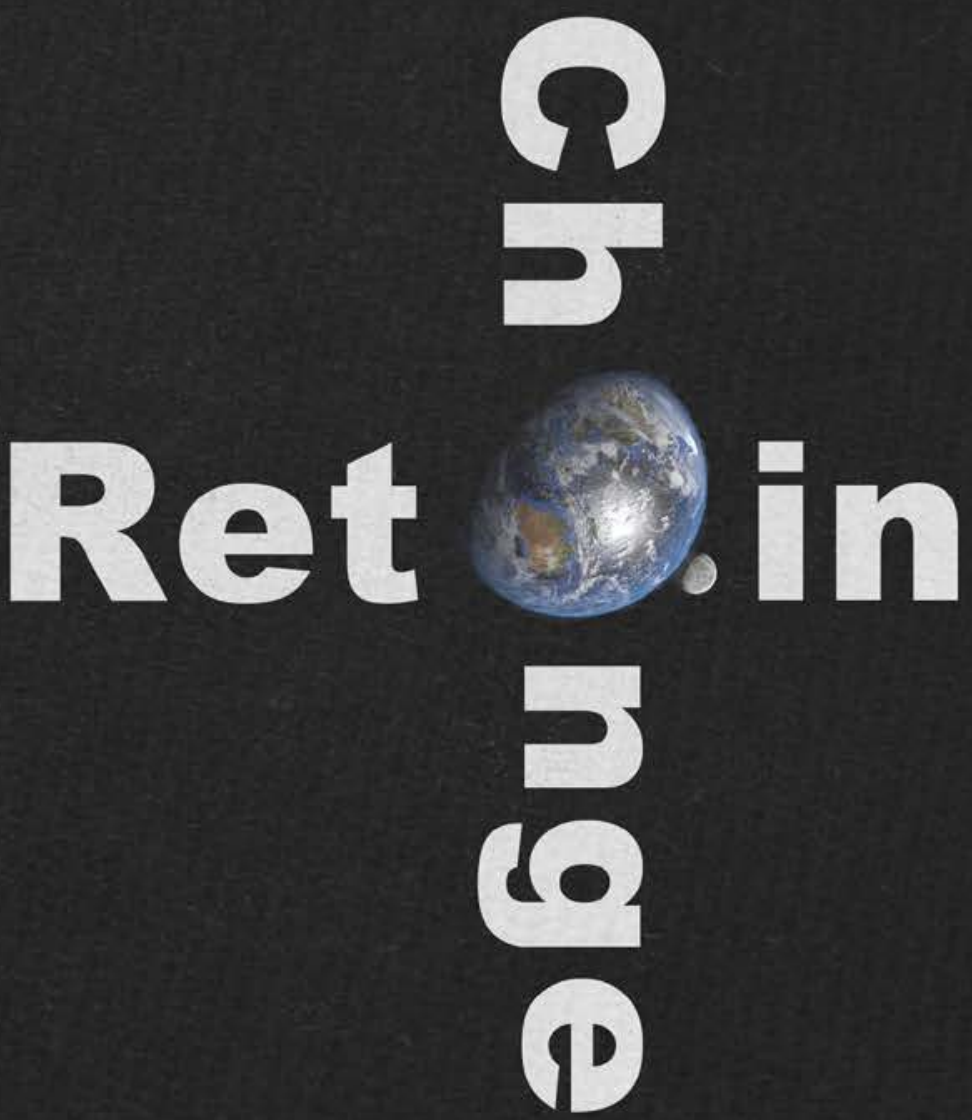



\title{
On the other side of change
}

Exploring the role that design can play in retaining sustainable doings

\author{
Wanjun Chu
}

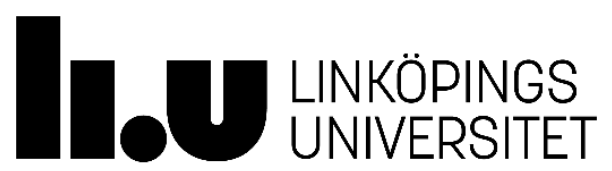

Department of Management and Engineering,

Division of Machine Design

Faculty of Science and Engineering

Linköpings universitet, SE-581 83 Linköping, Sweden

Linköping 2021 
(C) Wanjun Chu, 2021

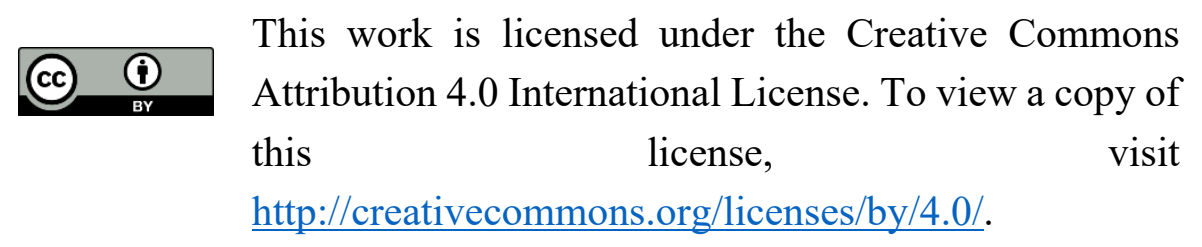

Printed in Sweden by LiU-tryck, 2021

ISSN: 0345-7524

ISBN: 978-91-7929-716-9 
To my family and friends 
"Beneath this mask there is more than flesh, beneath this mask there is an idea, and ideas are bulletproof."

-- V for Vendetta 


\section{Abstract}

The world keeps changing more rapidly. Induced by context change disruptions such as individual life-course changes and macro socio-economical events, the way people carry out their everyday life doings is also undergoing a dynamic transition process, which may open up windows of opportunity for design to transit people's behavior in a more sustainable direction.

A successful behavior transition entails not only changing people's wrongdoings but also retaining the existing desired doings. However, over the last decade, the field of Design for Sustainable Everyday Life seems to have grown accustomed to the concept of change. The potential role that design may play in retaining people's existing sustainable doings has been ill-addressed. This dissertation aims to develop an activity-based theoretical approach to help design researchers and practitioners better understand how people transit behavior when they undergo context change disruptions, and further explore design implications informed by the sustainable behavior retention perspective.

The study comprises two parts. In the first part, six explorative case studies were used to investigate the applicability of adopting activity theory (AT) as a theoretical lens for understanding context change-induced behavior transition phenomena. As a result, an ATbased framework was iterated, developed and validated. In the second part, by incorporating the proposed framework with the theoretical understanding generated from a prescriptive meta-synthesis study, an AT-informed toolkit prototype was developed and evaluated.

Three key findings can be identified. First, at a conceptual level, the study reveals that the design for sustainable behavior retention perspective may complement the design for behavior change perspective by facilitating a bottom-up and context-focused relative approach to achieve sustainability. Second, at a design analytical level, three dimensions of AT: i). hierarchical structure, ii). long-term development and iii). reality-based contextual scales of analysis are especially useful for systematically analyzing the impacts of context change disruptions on people's everyday life doings. Third, at a design synthesis level, the ATinformed design toolkit prototype and the extracted design implications can provide a systemic view that helps designers take both sustainable behavior change and retention perspectives into early-stage design ideation.

The contribution of the dissertation is two folds. First, it introduces the perspective of sustainable behavior retention into the field of Design for Sustainable Everyday Life. Second, it provides an activity-based theoretical framework as a potential lens for designers to better cope with context change disruptions.

Keywords: Design for sustainable behavior, behavior retention, behavior change, sustainable design, context change, activity theory 



\section{Acknowledgment}

Note that 谢谢 ("Xiexie") means thanks.

谢谢 my main supervisor Professor Renee Wever. Thank you very much for motivating me to explore the research topic that I am interested in, encouraging me to go out of my comfort zone. Thank you very much for your input, both research-wise and personal developmentwise. All in all, thank you very much for giving me such a precious opportunity to be your $\mathrm{PhD}$ student. It has been a really wonderful journey for me. "May the force be with you!"

谢谢 my secondary supervisor Wiktoria Glad. Thank you for supporting me all the way, encouraging me when I felt a bit down, giving me advice and answering my silly questions.

谢谢 my officemates and those colleagues who frequently visit me in the office: Goushenshen, Malinlin, Juanjuan, Daweiwei, NazNaz, Mats, Anton, Ludvig, Martijn, Fredrik, T-bear, David E, and of course Nike the office dog. You made my PhD study full of wonderful memories (maybe you also made my PhD study a little longer than I had expected).

谢谢 the Division of Machine Design at Linköping University for letting me do my research here. 谢谢 to those people in the smaller "research" groups: Banana Republic, Four Housemen of Awesome, Resor to China, Team MASKIN and The PhD council.

谢谢 my Chinese friends in Stockholm, Uppsala and Linköping for feeding me with home-made Chinese food. A special thanks goes to Maomao and his master!

Most important of all，谢谢老爸老妈的支持.

Linköping, December 2020

Wanjun Chu 


\section{Appended papers}

Paper I

Chu, W., Glad, W., \& Wever, R. (2019). Embracing Change While Retaining the Existing: Sustainable Behaviour Design Insights from Astronaut Food Consumption Transitions. In Proceedings of $8^{\text {th }}$ International Congress of International Association of Societies of Design Research: Design Revolutions, 2-5 September 2019, Manchester, UK.

Contribution: Chu conceived the study, carried out the data collection and analysis, and wrote the paper with feedback from the rest of the authors throughout the research process.

Paper II

Chu, W.; Steenstra, P.; Glad, W.; Wever, R. Understanding context change: An activity theoretical analysis of exchange students' food consumption. In Proceedings of the NordDesign 2018: Design in the Era of Digitalization, 14-17 August 2018, Linköping, Sweden.

Contribution: Chu and Steenstra conceived the study, Chu performed the data analysis with Steenstra, developed the $1^{\text {st }}$ version of the AT-based theoretical framework used in this study, and wrote the paper with feedback from the rest of the authors throughout the research process.

\section{Paper III}

Chu, W., Williams, H., Verghese, K., Wever, R., \& Glad, W. (2020). Tensions and Opportunities: An Activity Theory Perspective on Date and Storage Label Design through a Literature Review and Co-Creation Sessions. Sustainability, 12(3), 1162. DOI: $10.3390 /$ su12031162.

Contribution: Chu conceived the study, carried out the systematic literature review, conducted design co-creation sessions including interviews and workshops, performed the analysis of findings, and wrote the paper with feedback from the rest of the authors throughout the research process. 


\section{Paper IV}

Chu W., Wever R., Verghese K., \& Williams H. (2019). Thinking on the Box: Design On-pack Information Attributes to Influence Consumers' Food Waste Behavior. In proceedings of 21 $1^{\text {st }}$ World Packaging Conference of International Association of Packaging Research Institutes, 11-14 June, Enschede, The Netherlands.

Contribution: Chu conceived the study, carried out the data collection and analysis, designed and developed the prototype of the Augmented Reality-based mobile application, and wrote the paper with feedback from the rest of the authors throughout the research process.

\section{Paper V}

Chu, W., Glad, W., \& Wever, R. (forthcoming). A meta-synthesis of the use of activity theory in design for sustainability studies. Manuscript submitted.

Contribution: Chu conceived the study, carried out the qualitative meta-synthesis of literature, performed the analysis of findings, developed the $2^{\text {ed }}$ version of the ATbased theoretical framework, and wrote the paper with feedback from the rest of the authors throughout the research process.

\section{Paper VI}

Chu, W., Glad, W., \& Wever, R. User Activity Matters: An Activity Theory Informed Design Toolkit for Sustainable Behavior Design. EcoDesign and Sustainability II, 7995.

Contribution: Chu conceived the study, carried out the narrative literature review, developed the $1^{\text {st }}$ version of the AT-informed toolkit, conducted the design ideation workshops, carried out the analysis of findings, and wrote the paper with feedback from the rest of the authors throughout the research process. 
Table 1. An overview of the studies, the themes and research outcomes included in this dissertation.

\begin{tabular}{|c|c|c|}
\hline Study & Themes & Research outcomes \\
\hline Study Alpha & $\begin{array}{c}\text { A narrative review of } \\
\text { sustainable behavior retention }\end{array}$ & Documented in Section 4 \\
\hline Study A-I & Astronauts' food consumption on ISS & Paper I \\
\hline Study A-II & Exchange students' food consumption & Paper II \\
\hline Study B-I & Studenthuset microwave room redesign & $\begin{array}{l}\text { Documented in } \\
\text { Section } 5.3 .2\end{array}$ \\
\hline Study B-II & Sustainable kitchen activity design & $\begin{array}{l}\text { Documented in } \\
\text { Section } 5.3 .3\end{array}$ \\
\hline Study C-I & $\begin{array}{c}\text { Date labelling and } \\
\text { household food waste: } \\
\text { systematic literature review and co-creation }\end{array}$ & Paper III \\
\hline Study C-II & $\begin{array}{c}\text { Date labelling and } \\
\text { household food waste: } \\
\text { design explorations }\end{array}$ & Paper IV \\
\hline Study D & $\begin{array}{l}\text { Household food consumption activities } \\
\text { under Covid-19 lockdown }\end{array}$ & $\begin{array}{l}\text { Documented in } \\
\text { Section } 5.5\end{array}$ \\
\hline Study E-I & $\begin{array}{l}\text { A meta-synthesis of the use of Activity } \\
\text { Theory in design for sustainability }\end{array}$ & Paper V \\
\hline Study E-II & AT-informed design ideation toolkit & Paper VI \\
\hline
\end{tabular}




\section{Table of Contents}

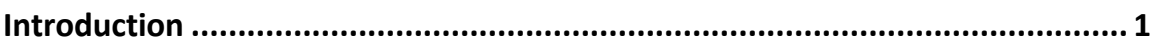

1.1 Design for sustainable everyday life .................................................. 1

1.2 Context change disruptions .......................................................... 3

1.3 Design for sustainable behavior retention............................................ 4

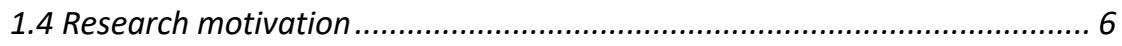

1.5 Knowledge gaps and research focus.................................................... 7

1.6 Aim and research questions............................................................... 9

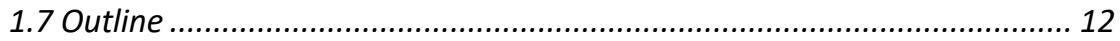

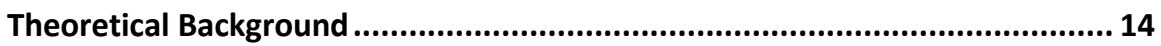

2.1 Theoretical background of Activity Theory (AT)................................ 14

2.2 AT's applicability for design research .............................................. 16

2.3 Rationales behind choosing Activity Theory (AT) ............................... 17

2.4 A brief introduction to AT's five key theoretical principles ..................... 17

2.4.1 Mediating effects of artefacts..................................................... 17

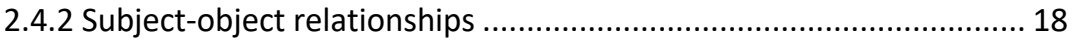

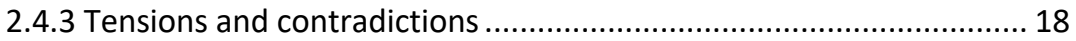

2.4.4 History and development ........................................................ 19

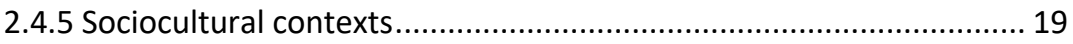

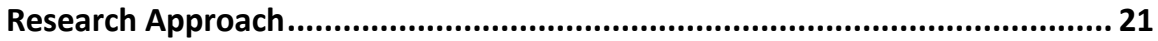

3.1 Philosophycal stance, ontology and epistemology view....................... 21 
3.3 Overall research design................................................................... 24

$3.4 \mathrm{~A}$ brief introduction to the selected research methods ...........................2. 27

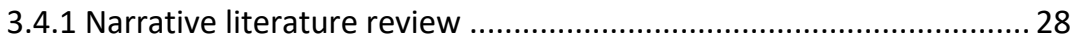

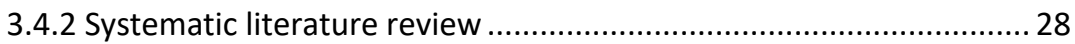

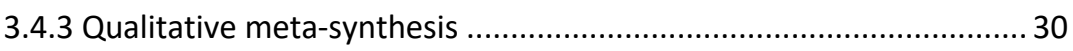

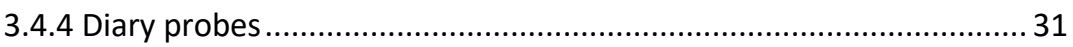

3.4.5 In-practice studies of everyday human activities............................. 32

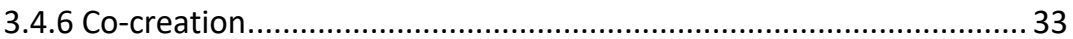

Current knowledge of design for sustainable behavior retention ................... 34

4.1 A narrative review within the field of Design for Sustainable Behavior..... 34

Development of the AT-based framework ............................................... 38

5.1 AT-based theoretical framework: Version_0.1 ..................................... 40

5.2 Development of the AT-based theoretical framework: the first iteration.. 41

5.2.1 Case study A-I: Understanding the mediating effects of artefacts in the behavior transformation.................................................................... 42

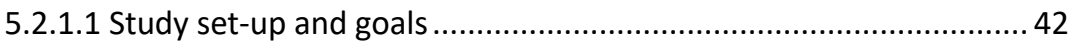

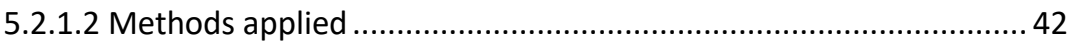

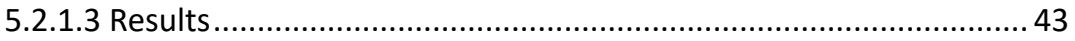

5.2.2 Case study A-II: Framing the dynamic development of activities ...... 46

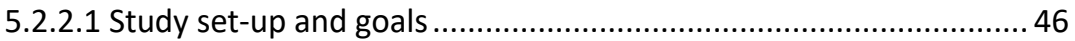

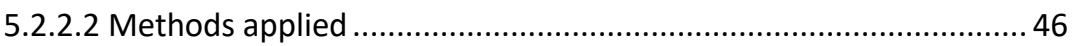

5.2.3 Reflections and AT-based theoretical framework: Version_1.0 ........50

5.3 Development of the AT-based theoretical framework: the second iteration 
5.3.1 Incorporating sociocultural contexts into sustainable design considerations

5.3.2 Case study B-I: Student microwave room intervention design.......... 54

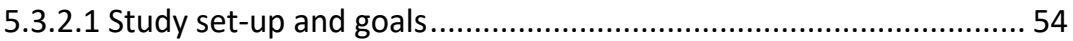

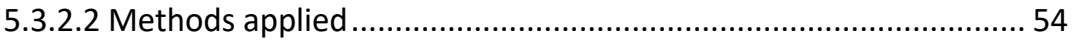

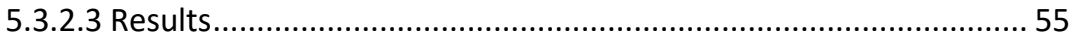

5.3.3 Case study B-II: flexible kitchen activity design ............................... 57

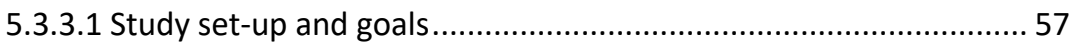

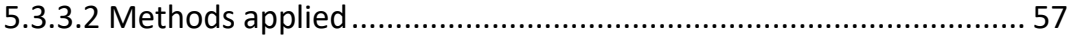

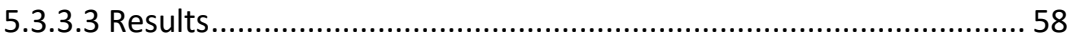

5.3.4 Reflections and AT-based theoretical framework: version 2.0.........60

5.4 Development of the AT-based theoretical framework: the third iteration 61

5.4.1 Study C-I: Uncovering tensions and contradictions within the activity

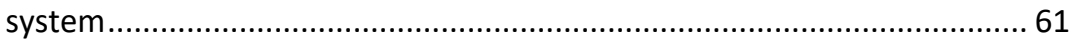

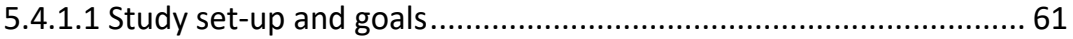

5.4.1.2 Method applied: a systematic literature review............................ 62

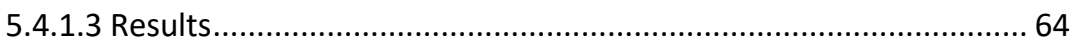

5.4.2 Reflections and AT-based theoretical framework: Version_3.0 ........68

5.5 AT-based theoretical framework: validation ............................................. 70

5.5.1 Study D: Household food consumption activities under Covid-19

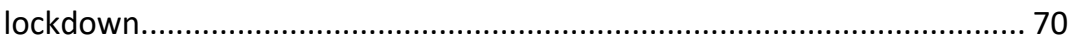

5.5.1.1 Study set-up and goals ........................................................... 70

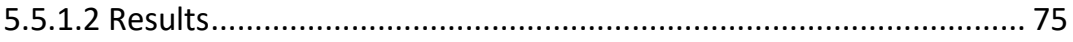

5.5.2 Reflections on the use of the AT-based theoretical framework Version_3.0 
6.2 Evaluation of the AT-onformed toolkit prototype

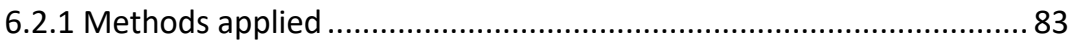

6.2.2 Evaluation results and reflections of the first version toolkit ............85

6.3 Extracting AT-informed design implications ....................................... 87

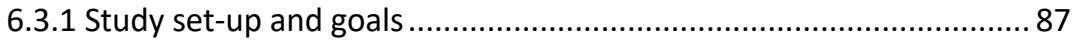

6.3.2 Methods applied: narrative literature review and theory-generating qualitative meta-synthesis ............................................................. 87

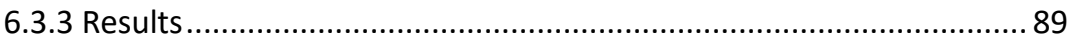

6.4 Translating the extracted design implications ...................................... 91

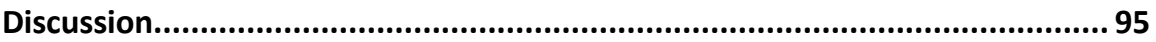

7.1 Revisit the concept of design for sustainable behaviour retention ............ 95

7.2 Peeking into the differences between the Activity-based, Behavior-based

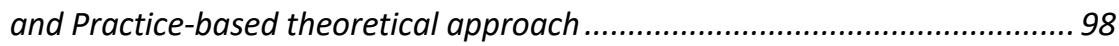

7.3 Reflections about the research approach and the knowledge generation

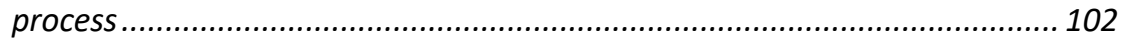

7.3.1 Reflections about the research approach and limitations .............. 102

7.3.2 Reflections about research credibility and transferability............... 103

7.3.3 Reflections about the methods used in relation to an activity theoretical lens .................................................................................. 105

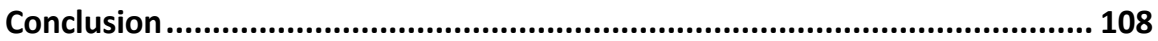

8.1 Fulfilling research aims and objectives .......................................... 108

8.2 Answering the research questions .................................................. 109

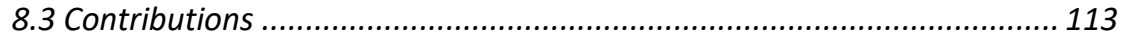

8.3.1 Theoretical contributions............................................................ 113

8.3.2 Potential societal values ............................................................ 113 


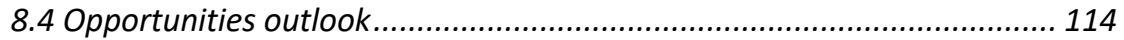

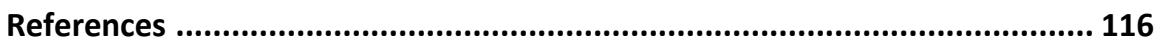





\section{1 \\ Introduction}

\subsection{Design for sustainable everyday life}

As many socio-ecological sustainability issues that the society is facing today are the direct consequence of a consumerism lifestyle, it is becoming more prominent to guide people to adopt a sustainable everyday life (Jackson et al., 2005). Design, given the transformative nature that it can bring to human doings, thus plays a critical role in supporting the transition towards a sustainable lifestyle (Thorpe, 2010). Design's responsibility for tackling sustainability issues has developed from focusing on technical and material aspects of the design (e.g., Green Design, EcoDesign and Cradle to Cradle Design) to the sociotechnical and useroriented aspects of design (e.g., Design for Sustainable Social Innovation and Sustainable Product-Service System Design) (Ceschin \& Gaziulusoy, 2016).

Under this trend, with the specific goal to reduce the negative environmental and social impact of products and services in the consumer usage phase, the field of Design for Sustainable Behavior (DfSB) emerged a decade ago (Lilley, 2009; Lockton, Harrison, \& Stanton, 2008; Wever, van Kuijk, \& Boks, 2008). The fundamental concept of DfSB is that products and services can be designed in a way to facilitate or constrain users to perform particular socio-ecologically desired or undesired behavior (Wever \& Vogtländer, 2015). Various toolkits have been developed to provide designers with practical guidance for influencing users' behavior in a more sustainable direction. A sample of toolkits includes Design with Intent developed by Lockton, Harrison, \& Stanton (2010), Behavior Change Design Sprints developed by Colusso, Do, \& Hsieh (2018), Dimensions of Behavior Change developed by Daae \& Boks (2014), and Change Points developed by Hoolohan \& Browne (2020). 
However, with the fast development of the DfSB in recent years, the research field has expanded from focusing on the user behavior aspect of design to covering the broader socio-environmental aspect of people's everyday life (Joore \& Brezet, 2015). Following this trend, DfSB seems to be evolving into the new field of Design for Sustainable Everyday Life. Compared with DfSB, Design for Sustainable Everyday Life shares the same overarching aim for promoting a sustainable consumption lifestyle. However, Design for Sustainable Everyday Life seems to bring in two important dimensions to the original scope of DfSB: 1). a spatial dimension that highlights the sociocultural contexts in which people's everyday life doings situate, and 2). a temporal dimension that highlights the long-term dynamic and evolving feature of people's everyday doings.

In the spatial dimension, products nowadays often function with other products and other people, forming a complex network that connects individual users with the macro sociocultural system (Mankoff et al., 2007; Wever et al., 2008). In order to be able to cope with this complexity from a system perspective, the focus of design thereby shifts from single products (e.g., energy efficiency and usability problems of a product) to tackling challenges at a sociocultural level (Adams, Jeanrenaud, Bessant, Denyer, \& Overy, 2016). When this shift of focuses comes down to the practical level of design, it implies that design practitioners need to not only analyze the interaction between an individual user and a designed artefact, but also take into account why and how a specific behavior can be influenced by the real-life sociocultural settings (Boon, Wever, \& Quist, 2015; Brynjarsdottir et al., 2012).

For instance, in her study about comparing the usage of washing machines in Germany and India, Honold (2000) found that a washing machine designed with the intention to promote users' sustainable energy and water consumption behavior in Germany resulted in countereffects in India. Based on this finding, they noted that people's laundry behavior is not only determined by product design of the washing machine, but also shaped by the sociocultural contexts such as the local climate, living conditions, division of labor and cultural values in which the laundry activity operates. Looking at this phenomenon from the spatial dimension of Design for Sustainable Everyday Life, it encourages designers to understand sustainability as a property embedded in the sociocultural system, rather than just treating it as an additional element added onto the designed artefacts (Ceschin \& Gaziulusoy, 2016). 
In the temporal lens, traditionally, the meaning of sustainability in design tends to be oversimplified to and interpreted as an ultimate state where the negative impacts of people's behavior are reduced to minimums (Faber, Jorna, \& Van Engelen, 2005). As a consequence, in order to achieve the ultimate sustainability state, design strategies and principles derived from DfSB focus on either promoting particular desired behavior or changing the undesired ones (Niedderer et al., 2014). Although these design strategies are proved to be effective for a certain period of time, how users might transform their behavior over the long-term still remains relatively seldom considered in DfSB (Coskun, Zimmerman, \& Erbug, 2015).

The temporal dimension provided by Design for Sustainable Everyday Life suggests that the ultimate state of sustainability only exists in a static context where everything remains unchanged. By contrast, in reality, the context in which people perform their everyday life doings is dynamic and ever-changing. Consequently, a design intervention that works at one specific point in time does not necessarily mean it would lead to the same outcome at another point in time. When it comes down to the practical aspect of design, the temporal lens implies that designers need to take a long-term perspective to study how people evolve or transform their doings over time (Coskun et al., 2015; van Dam, Bakker, \& van Hal, 2010). In other words, instead of setting the aim to achieve the static and ultimate state of sustainability, more focuses should be put on how to make constant improvements and adjustments of people's doings towards sustainability from a design perspective.

\subsection{Context change disruptions}

As pointed out in the preceding section, the spatial-temporal dimension brought by Design for Sustainable Everyday Life emphasizes the importance of understanding the dynamic nature of people's daily life contexts. Nowadays, the world is under a rapid changing process more than ever. Consequently, people's everyday life doings keep evolving as responses to this changing context.

Two types of context change disruptions commonly exist. First, individual lifecourse events such as leaving parents' home for the first time, new employment, residential relocation, and transition to parenthood, constitute a moment where existing habits of individuals can become disrupted (Verplanken, Walker, Davis, \& Jurasek, 2008; Verplanken \& Wood, 2006). Second, the macro socio-economical transitions such as the credit crunch and economic crisis in 2008 and the ongoing 
Covid-19 pandemic, can also shape how individual perform their everyday life doings (Thompson et al., 2011).

Looking at the phenomenon from the perspective of Design for Sustainable Everyday Life, the context change disruptions are regarded as windows of opportunity to intervene in people's behavior and habits towards a more sustainable direction (Verplanken \& Wood, 2006). According to Wood, Tam, \& Witt (2005), people tend to perform their habitual behavior under a stable interaction with the surrounding contexts. When certain contextual cues are disturbed by the changes that take place in the surrounding contexts, the corresponding habitual behavior might also be influenced. As a result, people may become more likely to reconsider their existing habitual behavior when they undergo context change disruptions (Verplanken \& Roy, 2016). However, how to utilize these disruptions that take place naturally or inevitably in individuals' daily life to promote a transition towards sustainability, especially from a sustainable design perspective, has been seldom explored. Moreover, as context change disruptions can open up a window of opportunity to change people's undesired behavior and habits, the existing socioecologically desired behavior and habits can also be influenced. Therefore, besides facilitating change, are there any needs for design to consider retaining people's existing desired behavior when they are undergoing context change transitions?

\subsection{Design for sustainable behavior retention}

When design meets the windows of opportunity to intervene in people's behavior, change has always been the fashionable term used in policymaking, business development and academic research (Lockton, 2017). This particular feature of design is not strange given that design has long been regarded as an efficient way to change the existing situations into preferred ones (Simon, 1969). Over the past decades, the particular focus on design for behavior change has dominated the research explorations in the DfSB field. A variety of design guidelines and toolkits have been developed with a specific aim to help designers to change people's undesired and unsustainable doings. A list of examples included but not limited to the Design with Intent Toolkit developed by Lockton, Harrison, \& Stanton (2010), Behavior Change Design Sprints developed by Colusso, Do, \& Hsieh (2018) Dimensions of behavior change developed by Daae \& Boks (2014), and Change Points developed by Hoolohan \& Browne (2020). Consequently, as most of the knowledge and strategies generated in the field of DfSB revolve around changing people's wrongdoings, the question of how to apply design as a potential means to retain people's existing desired and sustainable doings remains long neglected. 
What does design for sustainable behavior retention mean exactly? If one just interprets its meaning literally, then it might lead to a misconception that retention simply means maintaining things as they were, keeping people's daily doings to stay at the current status, or prohibiting potential changes from happening. To avoid such misinterpretation, it is crucial to set up the meaning of design for sustainable behavior retention. In this dissertation, the initial definition of the concept of design for sustainable behavior retention is:

To maintain and adjust people's existing socio-ecologically desired doings before the unsustainable ones become embedded when people undergo context change disruptions.

Although this definition is preliminary in this stage, it would help to build a common ground for readers to understand the research aim and questions proposed in the dissertation.

Building upon the preliminary definition indicated above, the next question comes to what does a retention perspective imply for sustainable behavior design? Take mobility for instance. Nowadays our society is facing a growing usage of private automobiles. Looking at this sustainability challenge from a design for behavior change perspective, the corresponding design interventions mostly emphasized reducing people's overreliance on private automobiles. However, we seem to have neglected the fact that most people who become frequent users of private automobiles must have had undergone a transition process from biking or taking public transportations to driving. This transition might be triggered by various reasons associated with context change disruptions, such as relocating to another residential area, getting a baby, finding a new job, becoming middle class and so on. By taking a sustainable behavior retention perspective, the design focus can then be placed on exploring how to retain people's existing green commuting doings and further support people in adjusting the sustainable doings while they are undergoing a transition process, thus preventing the undesired and unsustainable behavior patterns from happening in the first place. 


\subsection{Research motivation}

Before we begin exploring the behavior retention perspective in Design for Sustainable Everyday Life, one question that still remains explained is: why does a sustainable behavior retention perspective matter? In other words, what would be the benefits that the investigation of design for sustainable behavior retention might bring for the overall sustainable development of the society?

Discussions around the potential societal contribution of the study are elaborated in the conclusion chapter of the dissertation. This section only describes why I am motivated to choose this particular research topic. For readers who are holding the dissertation right now, knowing the motivation behind my research can hopefully help you gain a better view of the overall concept underlies this dissertation.

My research motivation comes from what I had seen and experienced when I grew up. I was born in Wuhan, China. I remembered when I was a little kid, in the 90s, people used to live in harmony with the surrounding environment. For example, in terms of food consumption, fridge and stove back then were much smaller with less function than the ones we use today. Nevertheless, almost nothing got wasted at that time as food items were always preserved and utilized smartly and efficiently. Moreover, there were no modern garbage classification facilities in the local community where I lived. Like many families in the community, my family separated organic food waste from other types of waste so that nutrition in food residue can be returned to the field to fertilize the soil. However, as we moved into newly constructed apartment buildings in the urban area, all of these desired sustainable doings have gradually faded away along with time.

This personal experience makes me wonder that besides changing people's undesired and unsustainable doings, are there any needs or possibilities for design to take the responsibility to retain people's existing desired sustainable doings when they are undergoing context change transitions? Furthermore, what insights this particular retention perspective might offer to better cope with the current sustainable consumption lifestyle challenges that the society is facing today? 


\subsection{Knowledge gaps and research focus}

In summary, this dissertation departures from the general inquiry: if sustainable behavior design is not only aimed at creating behavior change, but also takes the role of retaining people's existing sustainable behavior when people are undergoing context change disruptions, then what new sustainable design implications can be informed? Can this behavior retention perspective open up new opportunities for design to guide people's daily doings in a more sustainable direction? More precisely, this dissertation aims at addressing two specific knowledge gaps in the field of Design for Sustainable Everyday Life (see Figure 1).

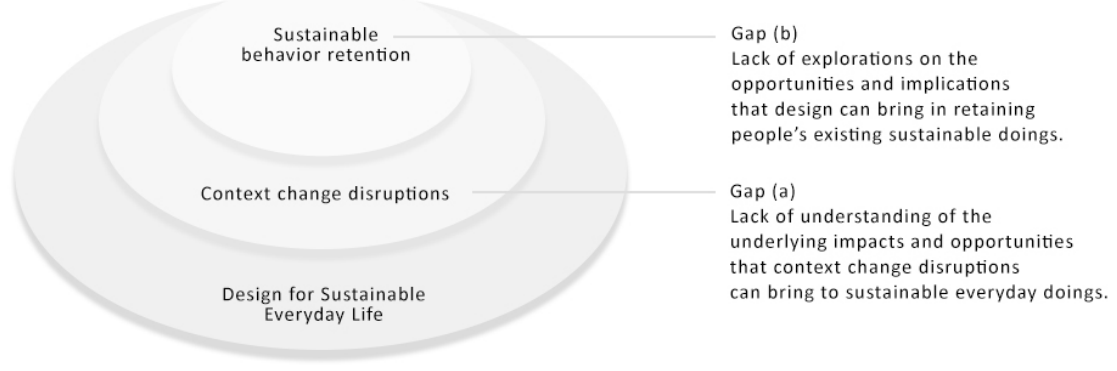

Figure 1. The knowledge gaps that this dissertation aims to address within the scope of Design for Sustainable Everyday Life.

\section{Gap (a). Impacts and opportunities of context change disruptions}

The daily doings that people perform in their everyday life contextual settings are not static but under a dynamic transition process. As presented in the preceding section, both socio-economic events and individual life-course events can, to a certain degree, disrupt people's existing habitual behavior. The underlying impacts and opportunities that context change disruptions can bring to people's sustainable behavior have been Ill-addressed. This dissertation thus looks at the research topic of design for sustainable everyday life with a particular focus on how people transit their doings when undergoing context change disruptions (as shown in Table 2).

\section{Gap (b). Design for sustainable behavior retention}

Over the past decades, the field of design for sustainable everyday life seems to have grown accustomed to the concept of changing people's wrongdoings. However, there has so far been little attention to exploring the opportunities and implications that design can bring in retaining people's existing desired and sustainable doings. A successful sustainable behavior transition entails not only 
changing the undesired doings, but also retaining the desired ones (Jotte I.J.C. de Koning, Ta, Crul, Wever, \& Brezet, 2016; Jotte Ilbine Jozine Charlotte de Koning, Crul, Wever, \& Brezet, 2015). This dissertation thus explores how to better guide design researchers' and practitioners' empirical analysis of and design explorations on sustainable behavior retention (as shown in Table 2.1).

Table 2.1. The knowledge gaps that this dissertation aims to address.

\begin{tabular}{lll}
\hline \multicolumn{1}{c}{ Knowledge gaps } & Wider consequences & \multicolumn{1}{c}{$\begin{array}{c}\text { Research focuses } \\
\text { of this study }\end{array}$} \\
\hline $\begin{array}{l}\text { a). Lack of understanding of } \\
\text { the underlying impacts and } \\
\text { opportunities that context } \\
\text { change disruptions can bring } \\
\text { to sustainable everyday } \\
\text { doings. }\end{array}$ & $\begin{array}{l}\text { Miss the windows of } \\
\text { opportunity to enhance } \\
\text { people's existing sustainable } \\
\text { doings. }\end{array}$ & $\begin{array}{l}\text { Explicitly focusing on } \\
\text { studying how people transit } \\
\text { their doings when } \\
\text { undergoing context change } \\
\text { disruptions. }\end{array}$ \\
\hline $\begin{array}{l}\text { b). Lack of explorations on the } \\
\text { opportunities and implications } \\
\text { that design can bring in } \\
\text { retaining people's existing } \\
\begin{array}{l}\text { desired and sustainable } \\
\text { doings. }\end{array}\end{array}$ & $\begin{array}{l}\text { Solely focusing on changing } \\
\text { the undesired outcomes of } \\
\text { people's doings but neglect } \\
\text { the importance of retaining } \\
\text { the desired ones. }\end{array}$ & $\begin{array}{l}\text { Explicitly focusing on } \\
\text { exploring the role that } \\
\text { design can play in retaining } \\
\text { people's existing sustainable } \\
\text { doings during context } \\
\text { change disruptions. }\end{array}$ \\
\hline
\end{tabular}

Food consumption is chosen as the practical field of application in this study. Food consumption is chosen due to two reasons. First, food consumption acts as a node that connects various doings that people perform in different aspects of everyday life. For example, purchasing and transporting food requires mobility; storing and cooking food in household environments involve the use of fridges and stoves thus energy consumption. Second, how people carry out food consumption is not static but under a constant dynamic transition process. For example, an individual who moves from his/her country of origin to another country may need to adapt to a new food consumption system, thus resulting in the development of a new food consumption routine. The food consumption doings of a kid who brings lunchbox to school every day is certainly different from the doings when she/he performs turns into an adult. Therefore, this unique characteristic makes food consumption an ideal area to explore how people transit their existing doings when undergoing context change disruptions. 


\subsection{Aim and research questions}

Given the knowledge gaps and research focuses identified in the preceding section, the thesis aims to:

Develop a theoretical approach to support design researchers and practitioners in better understanding how people transit behavior when they undergo context change disruptions, and explore what design implications can be informed by highlighting sustainable behavior retention aspect in the transition process.

The overarching aim of the study is broken down into three objectives, disrupting across three levels of research inquiry: conceptual level, design analytical level, and design synthesis level (as shown in Table 3).

Objective1 focuses on the conceptual exploration of the topic of design for sustainable behavior retention. Specifically, it aims to develop an overview of to what extent is the topic of design for sustainable behavior retention explored in the current body of research on design for sustainable everyday life. Objective1 leads to the first research question:

RQ 1: What is the status of current knowledge of sustainable behavior retention in the existing body of literature in the field of design for sustainable everyday life?

Understanding the behavior retention aspect would first require a theoretical lens that can help analyze how people transit their behavior when undergoing context change disruptions. Therefore, objective2 aims to develop such a theoretical framework. By focusing on the analytical level of design, the second research question sets out to explore:

$R Q$ 2: From the perspective of design for sustainable everyday life, how to systematically describe and analyze behavior transition induced by context change disruptions?

Objective3 aims to synthesize the conceptual understanding generated in objective1 with the theoretical framework developed in objective2 into a more practically applicable form for designers to use. An AT-informed idea generation toolkit prototype is developed and evaluated to facilitate structured design exploration in response to sustainable behavior retention. Two research questions arise from objective3: 
$R Q$ 3.1: How might the proposed AT theoretical lens be incorporated into a toolkit to highlight the behavior retention perspective in sustainable design explorations?

$R Q$ 3.2: Building upon the AT theoretical lens, what are the design implications that sustainable behavior retention perspective can bring to the field of design for sustainable everyday life.

The distribution of the research objectives and questions in relation to the research inquires in different levels is presented in Table 3. 


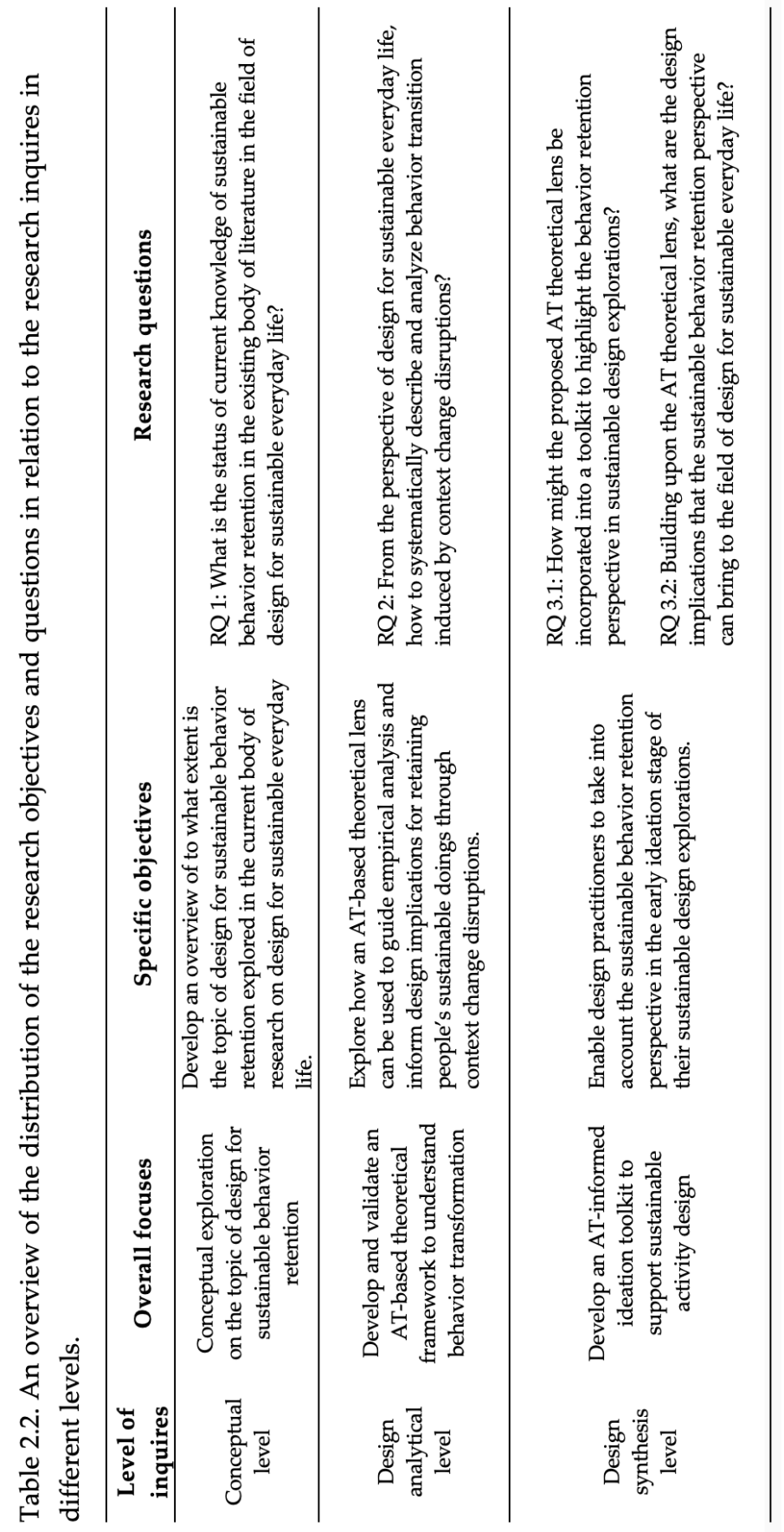




\subsection{Outline}

The dissertation is based on the works presented in the appended papers. Given the variety of the themes covered in the papers, to better connect the themes in a more coherent manner, the key findings and reflections of each paper are presented in the dissertation. An overview of the research outline is illustrated in Figure 2.

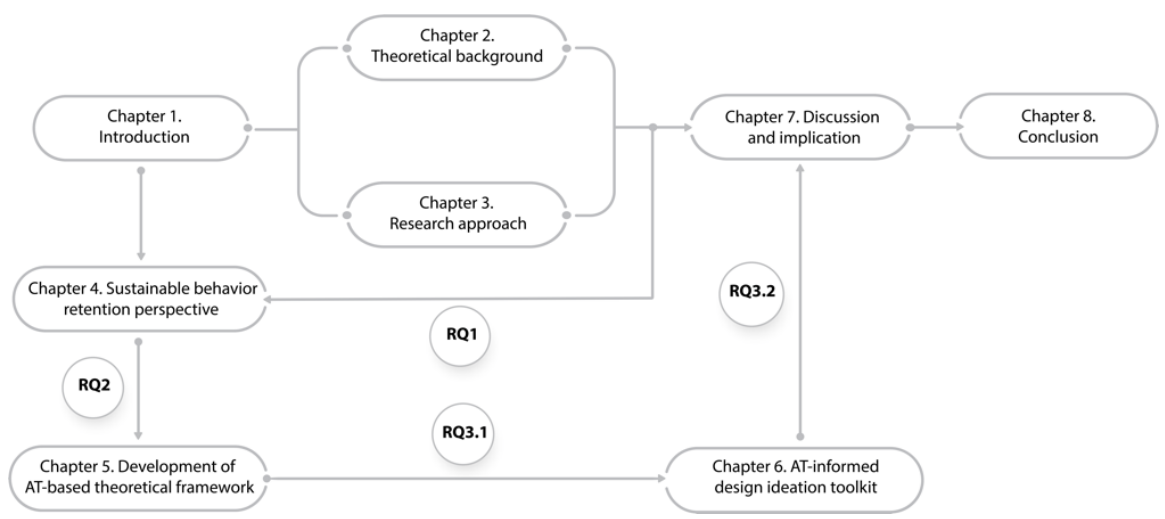

Figure 2. An overview of the research outline

A short summary of the eight chapters in this dissertation is presented below:

- Chapter 1: Presentation of research background, motivation, research gaps, aim and research questions.

- Chapter 2: Presentation of the theoretical lens adopted in the dissertation. The focus of this chapter is to introduce and discuss the key theoretical concepts and principles of AT. For clarification, as a comprehensive introduction of AT has already been provided in Paper V, this chapter is adopted from the theory section of Paper V.

- Chapter 3: Presentation of the methodology and selected methods in the dissertation. This chapter focuses on describing how the study is constructed and carried out.

- Chapter 4: Focus on answering RQ 1. Specifically, a narrative literature review investigating the current knowledge status of behavior retention perspective is reported in this chapter.

- Chapter 5: Focus on answering RQ 2. It presents the detailed development, iteration and application of the AT-based theoretical framework. 
- $\quad$ Chapter 6: Focus on answering RQ 3.1 \& RQ 3.2. It presents how the proposed theoretical framework is developed into an AT-informed ideation toolkit.

- Chapter 7: Discussion on the design implications that a behavior retention perspective can provide for the field of Design for sustainable Everyday Life. Furthermore, reflections on the research approach and knowledge generation process of this PhD study are also discussed.

- $\quad$ Chapter 8: Presentation of answers to each research question and the potential contributions of the dissertation. 


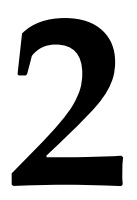

\section{Theoretical Background}

Chapter 2 focuses on introducing the theoretical, background, key concepts and principles of Activity Theory from a design perspective. For clarification, as a comprehensive introduction of AT is presented in Paper V, the major part of this chapter is adopted from the Activity Theory section of Paper V.

\subsection{Theoretical background of Activity Theory (AT)}

The conceptual origins of AT can be traced back to the work conducted by psychologist Lev Vygotsky and Sergei Rubinshtein in the 1920s and 1930s (Kaptelinin \& Nardi, 2006). According to Vygotsky (1978), the human activity is comprised of three key components: subject -the performer of the activity who is driven by a specific need to carry out an activity; object - the goal that the subject aims to achieve; artefacts - the tools which are used by the subject to achieve the object. Building upon the interaction between these three components, an activity is interpreted as purposeful need-based relationships between the subject and the object mediated by the use of artefacts (as shown in Figure 3).

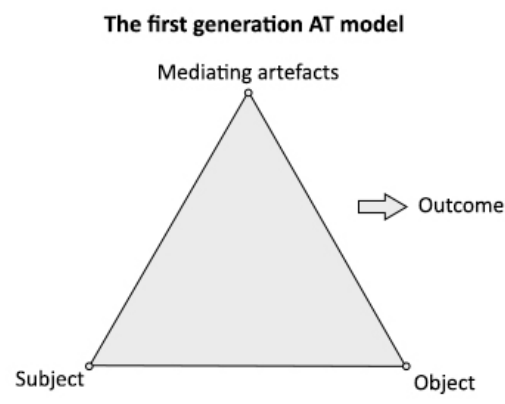

Figure 3. Vygotsky's first generation AT model. 
Established on Vygotsky's classic triangle AT model, a variety of models have been developed. As illustrated in Figure 4, Leontiev's hierarchical structure model (Leont'ev, 1974; Leont'ev, 1978)(referred to as the second generation of AT model) and Engström's Cultural-Historical Activity Theory model (Engestrom, 1987) (referred to as the third generation AT model) have been widely applied in the current research.

Specifically, Leontiev's AT model introduced the principle of hierarchical structure and expanded Vygotsky's AT model from a single layer to multiple layers, indicating that human activities comprise three hierarchical layers: activity layer, action layer, and operation layer.

- Activity layer: The activity layer is oriented towards a motive to achieve an object. It provides insights into why an activity is carried out.

- Action layer: Under the activity layer, the action layer is directed by intentional goals. It presents how goals within the activity are fulfilled.

- Operation layer: Under the action layer, the operation layer represents how a series of actions are adjusted into routinized operations.

Engström sets an explicit focus on collective activities by exploring how human activities are structured and carried out in socio-cultural contexts. He expanded Vygotsky's AT model by introducing the components of communities, rules and division of labor into the theory. A detailed description of the theoretical development process of AT can be found in Kaptelinin \& Nardi (2012).
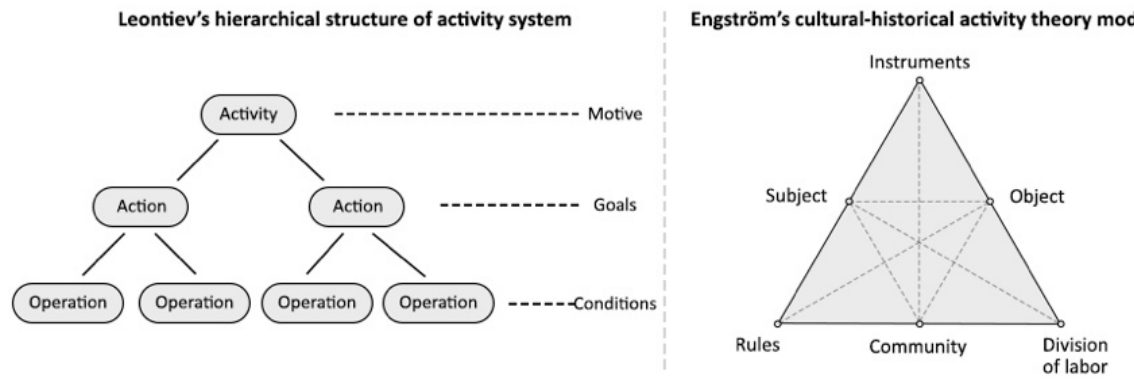

Figure 4. Leontiev's hierarchical structure model (adopted from Leont'ev, 1978) and Engström's cultural-historical activity theory model (adopted from Engestrom, 1987). 


\subsection{AT's applicability for design research}

Originating from a socio-cultural tradition in psychology, two distinguishing features make AT applicable for design research. First, unlike most of the behavioral and psychological theories which provide researchers with models to predict people's behavior, AT aims at supporting design researchers in formulating sensible inquiries based on the descriptive accounts of why and how people carry out a specific activity in a specific context to achieve a specific goal (Bødker \& Klokmose, 2011; Kaptelinin, 2014; Li \& Landay, 2008). In this respect, AT works as a theorybased conceptual framework that guides design researchers to generate and structure research inquiries rather than a traditional theory for making predictions (Karanasios, 2014).

Second, as Engeström (1999: p 29) noted that "activity theory has the conceptual and methodological potential to be a pathbreaker in studies that help humans gain control over their own artifacts and thus over their future." AT's particular focus on the role that artefacts play in people's activity system is in accordance with the design's tradition in understanding and shaping humanartefact relationships (Duignan, Noble, \& Biddle, 2006; Kuutti, 2011). Some recent works also pointed out that AT is a promising theoretical lens, especially when used in DfSB research (Renström, 2019; Selvefors, 2017). Five theoretical principles of AT have become the cornerstones that underpin the application of AT in design research (Kaptelinin, Nardi, \& Macaulay, 1999):

- Mediating artefact

- $\quad$ Subject-object relationships

- Tensions and contradictions

- History and development

- $\quad$ Sociocultural contexts.

Furthermore, approaching design for sustainability from the field of HumanComputer Interaction, Kaptelinin \& Nardi (2012) pointed out that AT's historical sensitivity, attention to complex systems, and reality-based solutions may be useful for tacking design-related sustainability problems. However, despite the wide application of AT as a theoretical lens in design research, how the above-mentioned theoretical principles of AT can support design researchers in understanding and addressing complex sustainability challenges remain ill-addressed. 


\subsection{Rationales behind choosing Activity Theory (AT)}

As noted in the introduction chapter, Design for Sustainable Everyday Life highlights two crucial dimensions: 1). The spatial dimension, that is, the sociocultural contexts in which people's everyday life doings situate, and 2). The temporal dimension, that is, the dynamic and evolving feature of people's everyday life. Consequently, the Design for Sustainable Everyday Life perspective seems to extend the sustainable design focus from user behavior to the long-term, multi-level and complex features of users' doings. To facilitate people's behavior transformation towards sustainability, a theoretical lens that systemically contextualizes people's doings in a spatio-temporal lens is thus needed. Activity theory (AT), given its primary focuses on the role that artefacts (and design of artefacts) can play in purposeful need-based human activities, along with its' spatiotemporal lens to interpret the dynamic development of human activity systems, is regarded as one of the leading candidates to systematically describe and analyze behavior transition induced by context change disruptions.

\subsection{A brief introduction to AT's five key theoretical principles}

In this section, the meaning of each theoretical principle of AT is briefly introduced from a design research perspective. How the theoretical principles may be potentially used to investigate sustainability issues is addressed in this section.

\subsubsection{Mediating effects of artefacts}

The theoretical concept of mediating artefacts plays a central role in AT. According to Vygotsky (1978), all purposeful interaction between the subject and the world is mediated by artefacts. The mediating artefacts include both external material tools (e.g., hammers, computers and digital interface) and internal immaterial tools (e.g., language, symbols and models) (Kaptelinin, 2014). This conceptualization of artefact is in line with the classic definition of artefacts proposed by Herbert Simon, that an artefact can take any forms on the continuum between abstract and concrete and act as a bridge between an internal and external environment (Simon, 1969). In reality, the human activity is seldom mediated by a single mediator. Rather, the real-life mediation process consists of a network of interconnected mediators involving both internal and external artefacts, forming a complicated ecological system (Bødker \& Andersen, 2005; Gay \& Hembrooke, 2004). As a result, the replacement of an existing artefact or the introduction of a new artefact in the activity system can potentially shape how the target activity is carried 
out. In turn, the artefacts are simultaneously reshaped and adapted to the target activity (Bødker \& Klokmose, 2011).

\subsubsection{Subject-object relationships}

The concept of subject-object relationships is regarded by many theorists as one of the fundamental notion underpinning the development of AT. In the view of $\mathrm{AT}$, subjects can be individual (e.g., individual users) and collective (e.g., different stakeholders, organizations and communities). Correspondingly, the object involves both tangible biological needs (e.g., eat food) and intangible psychological needs (e.g., comfortable living) of human life. When a specific need of the subject is coupled with a specific object, a motive is formed, and at the same time, an activity emerges. AT argues that it is the subject-object relationship, rather than the individual component of subject or object, that determines how an activity is carried out (Gay \& Hembrooke, 2004). As Kaptelinin \& Nardi (2006) indicated, when used in product and service design, this concept can enable designers to expand the scope of analysis from users' interaction with a specific product or service to how subjects carry out a meaningful motive-oriented activity.

\subsubsection{Tensions and contradictions}

Tensions and contradictions are broadly defined as misfits, problems, incoherencies and inconsistencies that subjects encounter in the target activity systems (Kuutti, 1996). When this concept was applied in design research, in some cases, it was only used to identify product usability problems. However, that is an oversimplification as tensions and contradictions do not only exist in the interaction between users and artefacts, but also can be found within and between different components of an activity system. It is due to this reason that understanding tensions and contradictions might provide design researchers with a systemic perspective of how sustainability problems take place at different levels of an activity system. Specifically, according to Engestrom (1987: p 98), four types of tensions and contradictions can be identified. Primary contradictions exist in each individual component of an activity system; Secondary contradictions exist between different components of an activity system; Tertiary contradictions take place between an existing activity system and a newly established competing activity system. Quaternary contradictions take place between the target activity system and its neighboring systems, which share the same objects. 


\subsubsection{History and development}

The triangle presentation of the activity systems may bring a misperception that all human activity systems are steadily constructed. In fact, the relationships between different components of an activity system are ever-changing (Gay \& Hembrooke, 2004). When subjects begin to cope with the tensions and contradictions within and between activity systems, the activity system might undergo a development process (Engeström, 1999). This development process does not just last for a certain period. On the contrary, in the view of AT, activities are under constant development and evolution (Kuutti, 1996). Based on this view, how we carry out a specific activity at a specific point in time is influenced by the historical evolution of the relevant activities. The present activities would also inevitably bring impacts to the future development of the activities (Kaptelinin \& Nardi, 2006). From the perspective of Design for Sustainable Everyday Life, two main features of this theoretical principle are relevant: First, AT has a special view for interpreting changes. It views changes as elements that naturally embed in human activities, driven by tensions and contradictions that take place in people's activity systems. When tensions and contradictions become materialized at a given point in time, the subject of the activity system may attempt to find temporary solutions to address the contradictions, it is under these moments that the activity undergoes a transformation process (Blackler, Crump, \& McDonald, 1999; Boer, van Baalen, \& Kumar, 2002). Second, unlike other mainstream behavior change theories which model changes according to behavior determinants such as norms, attitudes and perceived behavior control, AT postulates in its theoretical nature that a typical way to induce intentional changes is through re-mediation, that is, redesigning artefacts (such as products and services) to influence the way how subjects achieve the original object (Bødker \& Andersen, 2005; Nardi, 1996).

\subsubsection{Sociocultural contexts}

Gay \& Hembrooke (2004) connect AT to an ecological perspective and posit a human activity at three levels: the micro-level represents independent activities carried out by each individual, the meso-level represents collective activities carried out by a group of individuals or a community, and the macro-level represents broader sociocultural contexts. They argued that when an activity system is analyzed at one particular level or context, its relations with activities at other contextual levels (educational systems government, state and local processes) should also be taken into account. From the perspective of Design for Sustainable Everyday life, the sustainability effects of a product and service should not be limited to its 
environmental performance or its influence on individual user behavior. Instead, since the majority of people's daily life activities involve multiple motives and different meditating artefacts, which are all shaped by specific socio-cultural contexts, it thus becomes vital for design researchers to analyze or envisage the potential impacts of a particular sustainable design intervention on different sociocultural levels, covering individual to broader sociocultural contexts. Moreover, the theoretical concept of sociocultural contexts also highlights the importance of understanding people's behavior in real-life settings rather than taskbased laboratory settings (Kaptelinin \& Nardi, 2006: p 35). 


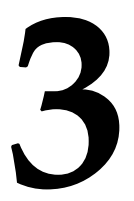

\section{Research Approach}

This chapter first presents the overall research methodology employed in the study and the research outlines. Following that is a brief introduction to the selected research methods and the rationales behind adopting these methods.

\subsection{Philosophycal stance, ontology and epistemology view}

I see myself as a pragmatist. This self-identity led me to choose a pragmatic philosophical stance in my research. Pragmatism originated from the United States in the $19^{\text {th }}$ century. The origination of Pragmatism is, to a large extent, inspired by the Theory of Evolution proposed in the $19^{\text {th }}$ century. Pragmatism believes that evolution is not only a biological feature; it can also be generalized to understand all the other aspects of nature as the whole universe is subject to an evolutionary process. Based on this worldview, pragmatism argues that truth is relative, dynamic and ever-changing (Johnson \& Onwuegbuzie, 2004). In other words, the reality that exists at one particular point in time and space might be radically different from the reality that exists at another point in time and space. Therefore, some of the knowledge that is useful in one particular in time and space may not be useful in another particular point time and space. Pragmatism's ontology view is partially in line with Social Constructivism, which argues that reality is subjective and has no absolute or stationary states (Guba \& Lincoln, 1994). Different understandings and knowledge thereby can co-exist (Creswell, 2003). In terms of epistemology, pragmatism claims that when researchers investigate the reality, they should remain open-minded and be willing to accept changes (Hicks, 2009). Reflecting on this epistemology stance from a design research perspective, it implies that when researchers investigate a particular phenomenon, they need to be ready to acknowledge the dynamic interplay between observation and analysis, gain direct access to participants, and be open to co-construct knowledge with the participants. This personal reflection of Pragmatism guides me to choose a combination of 
different research methods, including probes, observations, interviews, systematic literature review, and meta-synthesis.

Instrumentalism is closely connected to Pragmatism. It is commonly seen as a methodological view rooted in the epistemology of Pragmatism for acquiring knowledge. It explicitly argues that theories are instruments or tools by which we know reality. Theories are useful for predicting, categorizing, understanding, and modelling particular phenomena. They are derived from practices and applied to practices. Following this view, in the context of my $\mathrm{PhD}$ research, I adopt $\mathrm{AT}$ as the instrument to understand how people transform their doings when undergoing context change disruptions. As I tested the use of AT in different case studies, I adapted and further revised the theory to fit into the goal of my research and answer the research questions proposed in this dissertation. This epistemology view based on Pragmatism and Instrumentalism also guides me to choose a Design Research Methodology (DRM), which emphasizes developing understanding of empirical phenomena and translating the generated understanding into the design in an iteration manner (Blessing \& Chakrabarti, 2009).

\subsection{Design Research Methodology (DRM)}

According to Blessing \& Chakrabarti (2009), design research typically consists of two interconnected components: the development of understanding and the development of support. The objective of the first component is to an in-depth obtain understanding of a specific phenomenon which is of design interests. Such understanding can be formulated and validated in the form of theories, frameworks and models. The second component focuses on translating the understanding into various support to improve design practices. Such support can be developed as design knowledge, implications, guidelines, strategies, methods and tools to help design practitioners better attain the intended design outcome.

DRM comprises four research stages with different research focuses: Research Clarification, Descriptive Study I, Prescriptive Study, Descriptive Study II. Research Clarification and Descriptive Study I focus on developing an in-depth understanding of the targeted phenomenon, while prescriptive study and descriptive study II focus on developing support for design. The goals, basic means and deliverables of each stage are elaborated in the following.

Research Clarification is a preparatory stage. It helps researchers working with design challenges develop an overall understanding of the current scientific 
knowledge of the research topic, identify relevant research areas, clarify research aim and questions, and set up a research plan for the subsequent research stages. The basic means used in this stage is the review of existing studies.

Descriptive Study I (DS-1) aims to increase the understanding of the specific phenomenon clarified in the previous stage and identify key factors that influence the phenomenon. This is achieved by systematically summarizing relevant insights from existing literature review and undertaking empirical studies. The deliverables of this stage include the highlights of design-related problems, the key impact factors, and the corresponding implications that may determine the success of the design.

Prescriptive Study (PS) aims to transform the increased understanding developed in the previous stages to practical support that can improve the targeted design practices. This is achieved by synthesizing empirical results obtained from DS-1 with literature insights from $\mathrm{RC}$ to formulate a model/framework that represents the desired situation in design, along with key implications/actions that would support the transformation of the situation from the current to the desired status. The deliverables of this stage comprise the development of the Intended Support and Actual Support. It has to be noted that the Intended Support and Actual Support have a different emphasis. The Intended Support demonstrates the core concepts to improve the design. It is mainly in the form of frameworks and models. The Actual Support is the prototype of the Intended Support. It can take the form such as methods, guidelines, checklists, software and toolkits, in which the core concepts of the intended support are sufficient to be evaluated.

Descriptive Study II (DS-II) focuses on evaluating the effects of the proposed Intended Support and Actual Support. Note that DS-II is not merely a revision of DS-I. While DS-I aims to develop an in-depth understanding of a phenomenon, DSII focuses on analyzing what and how the proposed support may have actual effects on the targeted phenomenon. This is mainly achieved by evaluating the effects of the support through three criteria: usability, applicability and usefulness. The deliverables in this stage include the evaluation results and implications to further improve the proposed support. 
DRM is chosen as the leading research methodology due to three reasons.

- First, as indicated in the introduction section, the goal of the study mainly comprises two parts: 1). developing an understanding of the behavior retention phenomenon, and 2). incorporating the generated insights into a toolkit for designers to use in their early-stage ideation process. This aligns with the Understanding and Support component of the DRM mentioned earlier.

- $\quad$ Second, DRM provides design researchers with a clear division of different research stages with detailed guidance of what the goal is in each stage and how to achieve the goal. Moreover, it also highlights the connections between different research stages, for example, how the deliverables of the previous stages can be used to inform the research explorations in the subsequent stages. This methodological feature can systematically construct and translate the generated theoretical knowledge into practical design implications.

- Third, the methodological nature of DRM is heuristic rather than algorithmic (Blessing \& Chakrabarti, 2009 p: 14). It does not necessarily require researchers to strictly follow its methodological procedures and take an equal depth of investigation in each research step. Rather, it acknowledges the diversity of the research topics that researchers deal with in the design discipline and allows design researchers to flexibly adapt the methodology to suit different study focuses. Therefore, in the context of this study, instead of carrying out the research exploration in a step-by-step linear fashion, several studies were conceived and conducted in parallel, each of which informed the planning and development of the others. Some of the parallel studies belong to the same research stage (e.g., connections between Study A-I and A-II, Study B-I and BII), while some across different research stages (e.g., connections between Study C-I and Study E-I). The main reason behind this study set-up is to effectively integrate the understanding generated in different types of studies (including review-based study and empirical case study) within the limited time of the PhD study.

\subsection{Overall research design}

Following the methodological procedures suggested by DRM, the study is divided into four stages: Stage 1 - Research clarification (RC), Stage 2 - Descriptive Study I (DS-I), Stage 3 - Prescriptive Study I (PS-I), Stage 4 - Descriptive Study II (DS-II). Figure 5 illustrates the methodological procedures of the study. 


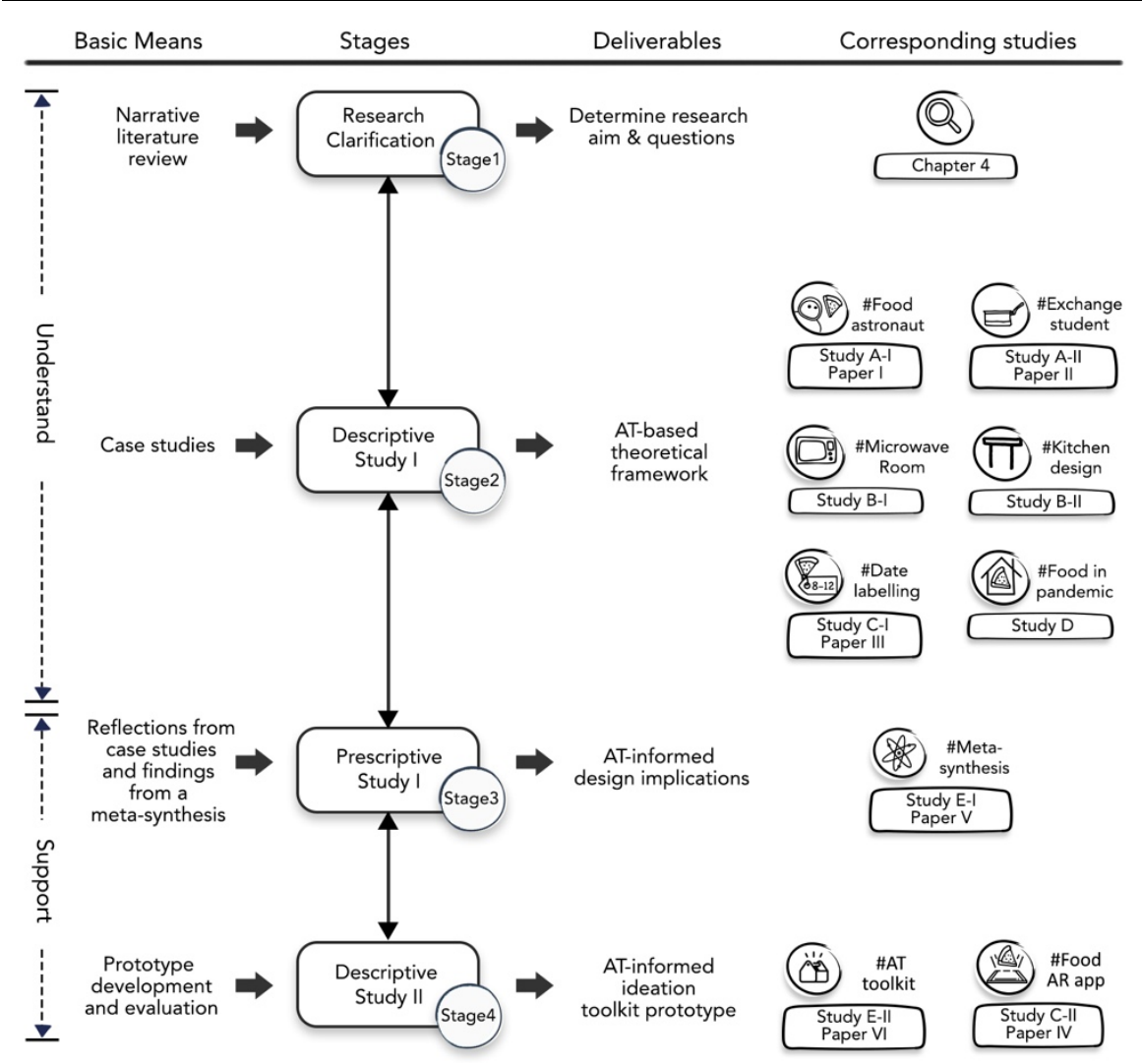

Figure 5. An overview of research stages, basic means and deliverables in each research stages.

\section{Stage 1 - Research clarification (RC):}

Following the DRM guideline presented earlier, in the initial stage of the research, efforts were made to 1). Conduct a narrative literature view in the field of design for sustainable everyday life to identify relevant studies, along with candidates of potential theoretical perspectives to analyze behavior transformation phenomena induced by context change disruptions. 2). Summarize findings from existing research and formulate preliminary research inquiries. 


\section{Stage 2 - Descriptive Study I (DS-I):}

Building upon the overview of the research topic and the potential theoretical perspectives identified in RC, the aim of DS-I is to develop understanding of the effects that context change disruptions may bring people's everyday doings. This aim is achieved by developing a theoretical framework for design researchers and practitioners to better describe and analyze the behavior transformation phenomena.

Study A, B, C, D were undertaken in this stage. In these studies, I adopted activity as the unit of analysis and applied an AT theoretical perspective as the analytical lens to interpret the empirical phenomenon. This theoretical perspective later became the guiding lens that directs the subsequent development of the ATbased framework and AT-informed toolkit later proposed in the PhD study.

To be more specific, first, in Study A, two case studies, one concerning astronauts' food consumption on the International Space Station (Study A-I, see Paper II) and the other concerning exchange students' food consumption (Study AII, see Paper I), were undertaken. The deliverable of Study A led to the development of the first version of the AT-based theoretical framework. Similarly, two case studies, Study B-I and Study B-II were undertaken in Study group B, which led to the development of the second version of the AT-based theoretical framework. Following that, results of study C-I, which focuses on investigating the interplay between on-pack date labelling and household food waste (see Paper III) led to the third version of the framework. The framework was then validated in Study D, which aims to uncover household food consumption transformation under lockdowns caused by the Covid-19 pandemic.

\section{Stage 3 - Prescriptive Study I (PS-I):}

Following the definition of Intended Support and Actual Support in DRM, while DS-I focuses on developing, iterating and validating the Intended Support (AT-based theoretical framework), PS-I focuses on translating the framework to a design toolkit to provide the Actual Support for design practitioners in their sustainable design practices. Study E-I was carried out in this stage.

As the insights and reflections regarding the theoretical framework resulted from the DS-I still largely rely upon findings from the case studies, to make the AT- 
based theoretical framework more generalizable, a more solid theoretical grounding is still needed. Therefore, I conducted a meta-synthesis study to systematically investigate the potential use of AT as a theoretical lens for guiding empirical analysis and design explorations in design for sustainability (see Paper V). The results of the meta-synthesis study then led to both theoretical and design implications that support design researchers in better framing and addressing design challenges concerning people's sustainable behavior in the context of people's activity systems.

\section{Stage 4 - Descriptive Study II (DS-II):}

The deliverable of PS-I and DS-II is an AT-informed toolkit prototype which aims to support design practitioners in incorporating sustainable behavior retention perspective into the ideation stage of their sustainable design practices. More precisely, while the focus of PS-I is to develop and iterate the AT-informed toolkit prototype, DS-II focuses on evaluating the applicability and usability of the prototype. In line with the overall topic of the other case studies included in the thesis, the evaluation was undertaken in the area of sustainable household food consumption.

\subsection{A brief introduction to the selected research methods}

As summarized in Table 3, the study is divided into four research stages with different research focuses. Answering the research questions in each research stage thus requires the application of different research methods. This section gives a brief overview of the methods applied in each research stage. It has to be noted that detailed information regarding how the methods was employed is also presented in the result chapter. This section focuses on describing the background and detailed set-up of each method. The focus of the method sections in the result chapter is on how different methods were combined and employed together in each case study.

Table 3. The research focuses, research questions and methods applied in each research stage.

\begin{tabular}{cccc}
\hline Research stages & Focuses & RQs & $\begin{array}{c}\text { Methods } \\
\text { applied }\end{array}$ \\
\hline $\begin{array}{c}\text { Research } \\
\text { Clarification } \\
(\text { RC) }\end{array}$ & $\begin{array}{c}\text { Formulate preliminary research } \\
\text { inquiry and identify relevant } \\
\text { theoretical perspectives }\end{array}$ & RQ 1 & $\begin{array}{c}\text { Narrative literature } \\
\text { review }\end{array}$ \\
\hline $\begin{array}{c}\text { Descriptive } \\
\text { Study I (DS-I) }\end{array}$ & $\begin{array}{c}\text { Develop and validate a theoretical } \\
\text { framework to systematically analyze } \\
\text { behavior transformation induced by }\end{array}$ & RQ 2 & $\begin{array}{c}\text { Diary probes; } \\
\text { In-practices studies; }\end{array}$ \\
\hline
\end{tabular}




\begin{tabular}{cccc}
\hline $\begin{array}{c}\text { Prescriptive } \\
\text { Study I (PS-I) }\end{array}$ & $\begin{array}{c}\text { Develop an AT-informed ideation } \\
\text { toolkit to support sustainable activity } \\
\text { design }\end{array}$ & RQ 3.1 & $\begin{array}{c}\text { Narrative literature } \\
\text { review; } \\
\text { Qualitative meta- } \\
\text { synthesis }\end{array}$ \\
\hline $\begin{array}{c}\text { Descriptive } \\
\text { Study II (DS-II) }\end{array}$ & $\begin{array}{c}\text { Evaluate the applicability and } \\
\text { usability of the toolkit prototype }\end{array}$ & RQ 3.2 & Co-creation \\
\hline
\end{tabular}

\subsubsection{Narrative literature review}

A narrative literature review is a comprehensive, critical, and objective evaluation of previous studies on a research topic (Machi \& McEvoy, 2012). It is often used to summarize the current knowledge development in a research area and explain why a particular topic within the research area is worthy of exploring (Allen, 2017; Baker, 2016). In this study, two narrative literature reviews were conducted.

The first narrative literature review was conducted in the RC stage to address the first research question: what is the status of current knowledge of sustainable behavior retention in the existing body of literature in the field of design for sustainable everyday life? Consequently, the scope of this narrative literature review is within the design for sustainable everyday life. In addition to the focus on the aspect of behavior change and retention, another special focus is given to the theoretical perspective that each study uses to analyze and understand behavior transformation. Therefore, insight gained from this narrative literature review not only contributes to the formulation of a general research background of $\mathrm{PhD}$ study, but also helps to identify and summarize the relevant theoretical perspectives included in this dissertation. The other narrative literature review was conducted in the PS-I stage. The goal is to explore how the key AT theoretical principles are applied in design research to address sustainability-related challenges. This review has a particular focus on the overlapping area between three general fields: activity theory, design research, and sustainability.

\subsubsection{Systematic literature review}

Compared with narrative literature reviews, a systematic literature view aims to use rigorous criteria to identify, select, assess, and critically analyze all the relevant literature relating to particular research questions (Cronin, Ryan, \& Coughlan, 2008). Depending on the specific features of each research area, different 
systematic literature review guidelines have been proposed. For example, the PRISMA's systematic literature review checklist (Moher et al., 2009, 2016) has been widely used in medical research, Petticrew \& Roberts (2008)'s systematic review guide has been widely adopted in social science disciplines. In this study, I adopted and adapted the systematic literature review methodological guideline developed by (Kitchenham, 2004). This systematic literature review guideline is chosen as it explicitly focuses on performing reviews in the field of engineering and design, which matches with the general background of the PhD study. Moreover, the guideline is potentially applicable to cover a wide range of research topics as it also draws on systematic literature review insights from medical and sociology research (Kitchenham \& Brereton, 2013; Kitchenham \& Charters, 2007).

A systematic literature review was conducted in Study C-I to compile existing knowledge regarding how consumers use date and storage labels in their food assessment activities. The systematic literature review is comprised of three phases: 1). Planning the review, 2). Conducting the review, 3). Reporting the review. Figure 6 shows a step-by-step procedure of the systematic literature review. A detailed description of how the systematic literature review was performed can be found in Section 5.4.1.2, also see Paper III.

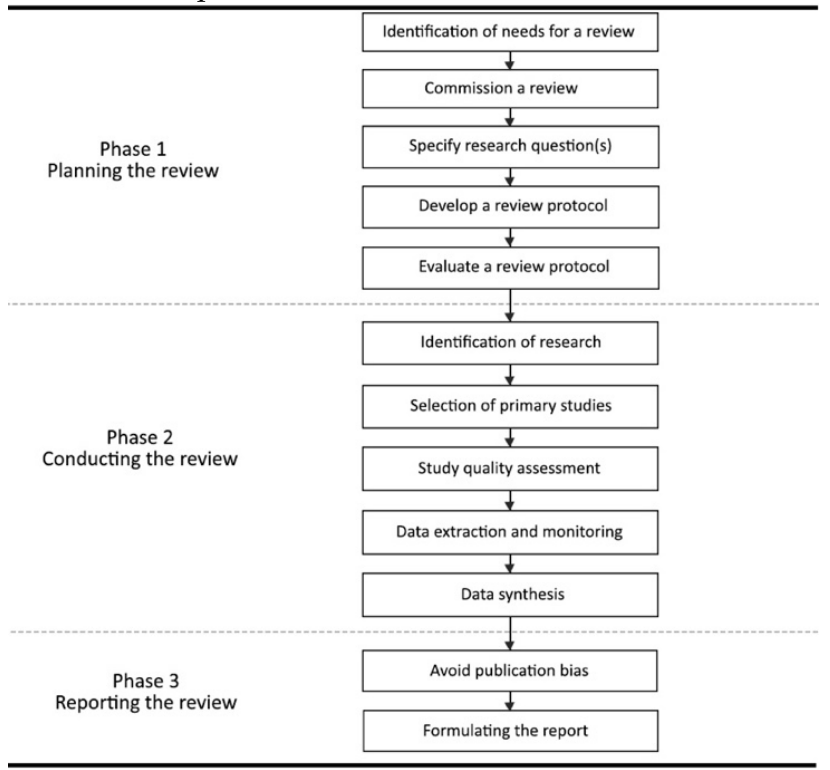

Figure 6. Systematic literature review procedures adapted from Kitchenham \& Charters (2007). 


\subsubsection{Qualitative meta-synthesis}

The qualitative meta-synthesis is conducted in Study E-I to systematically synthesize AT as a theoretical lens for guiding empirical analysis and design explorations in design for sustainability. A qualitative meta-synthesis is a hermeneutic approach seeking to generate understanding about phenomena by integrating, comparing, and translating original findings from a number of interrelated qualitative studies into coherent ones (Sandelowski, Docherty, \& Emden, 1997; Stern \& Harris, 1985; Walsh \& Downe, 2005)。 Unlike a narrative literature review and a systematic literature review, a meta-synthesis aims to transfer the findings from each independent primary study into more generalizable theoretical insights or conceptualizations that can be applied beyond the original study sample (Polit \& Beck, 2006). Therefore, compared with the literature review, qualitative meta-synthesis is more tailored for theory development and higher-level abstraction of a particular phenomenon (Zimmer, 2006).

A variety of meta-synthesis methodological guidance have been proposed in different research fields (e.g., Finlayson \& Dixon (2008) and Paterson, Thorne, Canam, \& Jillings (2001)). In the context of this study, the qualitative meta-synthesis method was applied in the PS-I stage with a specific focus on developing an ATinformed ideation toolkit to support sustainable activity design. Based on the explicit focus on generating and translating the activity theory into practical design applications, I adopted and adapted the theory-generating qualitative metasynthesis methodological guideline developed by Finfgeld-Connett (2018). This guideline is chosen due to its clear methodological procedures for identifying and synthesizing isolated and contextually distinct findings from each primary study into more generalizable theories and frameworks (Leary \& Walker, 2018).

As illustrated in Figure 7, the theory-generating qualitative meta-synthesis is comprised of seven steps. A detailed description of how the meta-synthesis was performed can be found in Section 6.4.2 (also in Paper V). 


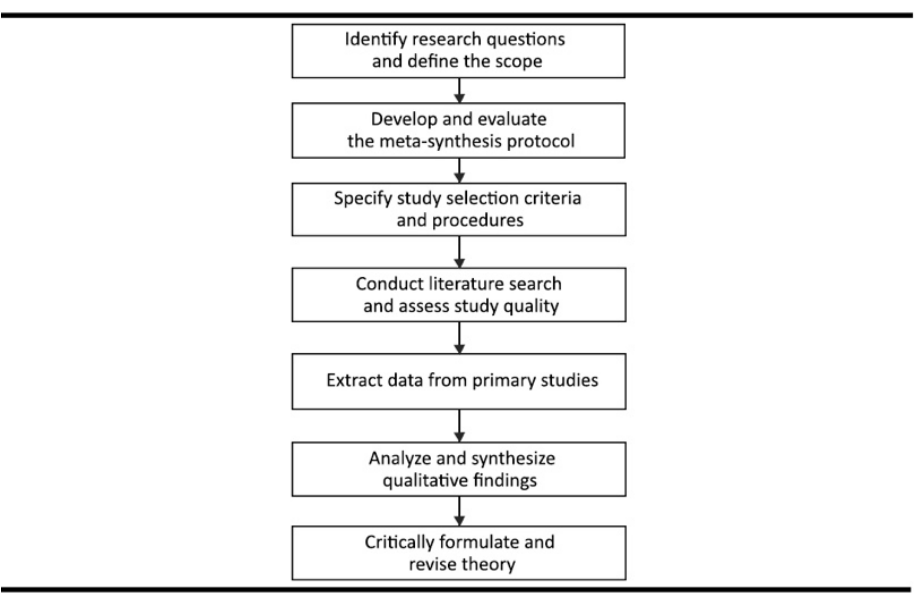

Figure 7. Theory-generating meta-synthesis procedures adapted from Finfgeld-Connett (2018).

\subsubsection{Diary probes}

The diary probe method is one of the sub-methods derived from cultural probes. Diary probes are often used to collect data related to participants' actual doings, feeling and experiences in an exploratory way by allowing participants to report relevant data by themselves (Gaver, Dunne, \& Pacenti, 1999). When used in design research, the strengths of diary probes are three folders. First, diary probes help researchers to understand users' subjective interpretations of the world. They are often used to explore a phenomenon from a design perspective rather than solving a problem (Hanington \& Martin, 2012). Second, the use of diary probes can minimize the influences that the physical presence of researchers may bring to participants when they are performing their everyday life doings, thus reducing the potential interruptions in the data collection process (Mattelmäki, 2005). Third, the self-documentation feature of diary probes can help participants arrive at new levels of awareness about their behavior and experiences when they are documenting and reflecting on their data (Pink \& Mackley, 2015).

However, participants' levels of engagement in self-reporting often very from each other. Some may report their data in detail, while some may lack motivations for reporting. Avoiding these potential risks associated with the use of diary probes requires researchers to carefully test and revise the probes in pilot studies before 
they are officially sent to participants. Drawing on this insight, the diary probes used in the context of this $\mathrm{PhD}$ study were all evaluated in pilot studies.

Specifically, diary probes were employed in two studies: Study A-II (also see paper II), which deals with the transformation of exchange students' food consumption activities, and Study D, which is about people's food consumption activities during strict city-scale lockdown measures caused by the Covid-19 pandemic. Both of the diary probes are seven-day diaries. Participants are supposed to document their food consumption patterns on a daily basis. The diaries comprise three parts: the first part is an instruction on how to report data in the diary. The second part is for participants to document their everyday food consumption doings in general. The third part is a set of reflective questions given by researchers with regard to participants' particular food consumption activities. There is a difference in the form of the diary probe used in these two studies. In Study A-II, a handwritten diary probe was sent to participants, while in Study D, a digital diary probe was used. Moreover, the handwritten diary was sent to participants and collected after seven days, while the digital diary was sent to and collected from participants daily.

\subsubsection{In-practice studies of everyday human activities}

In-practice studies are a suite of methods, such as interviews and field observations, interwoven with each other and conducted in the context where participants are doing their tasks (Pink, 2017). Unlike diary studies, in-practice studies require researchers to go into the field and collect empirical data when participants perform their daily doings in real-life settings (Pink, 2017).

The in-practice studies were used in Study A-II (see Paper II). As the topic of Study A-II is on food consumption, this method is referred to as participatory cooking. Specifically, the in-practice studies were conducted when participants visit local supermarkets and cook and eat at home individually. The purpose of employing this method is to gain a descriptive account of how participants perform their food consumption activities. First, a 30-45 minutes semi-structured interview was conducted to encourage participants to talk about how they carried out their food consumption activities in the context of their home university and during exchange study. After that, the researcher followed the participants in their food purchasing, and then joined in their cooking. 


\subsubsection{Co-creation}

Co-creation usually takes place in a workshop setting where designers and people not trained in design (e.g., customers, executives, and staff) work together to solve a problem (Sanders \& Stappers, 2008). Co-creation can be used in combination with many other methods (Stickdorn, Hormess, Lawrence, \& Schneider, 2017). In this dissertation, co-creation refers to collaborative design workshops and brainstorming sessions. The goals of co-creation can be summarized into two folds: 1). to identify potential design directions, 2). to gather a wide range of perspectives in the design process.

Co-creation was employed in Study C-I (see Paper III) and Study E-II (see Paper VI) to achieve different goals. In Study C-I, co-creation was used to generate early-stage design ideas to address on-pack date and storage labelling issues. In Study E-II, it was used to evaluate the use of the proposed AT-informed design ideation toolkit from different perspectives. 


\section{4}

\section{Current knowledge of design for sustainable behavior retention}

This chapter focuses on answering RQ 1. Specifically, a narrative literature review process and results regarding the current knowledge status of design for behavior retention perspective is reported in this chapter.

\subsection{A narrative review within the field of Design for Sustainable Behavior}

The goal of the narrative literature review is to develop an overview of how the topic of design for behavior retention is covered in the existing body of studies in the field of DfSB. The narrative literature review was conducted in March 2019. Scopus was used as the literature search database. Journal articles, conference papers, and book chapters published in all years till March 2019 are included in the literature search scope.

As shown in Table 4, the narrative literature review process comprises four steps: In step 1, two groups of search strings were used in the initial search. Group A focuses on the behavior change perspective. The search strings include a) "design for behavior(al) change and b) "sustainable behavior(al) change". Group B focuses on the behavior retention perspective. The search strings include a). "design for behavior(al) retention", b). "design to retain", c). "(retain behavior OR maintain behavior)" AND "Design", and d). "(behavior(al) retention" OR "behavior(al) maintenance") AND “Design". In step 2, after removing duplicated results, 233 
articles remained. In step 3 abstract and content screening, two exclusion criteria were used:

- The article that is not focused on a design perspective is excluded.

- The article that is not related to the human or technological aspect of design is excluded (as some articles deal with the behavior of physical and biological material).

Table 4. The narrative literature search steps and results.

\begin{tabular}{c|c}
\hline Literature search steps & Results \\
\hline $\begin{array}{c}\text { Step 1. Define search scope and } \\
\text { determine search keywords }\end{array}$ & Search strings \\
\hline Step 2. Carry out the literature search & $\begin{array}{c}233 \text { articles after removing duplicated } \\
\text { Step 3. Abstract and content screening }\end{array}$ \\
\hline Step 4. Full-text review & $\begin{array}{c}129 \text { articles remained } \\
\text { General DfSB: } 53 \text { articles }\end{array}$ \\
\hline
\end{tabular}

Step 3 results in 129 articles. Among the included articles, 69 articles were categorized into the behavior change perspective, while only 7 articles were categorized into the behavior retention perspective. In addition, 53 articles were categorized into the general DfSB perspective which might touch upon both change and retention perspectives, but they do not explicitly focus on any of the aspects. In Step 4, after full-text review, 8 articles were identified as behavior retention-related.

The results show that the meaning of retention is interpreted differently in the identified literature. For example, similar to the initial definition of behavior retention given in this dissertation (see Section 1.3), in their study about sustainable household fridge and freezer design, the concept of retention was used by Tang \& Bhamra (2012) as enhancing and reinforcing an existing desired behavior. Specifically, they observed that some participants tend to check what food is stored in the fridge in order to decide what needs to be purchased. This specific behavior is regarded as a desirable environmental behavior that contributes to household food waste reduction. To promote and enhance this fridge-checking behavior, they redesigned the layouts and drawers of the fridge to provide consumers with a clear display of the content inside. In addition to that, with the goal to explore how technology system can be designed to avoid rapid obsolescence, the term retention was used by Garud \& Kumaraswamy (1996) to refer to integrity, modularity and 
upgradability of a technological system. More precisely, the concept of upgrading a system by replacing some components while retaining the others without having to design the entire system.

Shin \& Bhamra (2016) referred to the concept of behavior retention as maintaining the stability of the changed behavior and minimize the need for repeated intervention. Similarly, the need to maintain the effects of behavior change over time is also pointed out in van Dam et al. (2010)'s study about the impacts of energy monitors on people's energy saving behavior. They found that participants tend to revert to their old energy consumption behavior patterns after medium-term. With a specific focus on promoting physical exercise, health and well-being, Zhou et al. (2018), Mitchell, Schuster, \& Drennan (2017) and Zhang \& Lowry (2016) also highlighted the importance for design interventions to consider how to maintain users' motivations of behavior changes and achieve long-lasting sustainable effects.

The concept of sustainable behavior retention was implicitly touched upon by Hielscher, Fisher, \& Cooper (2009) to explore opportunities in hair care sustainable product design. Drawing on a historical review of people's past hair care practices, they concluded that there is an opportunity to combine conventional hair care approaches (e.g., brushing, combing and dry-shampooing) with the modern chemical products-based hair care approaches to achieve less resource intensive practices. However, the focus on how people carried out the hair care practices in the past does not mean to retrieve the past. Instead, it is used in the study to discover new design opportunities by learning from the sustainable aspect of people's preexisting doings.

In summary, the narrative literature review results confirm that, compared with the design for behavior change perspective, the behavior retention perspective remains relatively barely covered in the existing body of DfSB studies. Moreover, the retention perspective is applied differently when dealing with different research topics. The concept of retention is commonly applied to maintain the positive effects of behavior change for a long-term time span, especially in the studies that focused on introducing sustainable design interventions to promote health and well-being. Other included studies implicitly used the concept of retention as a way to identify design opportunities based on sustainable elements embedded in people's existing and past doings. However, based on the review results, the specific question of how to retain people's existing desired and sustainable doings when they undergo context change disruptions, which is the research focus that this dissertation 
revolves around, has not been explored in DfSB studies both from theoretical and practical aspects. 


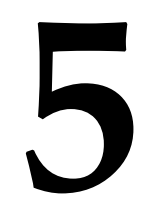

\section{Development of the AT- based framework}

This chapter presents the detailed development and application results of the AT-based theoretical framework. As shown in Figure 8, the framework underwent three iterations and one validation:

- The initial framework (version 0.1) is established on AT's theoretical principle of hierarchical structure, which has already been widely applied in previous design for sustainability relevant studies.

- Following that, with a particular focus on AT's principle of mediating artefacts and developmental perspective, the first version of the framework (Version_1.0) is proposed based on results from Study A-I and A-II.

- $\quad$ Then, results from Study B-I and B-II are used to develop the second version of the framework (Version_2.0), which takes sociocultural contexts into account.

- After that, through incorporating $\mathrm{AT}^{\prime}$ 's principle of tensions and contradictions, Study C-I iterates the framework to Version_3.0.

- $\quad$ Finally, Study D is used to validate the proposed framework. 


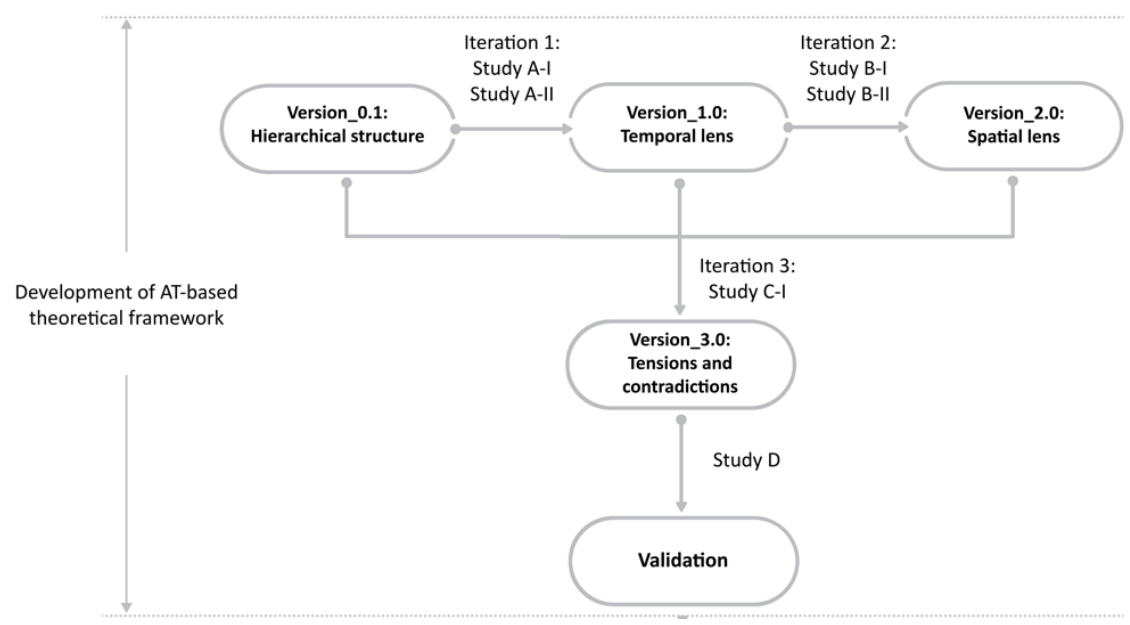

Figure 8. The iteration process of the AT-based theoretical framework.

It is worth noting that the development and iteration process of the AT-based theoretical framework is presented in detail due to two reasons:

First, as described in Chapter 2, five key AT theoretical principles are identified. Incorporating all these theoretical principles into the framework at once may, to a large extent, limit the exploration of the analytical features that AT can provide. Therefore, based on this particular concern, I adopted a step-by-step iteration process to enable both an in-depth (in the sense of one or multiple studies focus on one theoretical principle) and a comprehensive (in the sense of integrating results from different studies) exploration of the AT theoretical lens in design for sustainable everyday life.

Second, the studies presented in this thesis are not in a linear relationship, where one builds on the other's results. Instead, each study is assigned, planned and carried out with different focuses. The theoretical focus of some studies overlaps with others (e.g., Study B-I and Study B-II all focused on sociocultural contexts), while some studies inform a further exploration of others (e.g., The insights generated from Study A-II informed and influenced the theoretical exploration in Study C-I). By distributing the key results of these studies to different iteration stages, it might allow readers of the thesis to better understand the content and structure of the overall PhD study. 
To present the results in a more structured way, each study is presented in the following manner: First, background settings and specific goals of the study are introduced. After that, the applied research methods are briefly described. Then, key results and insights concerning the development and iteration of the AT-based theoretical framework are articulated. Table 5 clarifies the iteration of the AT-based theoretical framework in relation to the corresponding theoretical principles.

Table 5. The iteration of the AT-based theoretical framework in relation to different theoretical principles.

\begin{tabular}{c|c|c}
\hline AT framework version & $\begin{array}{c}\text { Corresponding theoretical principles incorporated } \\
\text { into the framework }\end{array}$ & Sections \\
\hline Version 0.1 & Hierarchical structure & Section 5.1 \\
\hline Version_1.0 & $\begin{array}{c}\text { Mediating effects of artefacts } \\
\text { \& developmental perspective }\end{array}$ & Section 5.2 \\
\hline Version_2.0 & Sociocultural contexts & Section 5.3 \\
\hline Version_3.0 & Tensions and contradictions & Section 5.4 \\
\hline Framework validation & Validating the proposed theoretical framework & Section 5.5 \\
\hline
\end{tabular}

\subsection{AT-based theoretical framework: Version_0.1}

As indicated in Section 2.1, the hierarchical structure of the activity system is one of the most fundamental theoretical principles in AT. This theoretical principle was previously applied in Selvefors (2017) and Renström (2019)'s studies to break down and analyze people's sustainable (and un-sustainable) doings from a sustainable product and service design perspective. Other relevant works that deal with the use of AT in product and service design also highlight the importance of understanding people's activity system in different hierarchical layers (Karlsson, 1996; Rexfelt, 2008).

Therefore, the hierarchical structure of the activity system is used as the foundation to begin the exploration of the potential use of AT in design for sustainable everyday life. As illustrated in Figure 9, the classic activity hierarchical structure model proposed by is adopted as the initial version of the AT-based theoretical framework (version_0.1). 


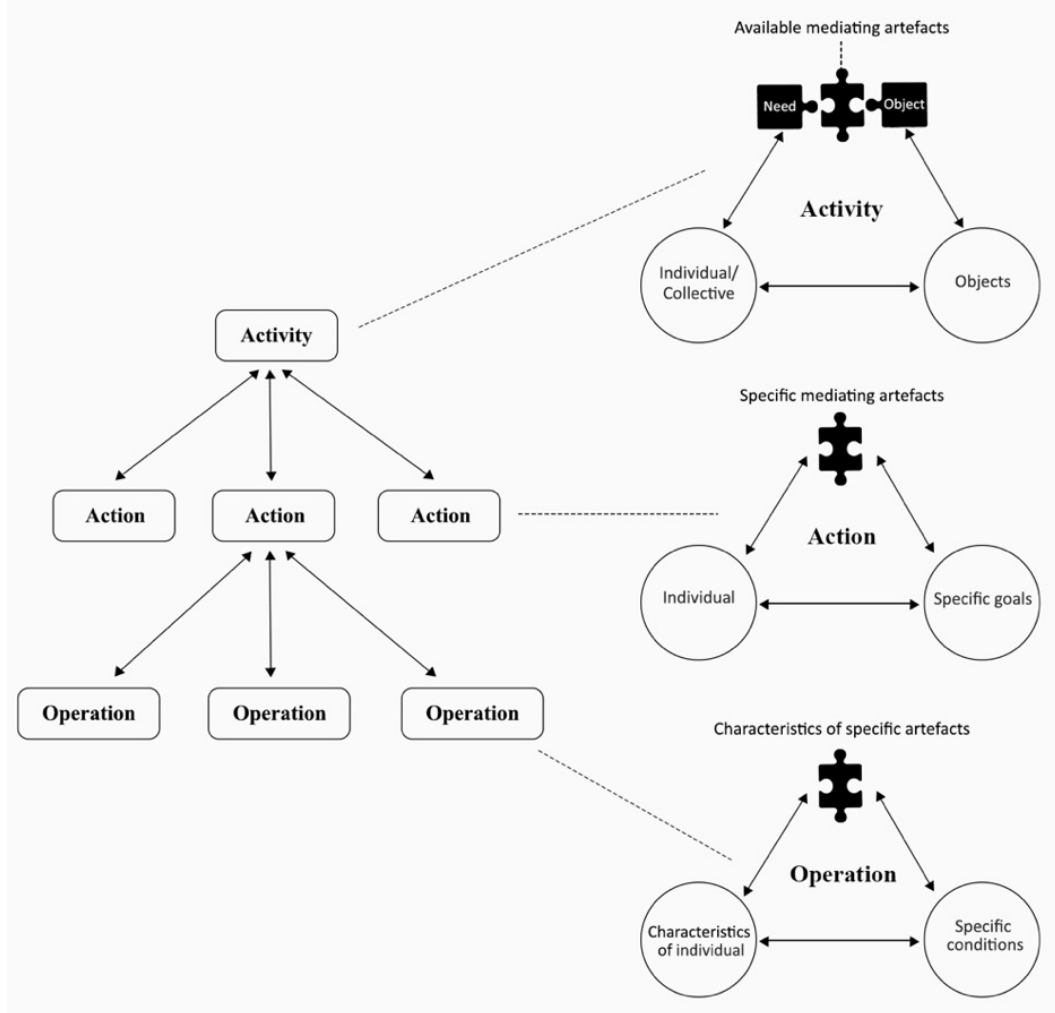

Figure 9. The initial AT-based theoretical framework that this study builds upon.

\subsection{Development of the AT-based theoretical framework: the first iteration}

In the first iteration, two explorative case studies: astronauts' food consumption activities on the International Space Station (Study A-I) and exchange students' food consumption (Study A-II), were conducted to gather insights and reflections regarding the use of the initial AT-based theoretical framework mentioned above. The overarching aims behind these two case studies are two folds: First, to obtain a holistic understanding of the impacts of context change disruptions on people's pre-existing everyday life doings, specifically, people's food consumption-related behavioral patterns. Second, from a theoretical perspective, I intended to explore how AT can be adopted and adapted as a design-related 
theoretical lens to systematically analyze the behavioral transformation during life event disruptions.

5.2.1 Case study A-I: Understanding the mediating effects of artefacts in the behavior transformation

\subsubsection{Study set-up and goals}

According to Stuster (2010), astronauts who have carried out long-term spaceflight expedition on the International Space Station (ISS) have experienced significant physical, social and psychological changes from Earth to a spaceflight environment. Therefore, the changes constitute a highly representative real case scenario where the subjects have to undergo a contextual transition and adapt to the new environment. Due to the contains of confined and microgravity living environment on the ISS. Food delivered to the ISS is mainly based on standard menus, which are pre-packed in thermostabilized foil pouches and cans for direct heating. However, to increase well-being, astronauts retained and further transformed their Earth-bound food consumption activity into what they called "space cooking", which is combining and assembling food ingredients into a more personalized meal.

Based on this reason, I selected astronauts' everyday food consumption activities on the ISS as the research set-up for this case study. In this particular setting, the goal of the study is to develop an overview of the mediating role that artefacts can play in transforming astronauts' pre-existing food consumption activities through context change disruptions.

\subsubsection{Methods applied}

The particular challenge of the case study lies in the data collection process. Conducting direct interviews or observational studies with astronauts who onboarded the ISS would be difficult. However, astronauts have documented their daily activities such as tasks and experiments, food consumption, exercises, leisure and entertainment activities, along with their subjective experiences and reflections in great detail in their expedition journals, some of which are available on NASA Life Sciences Database Archive, NASA Technical Report Server and Crews and Exhibitions page for public access. These expedition journals have already been used by NASA behavior scientists to study astronauts' psychology and behavior issues during spaceflight missions (see for example, Stuster (2000, 2010, 2016)), 
which laid a methodological foundation for the data collection and analysis of this study.

As this study sets a particular focus on astronauts' food consumption activities, relevant data regarding how astronauts carry out their food consumption, including meal preparation, eating and food disposal, were extracted from the aforementioned database. Both the primary sources (e.g., expedition journals, photos, and videoclips) and secondary sources (e.g., technical reports and research articles) were used as the empirical materials for analysis. An abductive approach was applied to analyze the collected data. Relevant data were extracted into segments in Excel sheets and later sorted into different themes. Themes with similar patterns were then organized in the same group and later abstracted at a higher level. After that, the AT-based theoretical framework (version_0.1) was used to analyze the results.

\subsubsection{Results}

As illustrated in Figure 10, by focusing on the mediating role that artefacts play in the hierarchical structure of astronauts' space cooking activities, two types of behavioral transformation that took place in astronauts' food consumption system can be identified. 


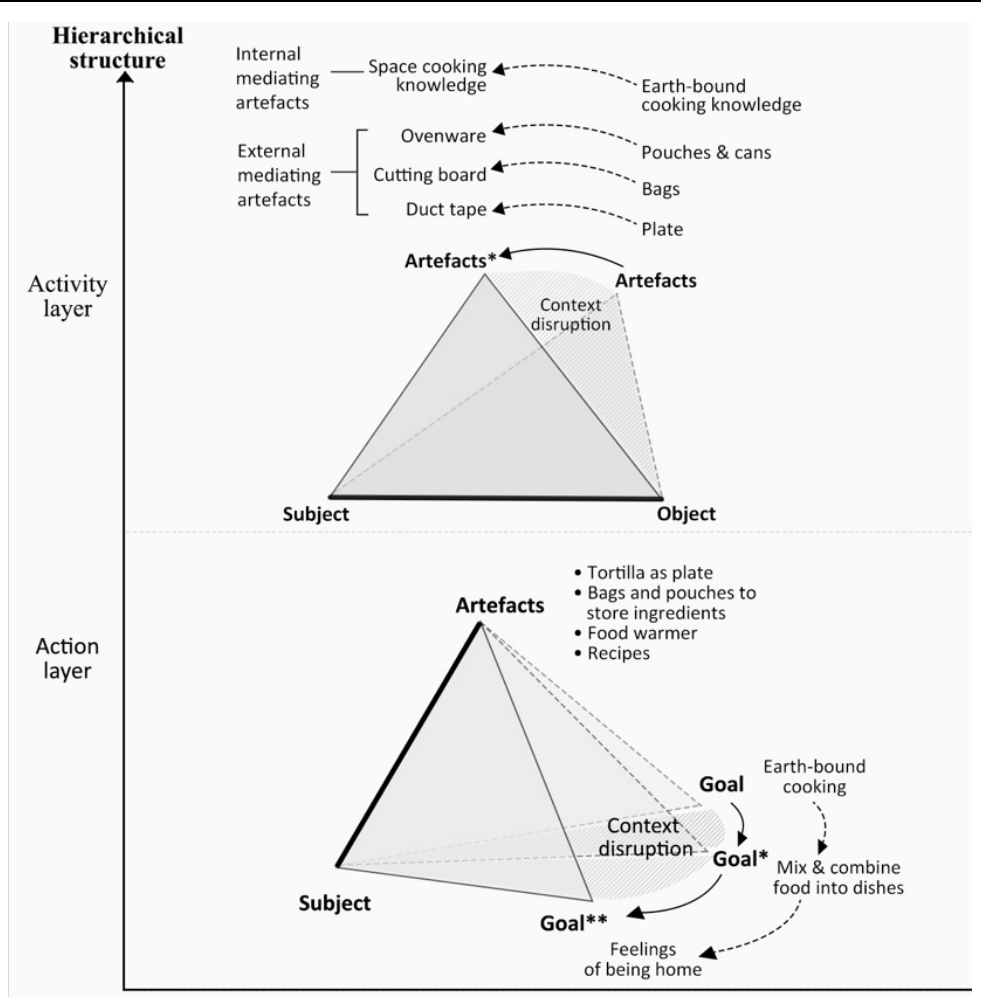

Figure 10. The transformation of astronauts' food consumption activities illustrated through an AT theoretical lens.

First, in the activity layer, the available artefacts that subjects used in their preexisting activity system have been changed due to context change disruptions, while the specific goals that subjects aim to attain in their pre-existing activity system remain the same. Consequently, the artefacts available in the new context are adopted and adapted to retain the original subject-object relationship (as illustrated in the activity layer in Figure 10). For example, in the context change transition from an earth-bound environment to the ISS, the goal of making a personalized meal remains unchanged. However, since the ISS does not provide cooking tools such as cutting board, pans and ovens that people commonly use on the ground, in order to attain the pre-existing goal, astronauts have to use duct tape as small plates to adhere food from floating away, foil pouches and plastic bags are reused as disposal cutting boards to cut ingredients inside thus to prevent food fragments from spreading in the air, empty foil pouches and food cans are reused as containers for 
heating the mixed ingredients in food warmers (see Figure 11). In addition to the transformation in the use of these external mediating artefacts mentioned above, they also improvised based on their Earth-bound cooking knowledge and developed space cooking skills.

Second, in the action layer, as the subjects underwent context change disruptions, they developed and adapted new goals from their pre-existing activity systems, while the original relationships between subjects and mediating artefacts used in the pre-existing activity system remain (as illustrated in the action layer in Figure 10). For instance, the astronauts' goal of cooking underwent a transformation process from earth-bound cooking to simply mix and combine different food ingredients on the ISS. In this transition process, the specific usage of certain artefacts, such as using plastic bags to temporarily store ingredients and using tortilla as plates to hold and mix different ingredients, remained the same (see Figure 11).
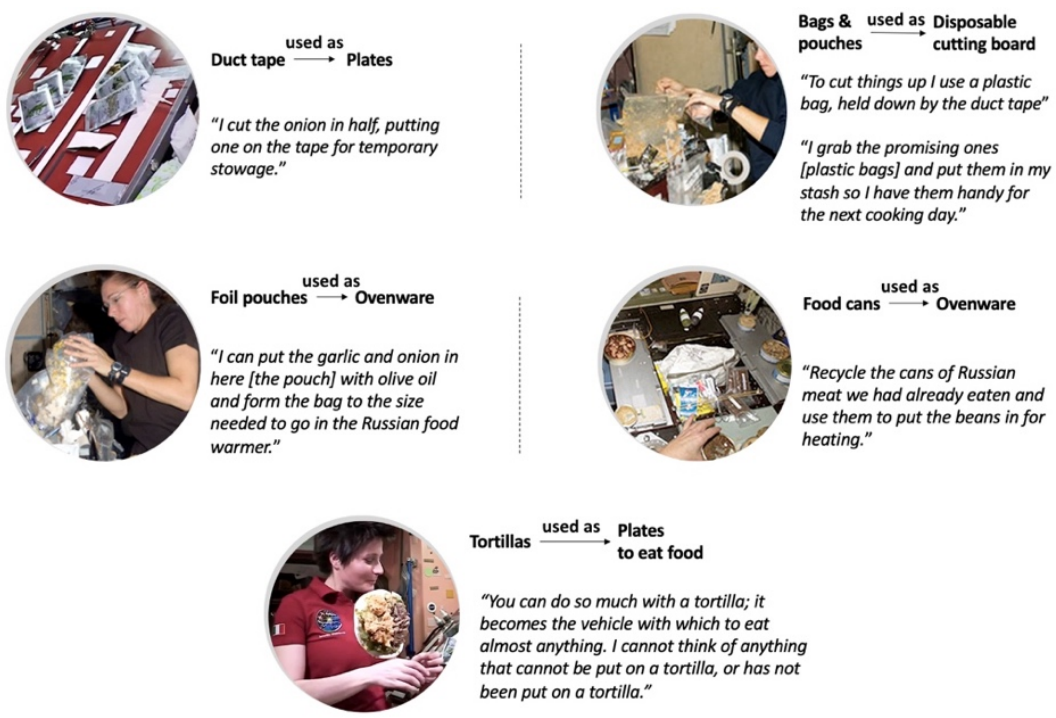

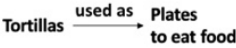

"You can do so much with a tortilla; it

becomes the vehicle with which to eat

almost anything. I cannot think of anything

that cannot be put on a tortilla, or has not

been put on a tortilla."

Figure 11. The mediating role that artefacts play in astronauts' space cooking activities. 
5.2.2 Case study A-II: Framing the dynamic development of activities

\subsubsection{Study set-up and goals}

Study A-II focuses on understanding the transformation of exchange students' food consumption patterns during exchange studies. Previous studies conducted in behavioral psychology showed that moving to a foreign country for study constitutes a moment of change that disrupts the pre-existing habitual behavior that the subjects used to perform (Wood et al., 2005). Therefore, I chose Asian exchange students in Sweden as the target group of participants in this case study.

By investigating the influences that exchange study has on participants' daily food consumption activities, I aim to explore how an AT theoretical lens may uncover the dynamic development process of people's activity systems during the course of life event transitions.

\subsubsection{Methods applied}

In-practice studies of everyday human activity and diary studies were applied to collect relevant data. The rationale behind using the combined method is not only to learn about what has been changed and retained during the life event disruptions, but also to gain a descriptive account of how and why participants transformed some of their specific doings when they were facing these disruptions.

As illustrated in Figure 12, first, the in-practice studies, which comprises field observations and semi-structured interviews, were tested and revised in a pilot study. Following that, the in-practice studies were conducted with all the participants individually when they were visiting the local supermarket, cooking and eating at home. The results of the in-practice studies were used to formulate tailored questions in a seven-day food consumption diary. The diary was designed for each participant to document and reflect on their food consumption-related doings on a daily basis. We also used the diary to collect empirical data regarding some of the themes that emerged from the in-practice studies. For example, data regarding participants' specific food consumption behavioral patterns such as the frequency of shopping, the amount of food consumed in one week, the most consumed food categories, which participants were unavailable to give accurate answers during the in-practice studies, were thus collected in the diary studies. 
The same abductive data analysis approach applied in Study A-I was adopted in this study. First, data collected from the diary studies and the in-practice studies of everyday human activity were analyzed inductively. Affinity diagram was used to summarize and identify themes that emerged from the raw data. Themes with similar patterns were organized into same groups. These groups were later categorized in a higher level of abstraction. Then, the Activity Theory (AT) model together with the key theoretical principles of AT were employed to analyze the results from the affinity diagram.

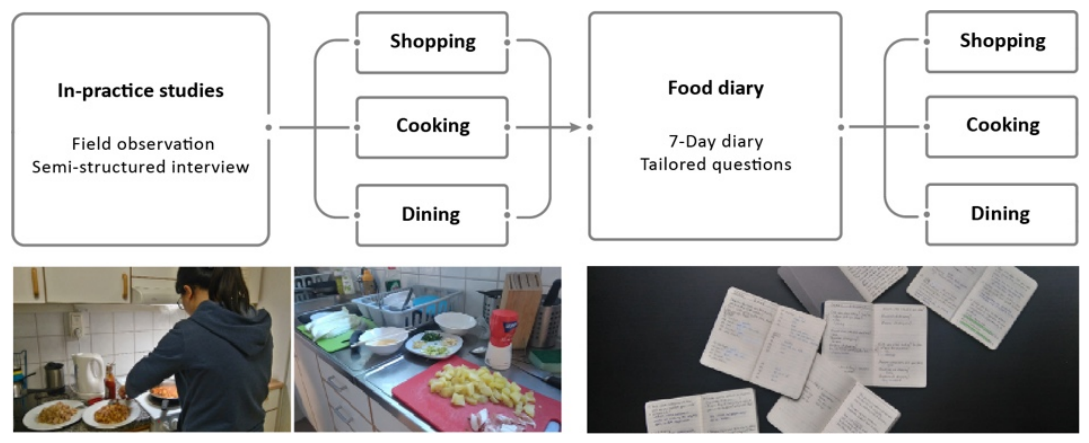

Figure 12. The data collection process in Study A-I.

\subsubsection{Results}

In total, six exchange students were recruited as the participants of the study. They all arrived at Linköping University in mid-January of 2017 with a planned stay for 5-6 months.

To better frame and describe how participants transformed their food consumption activities when they underwent life event disruptions caused by exchange studies, a development dimension is added to the initial AT-based theoretical framework. As shown in Figure 13, the newly proposed framework takes into account both the hierarchical layer and the development perspective of activity systems. 


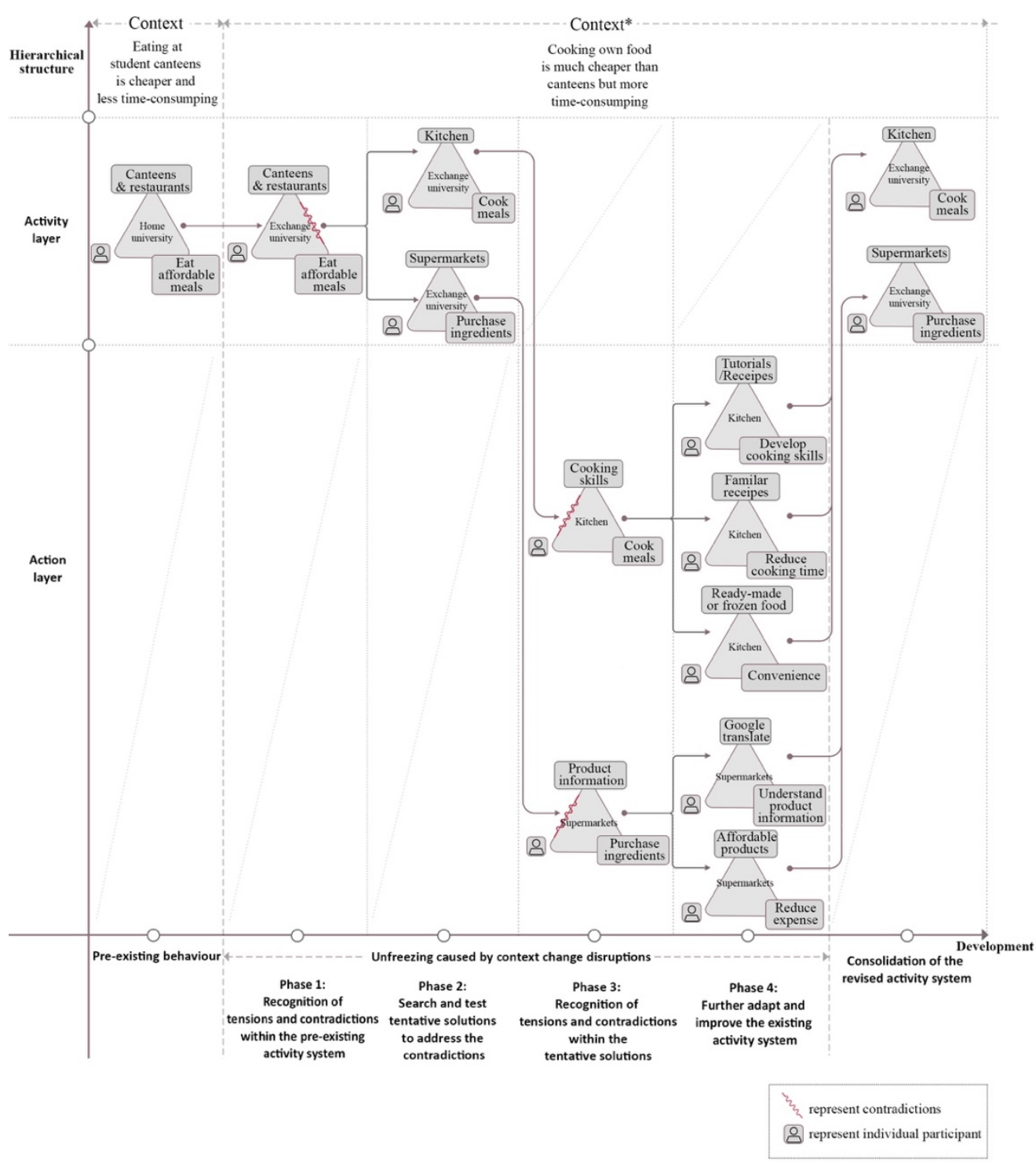

Figure 13. The development process of participants' food consumption activity systems illustrated according to an AT theoretical lens.

In line with the AT's development model proposed by Blackler et al., (1999), four development phases can be identified in this study: 1). Phase 1 is when 
participants recognize tensions and contradictions within the pre-existing activity system, 2). Phase 2 is when participants begin to search and test tentative solutions to address the contradictions, 3). Phase 3 is when participants recognize tensions and contradictions within their newly developed tentative solutions, and 4). Phase 4 is when participants further adapt and improve their existing activity systems to fit into the new context. Table 6 elaborates on how participants transform their food consumption activity in each phase.

Table 6. The developmental phases and corresponding behavior transformation from an AT theoretical lens (for details see Paper II).

\begin{tabular}{|c|c|}
\hline Transition phases & Corresponding results \\
\hline $\begin{array}{l}\text { Phase } 1 \text { : } \\
\text { Recognition of tensions } \\
\text { and contradictions } \\
\text { within the pre-existing } \\
\text { activity system }\end{array}$ & $\begin{array}{l}\text { - Participants' food consumption activities underwent a transformation process } \\
\text { from directly ordering ready-made meals at student canteens (before exchange } \\
\text { studies) to regularly cooking meals in student corridor kitchen (during exchange } \\
\text { studies). } \\
\text { - Participants' food consumption goals in both of the contexts were to eat } \\
\text { affordable meals. However, the price differences of meals between their original } \\
\text { university and exchange university were the major factors that triggered the } \\
\text { transformation. To reduce costs, participants started to plan, purchase and cook } \\
\text { their meals during their exchange study. }\end{array}$ \\
\hline $\begin{array}{c}\text { Phase 2: } \\
\text { Search and test } \\
\text { tentative solutions to } \\
\text { address the } \\
\text { contradictions }\end{array}$ & $\begin{array}{l}\text { - All the participants reported a significant difference between the type of food } \\
\text { products they purchased in the supermarket in their original university and } \\
\text { exchange university. Dairy products and snacks were what they usually bought back } \\
\text { in their original university, while during the exchange study, they had to purchase } \\
\text { raw food materials and ingredients such as vegetables and meat. } \\
\text { - None of the participants had enough cooking experience. To be able to cook, } \\
\text { several solutions such as searching and learning from recipes on the internet, } \\
\text { sharing recipes with friends, and checking food information on product packaging } \\
\text { were adopted to gain relevant cooking knowledge and skills. }\end{array}$ \\
\hline $\begin{array}{c}\text { Phase } 3 \text { : } \\
\text { Recognition of tensions } \\
\text { and contradictions } \\
\text { within the tentative } \\
\text { solutions }\end{array}$ & $\begin{array}{l}\text { - New tensions and contradictions emerged in the action layer of participants' food } \\
\text { purchases and cooking. Regarding food purchasing, participants reported that they } \\
\text { were not familiar with the products sold in the supermarkets. In addition to that, } \\
\text { they also had particular concerns about the expenses spent on food. } \\
\text { - Regarding cooking, participants reported that the average time they spent for } \\
\text { preparing each meal (including shopping and cooking) at the exchange university } \\
\text { was significantly longer than the time they spent in their original university, where } \\
\text { they can directly order food and eat at students' canteens. }\end{array}$ \\
\hline
\end{tabular}

Phase 4:

Adapt and improve the existing activity system
- To reduce expenses, most participants often purchase food ingredients that were affordable or on sales. Afterward, they would incorporate the purchased food ingredients into their familiar recipes. 
- To reduce the time spent on meal preparations, participants started to adapt and improvise their cooking routines based on the knowledge and experiences gained in the previous phases. As a result, a stable meal preparation pattern was thus solidified. In some particular case scenarios where there was not enough time to make a meal, eating ready-made frozen meals was considered as an alternative.

\subsubsection{Reflections and AT-based theoretical framework: Version_1.0}

Reflecting on the use of AT's hierarchical structure model in the two case studies presented above, along with the theoretical principles of mediating artefact and development, I developed the first version of the AT-based theoretical framework (version_1.0). As shown in Figure 14, by putting the hierarchical structure of an activity system (activity layer, action layer and operation layer) on the vertical axis, and the three major developmental phases (pre-existing activity, existing activity under transformation, and consolidation of the transformed activity system) on the horizontal axis, this version of the framework focuses explicitly on framing how activity systems develop and transform over time and describing the mediating role that artefacts play in this transformation process.

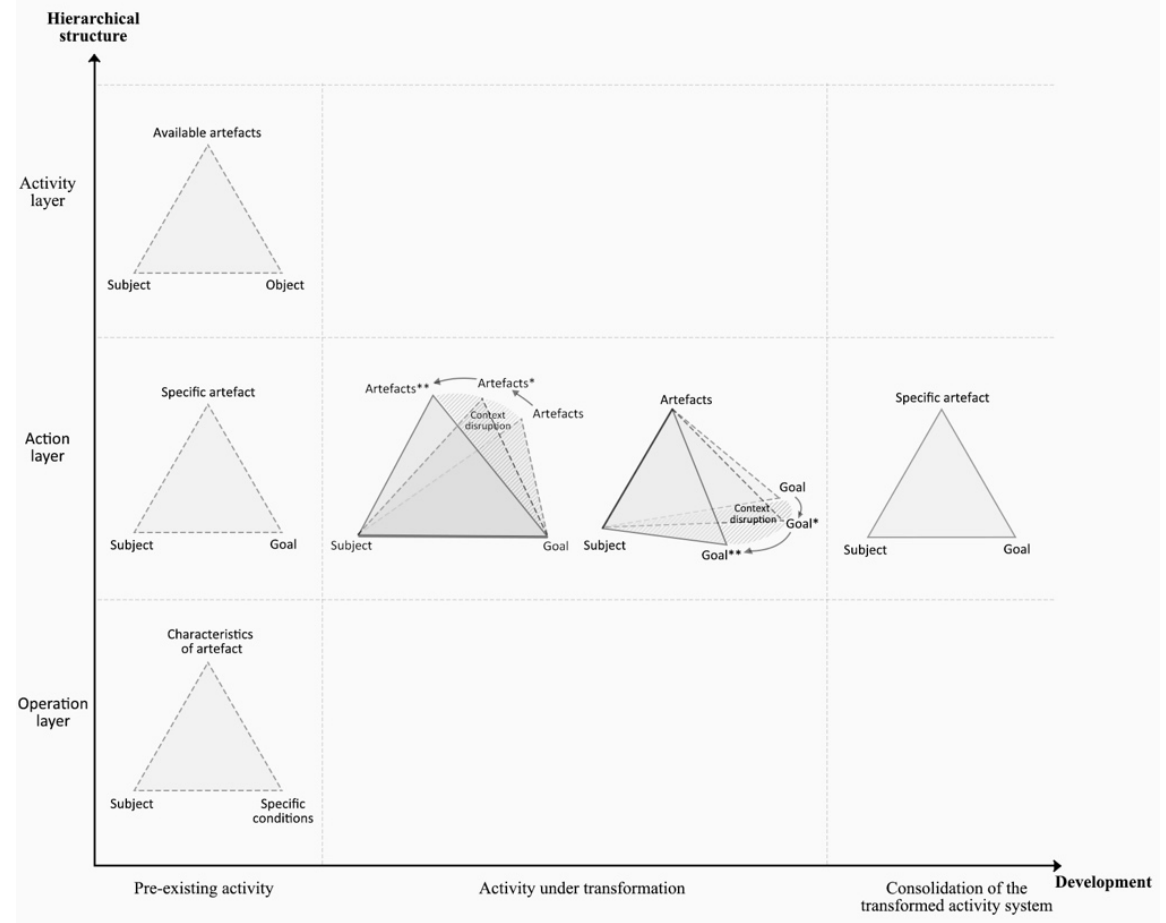

Figure 14. The first version of the AT-based theoretical framework. 


\subsection{Development of the AT-based theoretical framework: the second iteration}

This stage aims to iterate the first version of the proposed AT-based theoretical framework by adding a sociocultural dimension to the framework. Therefore, when presenting the results and findings in this stage, I will put a particular focus on discussing how to incorporate AT's theoretical principle of sociocultural contexts into sustainable design considerations.

Specifically, this stage consists of two studies: Study B-I and Study B-II. Both studies are student design projects under my supervision. Study B-I is a Design for Sustainable Everyday Life Course Project. The topic is on the sustainable usage of a microwave room in a newly constructed building at Linköping University. Study BII is a degree project in the Master of Design and Product Development at Linköping University. The topic is on designing furniture for flexible and circular kitchen activities. Moreover, part of the key insights related to AT's sociocultural contexts extracted from Study E-I is also presented in this section as it lays the groundwork for the theoretical exploration.

\subsubsection{Incorporating sociocultural contexts into sustainable design considerations}

Results from the meta-synthesis of studies that applied AT as the theoretical lens in design for sustainability (see Study B-I) show that, the theoretical principle of the sociocultural contexts is commonly used to guide the analysis of sustainability-related issues at different sociocultural levels. However, as each study's research focus varies from each other, the division of the analytical levels of sociocultural contexts used in each study also differs. In general, three types of division can be identified: 1). individual and societal level, 2). institutional and community level, and 3). individual, collective (group or community), and societal level.

\section{Individual and societal level:}

In their project about designing and evaluating the effects of an ICT platform on promoting local community members' transition towards sustainable lifestyles in southern Chile, Aguayo (2016) and Aguayo \& Eames (2017) applied AT to take into account the sociocultural elements regarding the use of technological interventions in influencing human behavior. They found that "individuals' motivations in terms of performing sustainability actions are directly related to their sociocultural contexts, such motivations can be more meaningful to users when they are linked with users' socio-cultural reality." This finding emphasized that 
individual users' characteristics and needs cannot be fully understood if they were analyzed separately from the social, cultural, and historical context of the activity system.

Similarly, AT was chosen by Smith \& Turpin (2017) as the theoretical framework to guide the evaluation of an ICT platform designed to empower elderly women in a rural community in South Africa. Their reflections showed that the sociocultural aspects of AT helped them to make the social and political dimensions of the local community and the relationship between the user (elderly women) and the design intervention (the installed ICT platform in the local community) visible to design researchers. They further pointed out that: “By emphasizing socio-cultural factors, the interaction between human actors and their environments, and the concept of tool mediation, activity theory can provide a suitable foundation for the Design \& Development and Demonstration activities of this research project." Unvoiced sociocultural problems, such as elderly women's limited access to the ICT platform installed within the community and the needs for financial support to use and maintain the platform, were thus revealed and incorporated into sustainable design considerations.

Furthermore, Khan et al. (2015) employed the theoretical concept of sociocultural contexts to solve environmental management issues of electric and electronic waste. AT was used in their study to involve all the relevant actors in the decision-making process of waste management to gain sustainability at the system level and simultaneously create behavior change at the individual level. Drawing on the use of the sociocultural perspective of AT, they noted that one of the strengths of AT is that "[AT] works as a magnifying lens in dealing with the problems that are generated in the domain of sociocultural and sociohistorical environment through which designers can visualize and analyze human activity systems in a broader sense."

\section{Institutional and community level:}

In the study conducted by Ssozi-Mugarura et al. (2016), they reported that by focusing on understanding the sustainability effects of technology-based design interventions on people's water management in rural Uganda, AT's sociocultural contexts were applied to evaluate the design intervention at two levels: institutional level and community level. The analysis at the institutional level focuses on the broader technology engagement of the design intervention, while the community 
level focuses on the interaction that takes place between the individual user, the introduced design intervention, and other users within the community.

3. Individual, collective (group or community), and societal level:

In their study about developing new sustainable telehealth services, Lin \& Hsieh (2014) applied AT in three levels of analysis: individual, group and institutional levels. They noted that the theoretical concept of sociocultural contexts can help design researchers to better understand the relationship between the individual and the broader sociocultural levels, particularly when individuals and societies undergo a transformation process. Similarly, in Hansan et al. (2017)'s study about the potential of using IS to support the planning and execution of design interventions for climate change adaptation, the climate change adaptation problems were also analyzed at three levels, from global concerns to local governments' measures to individual behavior change.

In summary, insights extracted from the above studies showed that, AT's theoretical principle of sociocultural contexts can help design researchers to put sustainability issues in the perspective of both individuals' needs and the macro sociocultural contexts in which the target activity system situates. However, there lacks a consensus on the division of the analytical scale of sociocultural contexts. Drawing on the results presented above, I divide the contextual scale of analysis into three levels:

- Independent activity: The specific targeted individual activity that is carried out in a specific context. For example, cooking at home, working in an office, dining at a restaurant, exercising in a gym, etc.

- Neighboring or supporting activities: The activities which are directly connected to the independent activity. These activities can be in the form of a supporting activity. For instance, to carry out the cooking activity at home, one might need to first shop in grocery stores. In order to work in an office, one might need to commute from home to office. These activities can also be in the form of a directly related neighboring activity, for example, cleaning the kitchen after cooking, taking a shower in the gym after exercising.

- Implications at the societal level: The potential sustainability or unsustainability effects brought by the independent activity and the 
neighboring or supporting activities on the societal level. For instance, unsustainable household cooking behavior may result in household energy and food waste, overreliance on private automobiles for commuting may lead to unnecessary $\mathrm{CO} 2$ emissions and traffic congestion.

\subsubsection{Case study B-I: Student microwave room intervention design}

Based on the above result, Study B-I and Study B-II were conducted to test the three-level division of AT's sociocultural contexts.

\subsubsection{Study set-up and goals}

Finished in July 2019, Studenthuset is currently the largest and newest building at Linköping University. With an explicit focus on the sustainability aspect of design, the building has received the highest award in environmental classification. As a student center, Studenthuset offers a microwave room (in total 22 microwaves) on the ground floor for students to heat food (see Figure 15). However, the design of the room does not reflect the sustainability value of the building as it has received complaints from students regarding the chaotic usage of microwaves. Therefore, the goal of the project's goal is first to identify the sustainability-related problems that exist in the usage of the microwave room, and then propose design interventions to address the identified problems.

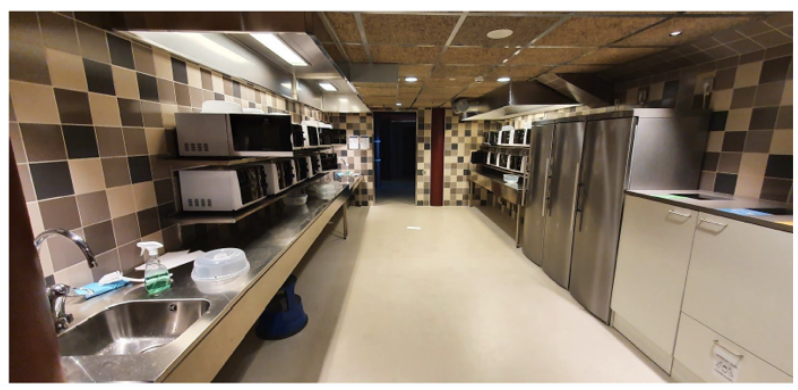

Figure 15. Student microwave room in Studenthuset, Linköping University.

\subsubsection{Methods applied}

The overall research process is illustrated in Figure 16. First, field observations and interviews were conducted to gather preliminary insights about how the students use the microwave room and its facilities. Following that, the insights were 
used to inform questions in an online survey (sample number $=60$ ). In-depth observations were later carried out to measure the average active running time of microwaves in rush hours. After that, the graffiti wall was used to gather qualitative data regarding students' overall experiences, difficulties, and suggestions when using the microwave room.

With a particular focus on identifying and solving the contextual factors that trigger the sustainability problems in the microwave room, AT's theoretical principle of sociocultural contexts was not only applied for analyzing the collected data but also for proposing potential design interventions.

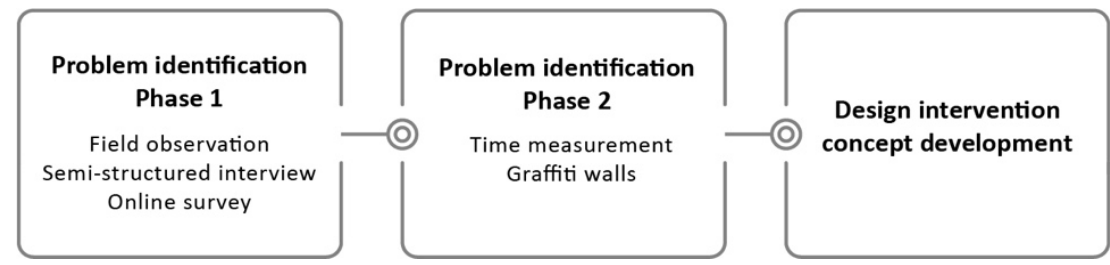

Figure 16. An overview of the research process in the student microwave design project.

\subsubsection{Results}

As shown in Table 7, the empirical results were mapped according to the three contextual levels of analysis that I proposed in the preceding section.

Table 7. Problems and proposals for design interventions mapped according to the three contextual levels of analysis.

\begin{tabular}{|c|c|c|c|}
\hline $\begin{array}{l}\text { Levels of } \\
\text { analysis }\end{array}$ & Targeted activities & $\begin{array}{c}\text { Sustainability-related } \\
\text { problems }\end{array}$ & Proposals for design interventions \\
\hline $\begin{array}{l}\text { Independent } \\
\text { activity }\end{array}$ & $\begin{array}{l}\text { Heat food in the } \\
\text { microwave }\end{array}$ & $\begin{array}{l}\text { Difficulties in identifying which } \\
\text { microwave is occupied and } \\
\text { which is currently available }\end{array}$ & $\begin{array}{l}\text { Microwave design intervention: } \\
\text { - Put on reminders and stickers on } \\
\text { each microwave }\end{array}$ \\
\hline $\begin{array}{l}\text { Neighboring } \\
\text { or } \\
\text { supporting } \\
\text { activities }\end{array}$ & $\begin{array}{l}\text { Waiting and } \\
\text { transitioning }\end{array}$ & $\begin{array}{l}\text { - Long waiting time in the } \\
\text { microwave room; } \\
\text { - Unorganized operation area } \\
\text { during rush areas. }\end{array}$ & $\begin{array}{l}\text { Workflow adjustment intervention: } \\
\text { - Allocate a waiting area } \\
\text { - Put on guidance on the floor } \\
\text { - Install a digital notice board }\end{array}$ \\
\hline $\begin{array}{l}\text { Implications } \\
\text { at the } \\
\text { societal level }\end{array}$ & $\begin{array}{l}\text { The use of the } \\
\text { microwave room }\end{array}$ & Low resource efficiency & $\begin{array}{l}\text { Spatial intervention: } \\
\text { - Rearrange microwave placement } \\
\text { - Put on efficient usage guide }\end{array}$ \\
\hline
\end{tabular}


1. Independent activity:

At the independent activity level, some respondents reported that when the room is crowded during the rush hours, the black cover on the microwave's door makes it difficult for them to judge whether the microwave is occupied or not. Moreover, the routinized habit of closing microwave doors when finish heating also worsens the situation. Some respondents also pointed out that it is sometimes difficult to remember the microwave in which they put the food. Therefore, the design interventions proposed at this level focus on improving the interaction between an individual user and the microwave. Interventions including reminders of leaving the door open when finishing heating food so that the next user can easily tell whether the microwave is available or not, animal stickers on the door of the microwaves to differentiate microwaves for users to remember the microwave in which their food is placed, were proposed to address the identified problems (see Figure 17).

\section{Neighboring or supporting activities:}

At the neighboring or supporting activities level, the unorganized operation area in the room was identified as the key factor that led to a long waiting time. Correspondingly, the design interventions proposed at this level include adjusting the workflow (e.g., allocating a waiting area, putting on signs and guidance on the floor to improve the workflow) and introducing a digital notice board to visualize which microwave is currently available, where the available microwave locates, and whether the microwave in which the food is placed is still in progress (see Figure 17).

\section{Implications at the societal level:}

While students are often waiting in queues for using the microwaves during rush hours, the microwave placed closet to the queue where students can see whether the microwave is occupied or not reaches an average of $71 \%$ of active running time. On the contrary, the active running time of the microwave which is placed in the middle of the room (away from the queues on both ends) is only $61 \%$. Similarly, the microwave that stands in the corner of the room only has $64 \%$ of active running time during rush hours. This finding points out that the problems are not only associated with users' interaction with the microwave, but also related to the overall layout of the room. Therefore, the intervention proposed in this level focuses on spatial design, for example, rearrange the layout of the room, moving the microwaves from two sides to the center of the room, and putting up guidance on how to use the microwave in more efficiently (see Figure 17). 


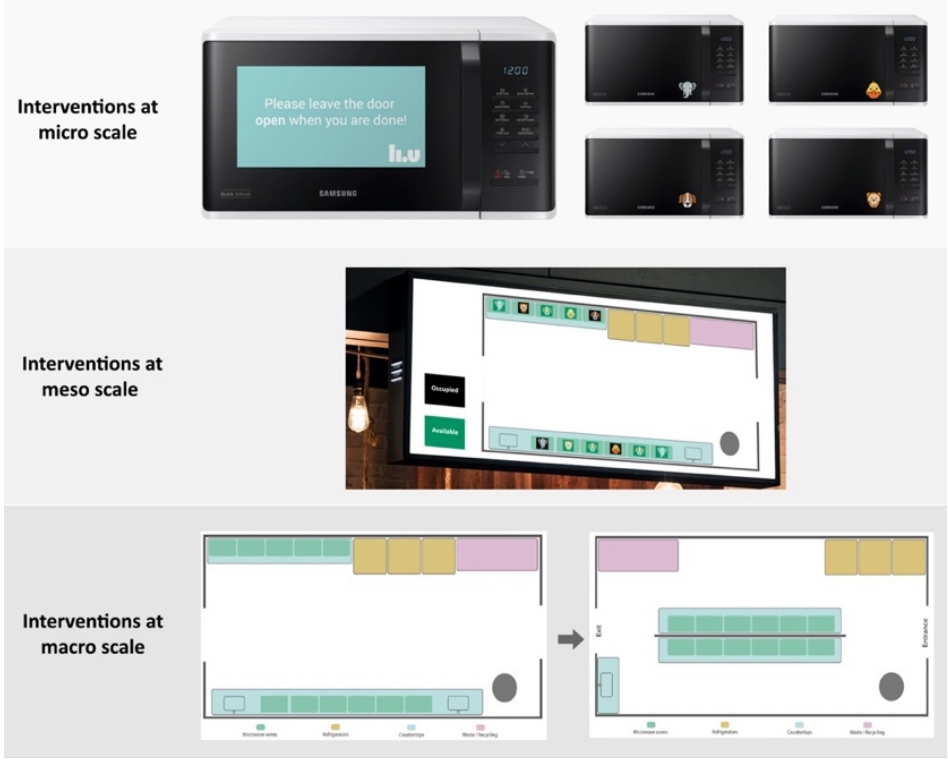

Figure 17. The proposed design interventions to guide more sustainable use of microwave room at different contextual scales.

\subsubsection{Case study B-II: flexible kitchen activity design}

\subsubsection{Study set-up and goals}

As people's food consumption activities keep evolving, so does the design of kitchen space and furniture. The kitchen nowadays is under a transformation process from a place designated for cooking and food handling to a center of the home where leisure and social activities take place. This project aims first to develop a holistic understanding of the activities that people carry out in the kitchen today, then propose kitchen furniture design guidelines that support people in carrying out these activities in a more sustainable direction in the future.

\subsubsection{Methods applied}

As illustrated in Figure 18, the research process of the project is divided into 4 phases. In phase 1, an online survey was first sent to collect data about what activities are often conducted in the kitchen today. Following that, field observations and semi-structured interviews were conducted in participants' home environments 
to gather descriptive qualitative data regarding how people perform their daily activities in the kitchen and what problems exist in these activities. In phase 2, the collected empirical data were analyzed through an AT theoretical lens, focus group discussions and ideation workshops were conducted to translate the insights into design concepts, which were iterated in phase 3 concept development and phase 4 prototyping and concept realization. Similar to the microwave room case study, AT's theoretical principle of sociocultural contexts was applied not only for analyzing the empirical results, but also for proposing potential sustainable design guidelines to solve the identified problems.

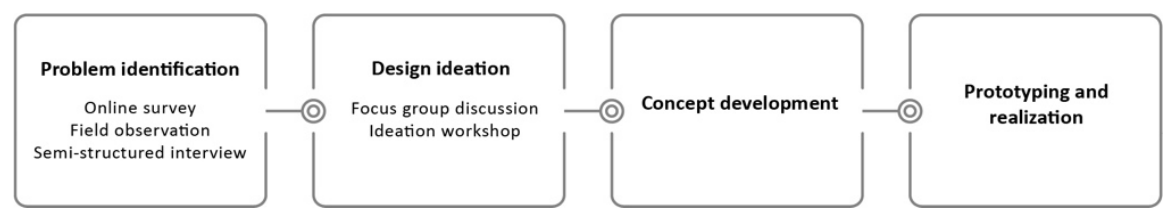

Figure 18. An overview of the research process in the flexible kitchen activity design project.

\subsubsection{Results}

As shown in Table 8, similar to Study B-I, the empirical results were mapped according to the three contextual levels of analysis: independent activity, neighboring or supporting activities, and implications at the societal level.

Table 8. Problems and proposals for design solutions mapped according to different contextual levels of analysis.

\begin{tabular}{|c|c|c|c|}
\hline $\begin{array}{c}\text { Levels of } \\
\text { analysis }\end{array}$ & Targeted activities & Problems & Proposals for design solutions \\
\hline $\begin{array}{l}\text { Independent } \\
\text { activity }\end{array}$ & $\begin{array}{l}\text { Prepare, cook and eat } \\
\text { food }\end{array}$ & $\begin{array}{l}\text { Various usages in different } \\
\text { demographic groups }\end{array}$ & $\begin{array}{l}\text { Improve the ergonomic design for } \\
\text { different demographic groups of } \\
\text { users }\end{array}$ \\
\hline $\begin{array}{l}\text { Neighboring } \\
\text { or } \\
\text { supporting } \\
\text { activities }\end{array}$ & $\begin{array}{l}\text { - Cleaning } \\
\text { - Socializing } \\
\text { - Productivity } \\
\text { - Entertainment }\end{array}$ & $\begin{array}{l}\text { - Lack of space in kitchen } \\
\text { - Kitchen furniture does } \\
\text { not support multiple } \\
\text { activities }\end{array}$ & $\begin{array}{l}\text { - Design beyond cooking } \\
\text { - Design for space-efficiency } \\
\text { - Emphasize the social function of } \\
\text { kitchen } \\
\text { - Multi-functional kitchen furniture }\end{array}$ \\
\hline $\begin{array}{l}\text { Implications } \\
\text { at the } \\
\text { societal level }\end{array}$ & $\begin{array}{l}\text { More integrated } \\
\text { activities at homes }\end{array}$ & $\begin{array}{l}\text { - Compact living } \\
\text { environment } \\
\text { - Unsustainable } \\
\text { consumption that takes } \\
\text { place in kitchen }\end{array}$ & $\begin{array}{l}\text { - Flexible and adaptive kitchen } \\
\text { design } \\
\text { - Design for modular system } \\
\text { - Incorporate technological } \\
\text { innovations }\end{array}$ \\
\hline
\end{tabular}


1. Independent activity

Results indicated that the most commonly performed activity in the kitchen is to prepare, cook and eat food. However, as different demographical user group tends to use kitchen furniture in different ways, the design guidelines proposed in this category thus centers around:

- Improving the ergonomic design of kitchen furniture for different demographic groups of users.

\section{Neighboring or supporting activities}

Results showed that cleaning (e.g., dishwashing), socializing (e.g., spending time with family and hang out with friends), productivity (e.g., working), and entertainment (e.g., watching videos and playing games) are the main activities that the respondents carry out in kitchen besides cooking and food handling. However, the lack of space, including the operational surface and the overall kitchen space, creates difficulties for respondents to perform these activities. Moreover, the valuable space in the kitchen is often occupied with furniture that mainly serves single-purpose (e.g., dining table for eating food). Based on these identified problems, the corresponding design guidelines proposed in this level include:

- Allowing users to carry out other activities, especially productivity and entertainment activities in the kitchen.

- Applying kitchen island design as a potential solution to promote spaceefficiency in the kitchen.

- Supporting kitchen in becoming the social focal center of the home.

- Developing multi-functional kitchen furniture to fit into other rooms for other usage purposes (e.g., working as tables in the living room).

3. Implications at the societal level:

Societal factors, including the compact living environment in urban areas and the linear consumption lifestyle, can largely shape how kitchen activities are carried out. Taking into account the potential impacts that kitchen design may bring to society and the environment, the sustainable kitchen furniture design guideline proposed in this category are:

- Supporting the development of long-lasting and adaptive features of the kitchen so that it can evolve as the owner undergoes different stages in life.

- The kitchen furniture needed for cooking, productivity, entertainment and socializing varies across each other; therefore, modular design is recommended. Old modules can be ungraduated or modified and new modules can be added to transform the function of the furniture. 
- Adopting technological innovations such as the Internet of Things (IoT), digitalization and artificial intelligent agency to help with food handling activities that people perform in the kitchen.

5.3.4 Reflections and AT-based theoretical framework: version 2.0

In this stage, the AT-based theoretical framework is iterated with a particular focus on exploring how to incorporate the sociocultural contexts of activity into sustainable behavior design considerations. As a result, a third dimension, which represents the contextual scale of analysis, is added to the previously proposed framework (version 1.0).

The contextual scale of analysis consists of three levels:

- Independent activity: The specific individual activity that is carried out in a specific context.

- Neighboring or supporting activities: The related activities which are directly connected to the targeted independent activity.

- Implications at the societal level: The potential sustainable or unsustainable effects of the independent activity and its neighboring or supporting activities at societal level.

The three-level contextual analysis presented above is informed by the findings of the meta-synthesis study and further tested in the two case studies (Study B-I and B-II). Drawing on the insights of the studies conducted in this stage, the three-level contextual scale proved to be useful as it can allow designers to identify and analyze sustainability-related issues in different analytical levels, and inform corresponding design interventions specifically targeted in different levels. The second version of the AT-based theoretical framework resulted from this stage is illustrated in Figure 19. 


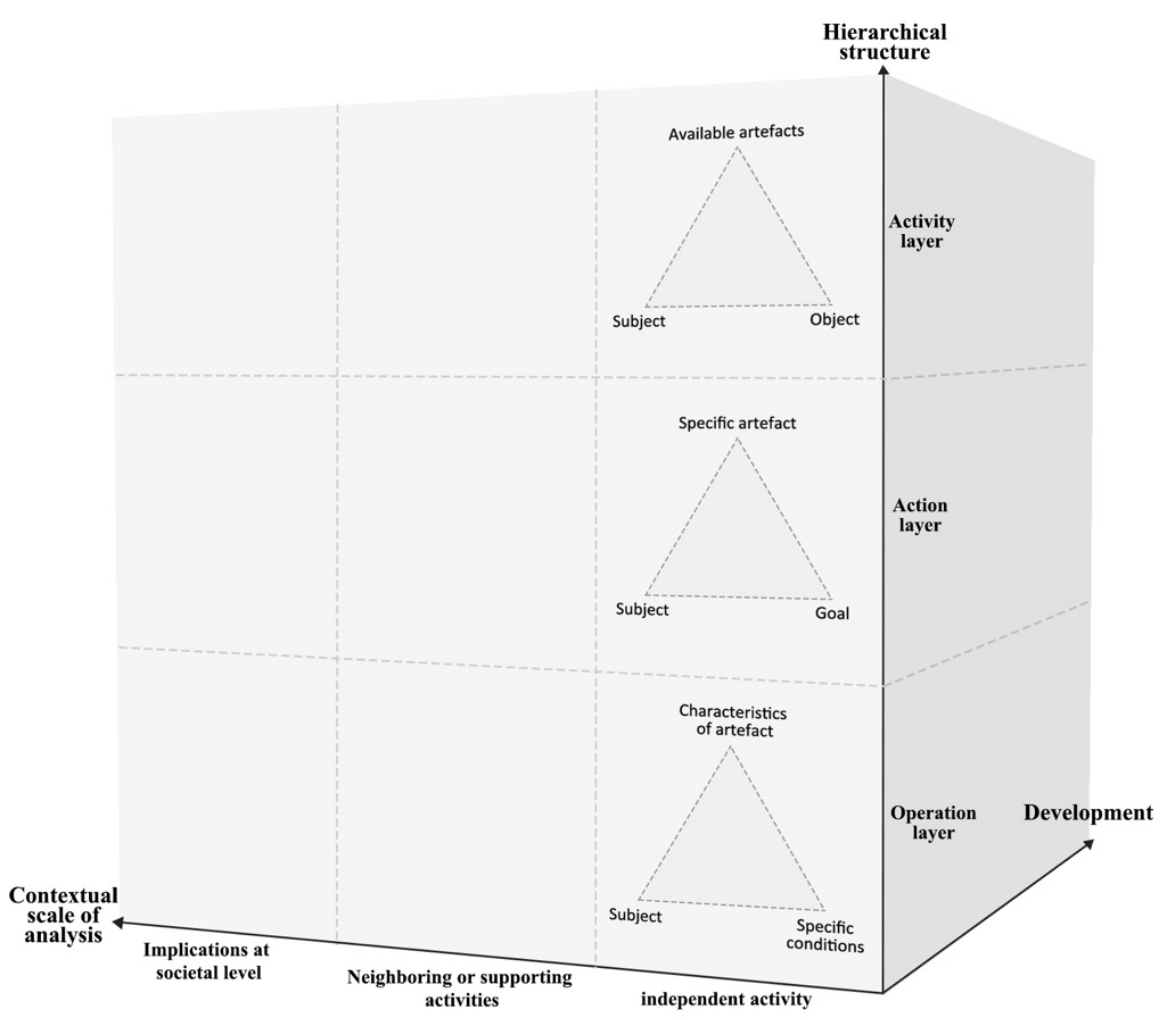

Figure 19. The second version of the AT-based theoretical framework.

\subsection{Development of the AT-based theoretical framework: the third iteration}

Study C-I is conducted in this stage. When presenting the results of Study C-I, I will put a particular focus on discussing the potential use of the fifth theoretical principles of AT, that is, tensions and contradictions, for guiding empirical analysis and design explorations in design for sustainability studies.

5.4.1 Study C-I: Uncovering tensions and contradictions within the activity system

\subsubsection{Study set-up and goals}

Consumers' misunderstanding and misusage of on-pack date and storage labels is one of the significant factors that contribute to household food waste. Study C-I sets a particular focus on understanding the relation between date labelling and consumer household food waste behavior. Based on the AT theoretical lens, people's 
food edibility assessment activity system, in other words, how people determine whether a food item is edible or not, is taken as the unit of analysis. The goal of the study is to systematically understand the tensions and contradictions that consumers encountered when using on-pack date and storage labels to assess food edibility, and to explore the potential opportunities for design to intervene in the interaction between consumers and date and storage labels to reduce household food waste.

Study C-I comprises of three phases: a systematic literature review, a cocreation with general consumers and food industry practitioners, and a crossanalysis of the empirical results. Figure 20 presents an overview of the research process applied in this study. To better align the results of Study C-I with the structure of the dissertation, the systematic literature review part is presented separately with the co-creation and cross-analysis. The results from the systematic literature review are presented in this section, while the co-creation and crossanalysis results are presented in Section 6.3.

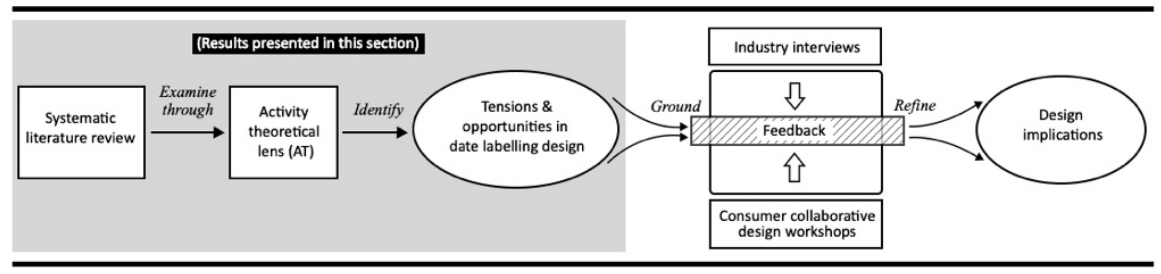

Figure 20. An overview of the research process in Study C-I.

\subsubsection{Method applied: a systematic literature review}

The systematic literature review was comprised of 8 steps (see Figure 21): 1) identify relevant technical reports, 2) develop a literature search strategy and conduct the initial search, 3) eligibility screen, 4) title and abstract screen for, 5) firstround review, 6) perform a second-round review and data extraction, 7) snowballing, and 8) perform data analysis. To gain an overview of the method, only the key steps and results will be presented in the following.

Two types of sources were included in the review: technical reports and academic articles. The systematic literature review began with identifying technical reports that are relevant to the topic. Twenty-four technical reports were included in the review. Following that, the literature search was conducted in March 2019. 
Scopus was chosen as the search platform. Book chapters, peer-reviewed conference papers and journal articles published from the 1960s to March 2019 are included in the review scope. As shown in Figure 21, 530 articles went through a systematic literature screening process. As a result, 27 articles were included in the final fullpaper review. For a detailed description of the materials and methods, please see Paper III.

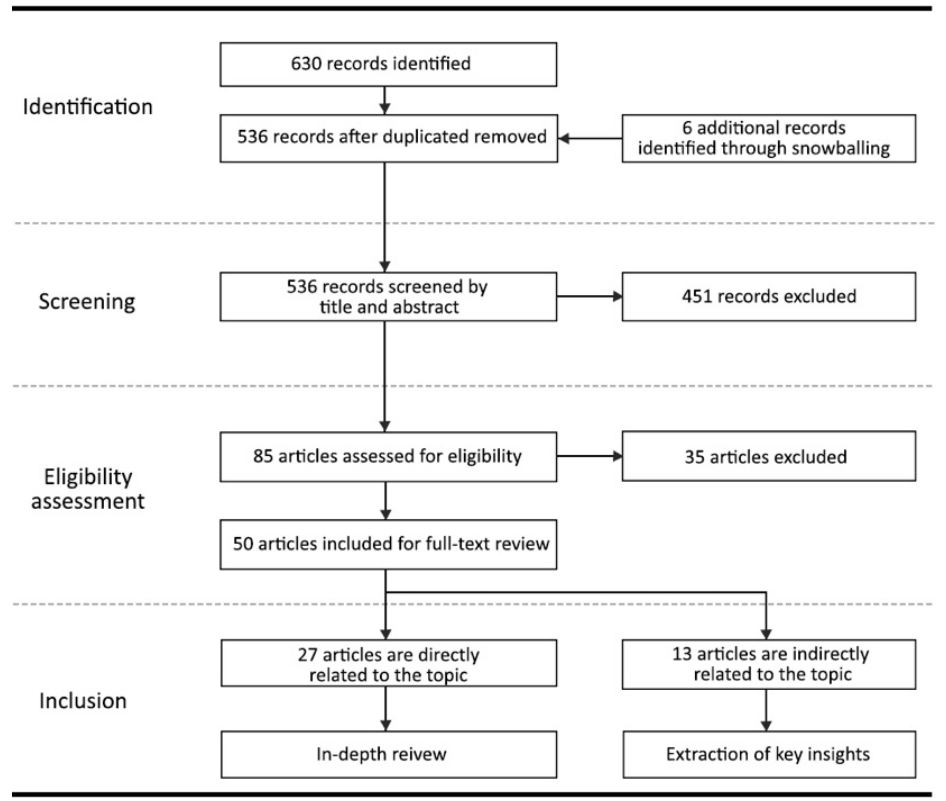

Figure 21. An overview of the systematic literature review procedures applied in Study C-I.

For data analysis, a similar abductive data analysis approach applied in Study A-I and A-II was also adopted here. To put it briefly, first, recurring themes with similar patterns or contradictory results were grouped and summarized. Following that, AT's key theoretical concepts, such as motivations, goals, meditating tools, contradictions and tensions, were applied to compile the identified themes (see Figure 22). 


Overall tools

Figure 22. People's food edibility assessment analyzed through an AT theoretical lens.

\subsubsection{Results}

Looking at people's food edibility assessment from an AT theoretical lens, the overarching motivations behind consumers' food edibility assessment activity can be broken down into three specific goals: assess food safety, assess food quality, and avoid unnecessary food waste. Correspondingly, three mediating artefacts: "Use by" date, "Best before" date, and consumers' sensory perceptions, were commonly used to achieve these goals. According to AT's definition of mediating artefacts, date labels such as "Use by" date and "Best before" date can be categorized as the external mediating artefacts, while the sensory perception that consumers use in their food assessment activities can be categorized as the internal mediating artefacts. In other words, both external mediating artefacts (in the form of on-pack date labels and institutionalized knowledge related to the use of date labels) and internal mediating artefacts (in the form of sensory perceptions and embodied knowledge related to food attributes) can be used to make a judgement regarding whether a food item should be discarded or not.

Building upon the food edibility assessment activity model described above, AT's theoretical principle of tensions and contradictions was then used to further synthesize the literature review results (see Table 9). Findings from the literature review were then categorized into:

- Group 1: tensions and contradictions that take place in the action layer where individual subjects use on-pack date labels to judge food edibility (see A\&B in Table 9).

- Group 2: tensions and contradictions that take place in the action layer where individual subjects judge food edibility based on their sensory perceptions (see C\&D in Table 9). 
- Group 3: tensions and contradictions that emerged in the operation layer where individual subjects need to use date labelling-related institutionalized knowledge to interpret products' shelf-life information (see E\&F in Table 9).

- Group 4: tensions and contradictions that take place in the operation layer where individual subjects need to interpret products' sensory attributes based on their embodied food-related knowledge (see G\&H in Table 9).

Table 9. Categorization of tensions and contradictions that consumers encountered in their food edibility assessment activities.

\begin{tabular}{|c|c|c|}
\hline $\begin{array}{c}\text { Hierarchical } \\
\text { layers }\end{array}$ & Distribution & Specific tensions and contradictions \\
\hline $\begin{array}{l}\text { Action } \\
\text { layer }\end{array}$ & Assess food & $\begin{array}{l}\text { A1). A gap between labeling information presentation and } \\
\text { information usage. } \\
\text { A2). A variation in the effects of the "Use by" date, } \\
\text { especially when consumers are unwilling to discard food } \\
\text { items that passed the date. } \\
\text { A3). A variation in the effects of the "Best before" date, } \\
\text { especially when consumers hold excessive concerns on food } \\
\text { quality. } \\
\text { B1). An inadequate explanation of the labeling terminology } \\
\text { on the packaging. } \\
\text { B2). An inadequate date and storage guidance on opened } \\
\text { products. }\end{array}$ \\
\hline $\begin{array}{l}\text { Action } \\
\text { layer }\end{array}$ & $\sum_{\begin{array}{c}\text { Assess food } \\
\text { quality \& safety }\end{array}}(\mathbf{D})$ & $\begin{array}{l}\text { C1). A lack of confidence in using sensory assessment in } \\
\text { conjunction with date labels. } \\
\text { C2). An overreliance on sensory assessments instead of } \\
\text { strictly following the "Use by" date on the packaging. } \\
\text { C3). Discard food items that passed the "Best before" date } \\
\text { without assessing the item's quality attributes through } \\
\text { sensory perceptions. } \\
\text { D). A variation of sensory assessment criteria and methods } \\
\text { used in different case scenarios with different food products. }\end{array}$ \\
\hline $\begin{array}{l}\text { Operation } \\
\text { layer }\end{array}$ & $\begin{array}{c}\text { (E) } \\
\text { Individual } \\
\text { consumer }\end{array}$ & $\begin{array}{l}\text { E). Consumer confusion over the meanings of label } \\
\text { terminology (e.g., the meaning of the "Best before" and "Use } \\
\text { by" date). } \\
\text { F). A lack of consistency and standardization of labeling } \\
\text { content and display. }\end{array}$ \\
\hline
\end{tabular}




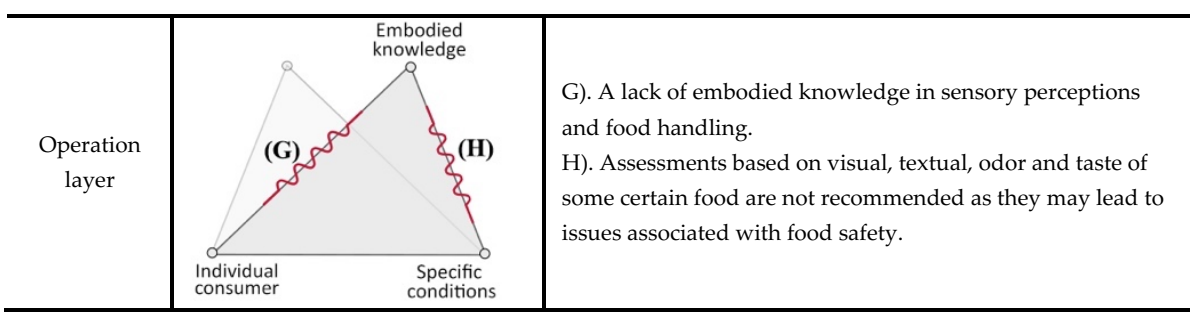

By adopting the $2^{\text {nd }}$ version of the AT-based theoretical framework, how the tensions and contradictions identified above manifest themselves in consumers' food edibility assessment systems is shown in Figure 23.

First, in the operation layer, the lack of knowledge on date labelling and sensory assessment (as identified in Group 3\&4, see E, F, G and H) is the major tension and contradiction that consumers face. Consequently, consumers often need to search for relevant knowledge such as the meaning of the specific type of date labels, storage methods that can extend food shelf-life in the household environment and typical deterioration signs. Therefore, interventions that target providing such knowledge and convenience for consumers can be a promising solution to help consumers reduce labelling-related food waste. Meanwhile, the societal level offers insights regarding in which contexts such knowledge assistance should be provided. Existing literature indicates that strategically communicating relevant knowledge at consumers' actual food-handling contextual settings such as at the point of sale and meal preparation is more effective than just implementing general consumer education campaigns.

Moving up to the action layer, tensions and contradictions mainly center around the misunderstanding of "Best before" date and "Use by" date, misusage of sensory judgements, overreliance on one type of methods to make decisions (as presented in Group $1 \& 2$, see A to D). To solve these tensions and contradictions, consumers tend to look for other reliable channels (e.g., ask for family members' or friends' opinions) to help them in the food edibility assessment process. This gives rise to the opportunity of applying technological interventions such as timetemperature indicators to show product freshness in real-time. However, at the societal level, these technological solutions still cannot replace the wide usage of date labels due to technical difficulties and cost-related concerns held by the food and packaging industry. The standardization of label terminologies and consumerfriendly label presentations are still the most cost-effective solutions to solve the identified tensions. 
In the activity layer, decisions made in consumers' food edibility assessment might influence the subsequent food consumption activities such as meal planning and cooking, leading to potential household food waste. Insights extracted from the existing literature suggest that, helping consumers better utilize the food that is close to the expiration date (e.g., incorporate the food into a meal) and manage food items stored in the household environment are promising solutions to avoid food waste. Although these solutions seem to be irrelevant to the design of on-pack date and storage labels, they reveal how other interventions can be used in combination with date labelling design to address the broader household food waste issues at a societal level.

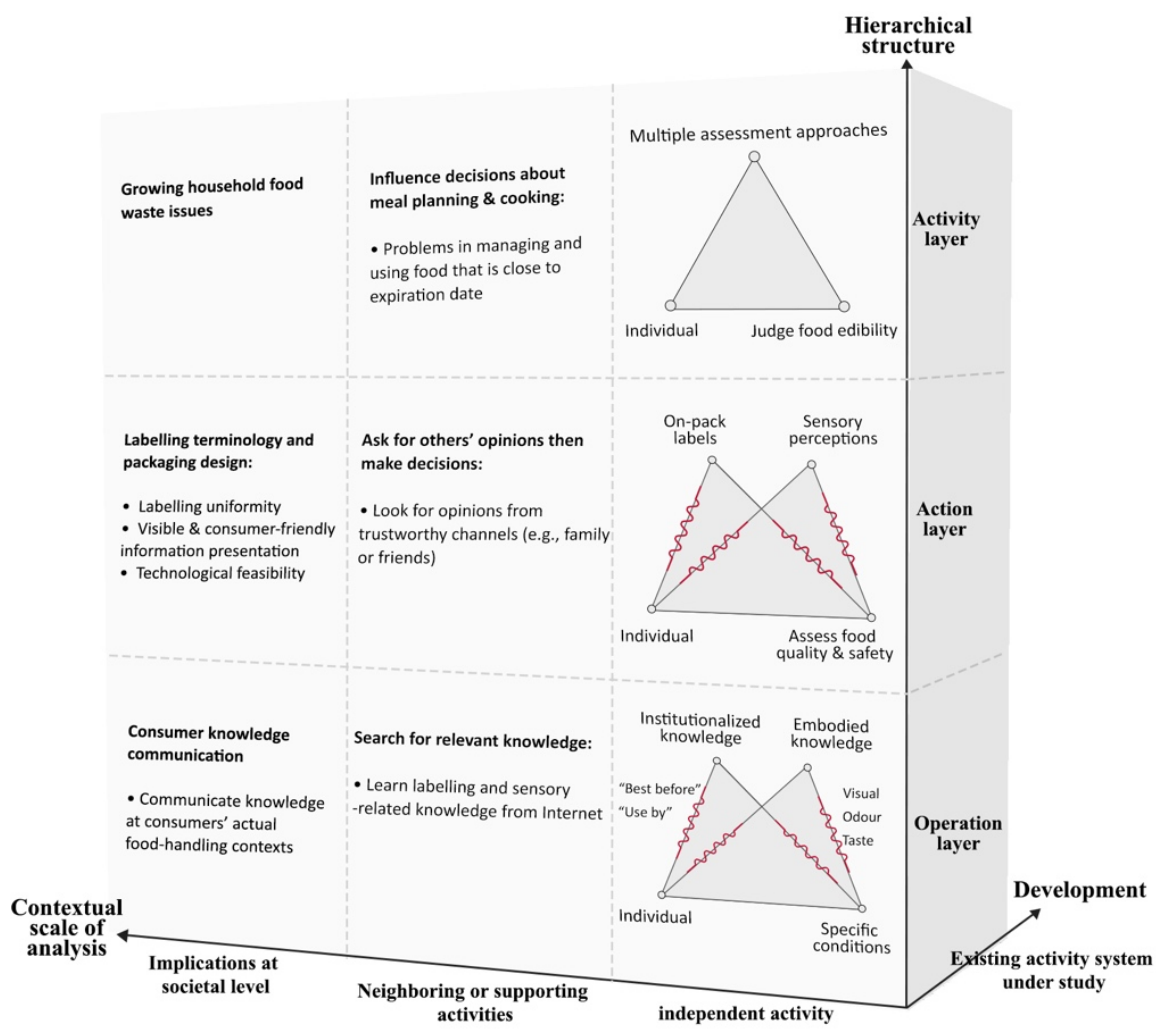

Figure 23. Mapping tensions and contradictions that consumers encounter in food edibility assessment according to the AT-based theoretical framework. 
5.4.2 Reflections and AT-based theoretical framework: Version_3.0

In summary, reflections from the above case studies indicate that the AT-based theoretical framework can offer two analytical strengths for sustainable design research:

1). By laying out tensions and contradictions according to the hierarchical layers of an activity system, it allows researchers to systematically identify and break down the sustainability challenges into smaller segments for analysis without losing a holistic view.

2). By mapping tensions and contradictions on the different contextual scales of analysis, it helps researchers understand the causes of sustainability issues within the scope of an integrated activity system. Meanwhile it can also support researchers in positioning the impacts of the targeted activity system on a broader sociocultural context.

Building upon the analytical strengths, the AT-based theoretical framework can also provide two strengths when it comes to practical sustainable design explorations:

1). As tensions and contradictions often manifest themselves differently in different hierarchical layers of an activity system, it implies that the corresponding sustainable design interventions should also have different emphases, specifically targeting at addressing one or multiple tensions at different layers.

2). In order to fully explore the potential design opportunities to tackle the identified sustainability challenges, design explorations should not only be focused on the targeted independent activity, instead, the relations between the targeted activity and its neighboring or supporting activities, as well as the societal level of the targeted activity, also need to be taken into account in the design ideation process.

As a result, based on the insights and reflections identified above, the third version of the AT-based theoretical framework was developed (see Figure 24). In this version, AT's theoretical principle of tensions and contradictions is incorporated into the framework (note that in the figure, the spring sign is used to conceptually represent the tensions and contradictions). 


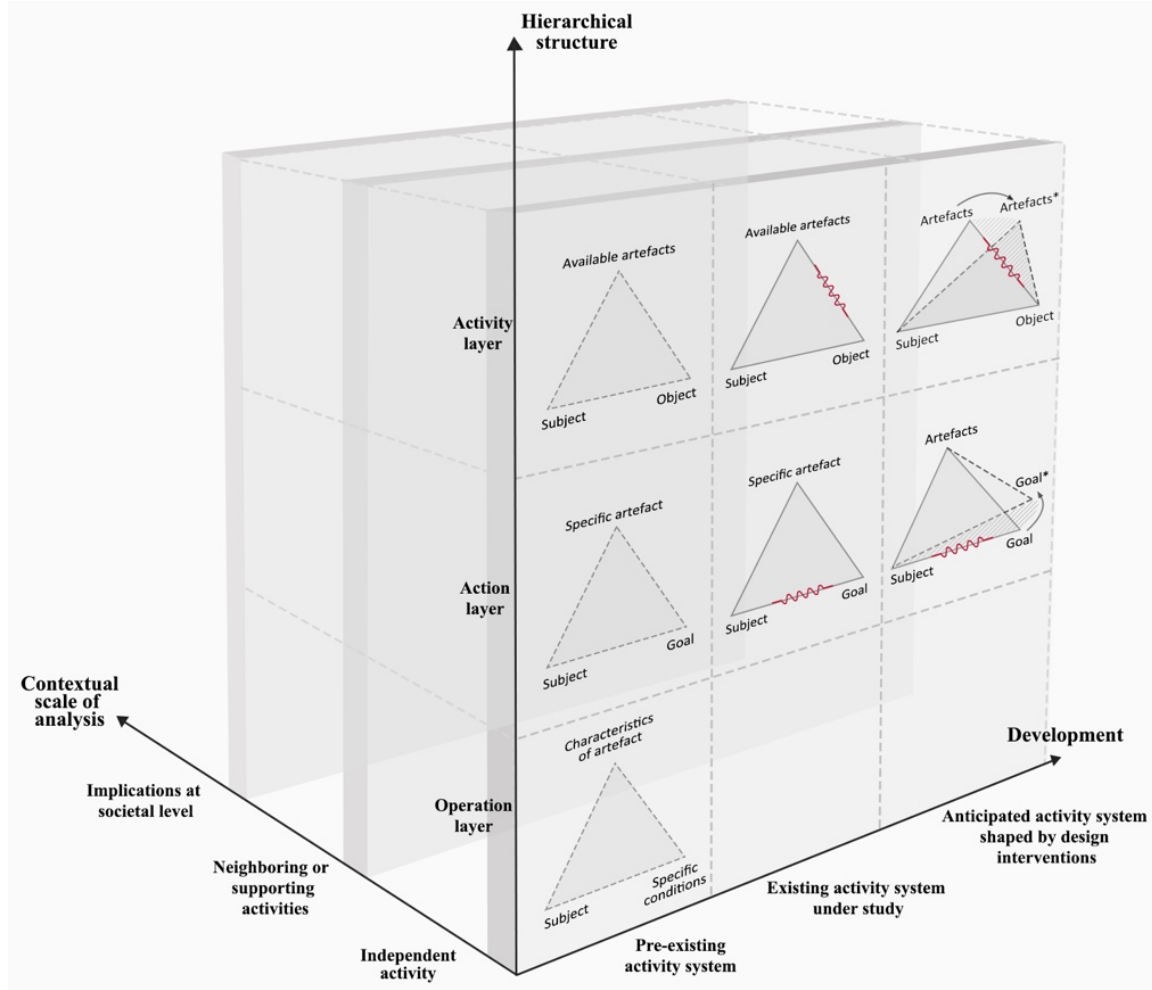

Figure 24. The third version of the AT-based theoretical framework.

Furthermore, to support the use of the proposed framework, a step-by-step guide is formulated. The guide is adopted initially from the AT-based methodological approach applied in Mwanza (2001), Uden (2007), and Boer et al. (2002). It is then tested, adapted and refined in the previous case studies.

- $\quad$ Step 1: Identify the three key components which constitute the activity system: subjects (users), objects (motivations and goals) and mediating artefacts (tools).

- $\quad$ Step 2: Break down the activity system into three hierarchical layers: activity layer, action layer and operation layer. 
- $\quad$ Step 3: Distribute the activity system and its related effects across different contextual levels of analysis: independent activity level, neighboring or supporting activities, and implications at the societal level.

- $\quad$ Step 4: Illustrate how the target activity system develops over time: the preexisting activity, existing activity under the influence of context change disruptions, and anticipated forms of activity shaped by design interventions.

- $\quad$ Step 5: Identify tensions and contradictions that take place within the different hierarchical structure and contextual levels of analysis, along with how the tensions and contradictions are resolved and how they may lead the future evolution of the activity system towards a more sustainable direction.

\subsection{AT-based theoretical framework: validation}

Study D, which is about the transition of household food consumption activity in lockdown and pos-lockdown, is used to validate the framework. This project is not initially planned in this PhD study. The idea emerged when the Covid-19 pandemic was spreading all over the world. Note that Study D is still ongoing when the thesis is written. Therefore, the key results presented in the thesis are only used to examine and validate the AT-based framework.

\subsubsection{Study D: Household food consumption activities under Covid-19 lockdown}

Looking at the crisis from the behavior transformation research perspective of this thesis, as the onset of the Covid-19 pandemic has already brought unprecedented impacts on the socio-economic development of our society and people's everyday life, it also offers a special moment from which we can learn a lot. On the one hand, design researchers' social responsibility motived me to carry out a small-scale explorative case study to investigate people's food consumption under lockdown and post-lockdown. Since people are forced to transform their daily life doings to cope with the challenges and disruptions brought by the pandemic. It is a perfect real-world and ongoing case scenario to further examine and refine the proposed theoretical framework.

\subsubsection{Study set-up and goals}

The Covid-19 pandemic has already disrupted people's pre-existing daily life doings. Food consumption, as one of the most critical aspects of everyday life, is also undergoing a significant transition process. For example, due to social distancing, 
remote working and lock-down regulations imposed globally, the pandemic has disrupted people's food consumption practices, forcing millions of people to consume meals at home while bringing new challenges to the fight against food waste. Existing studies have shown that during the early stage of the Covid-19 outbreak, household food waste increased due to factors such as shifts to in-home eating habits (Aldaco et al., 2020), panic buying of perishable food products (Sharma et al., 2020), and household hoarding (Fleetwood, 2020; ReFED, 2020).

At the same time, the pandemic has also opened up a window of opportunity where people became more likely to rethink their pre-existing food consumption behavior (Roe et al., 2018). Relevant studies showed that $89 \%$ of Tunisian consumers reported that they became more aware of food waste (Jribi, Ben Ismail, Doggui, \& Debbabi, 2020). 36\% of UK consumers reported that they discarded less food during the pandemic than usual. An increased focus on prudent use of food and leftovers has also been found among China and U.S. consumers (Dou et al., 2020; ReFED, 2020).

Evidence from the existing studies showed that under the impacts of Covid19, people who entered lock-down improved their in-home food storage management, meal planning and leftover management skills (Bender et al., 2020; WRAP, 2020). Following this direction, this study takes an AT theoretical perspective and aims to:

1). Identify the household food waste prevention-related doings that consumers developed during the strict lockdown caused by the pandemic.

2). Explore how people transit these doings in the post-pandemic time.

The study investigates people' food consumption activities in Wuhan, where the Covid-19 outbreak in China was first reported and the first strict city-scale lockdown measure was imposed. Following the lockdown, all the public transportation services and public places except hospitals, supermarkets, farmers' markets, gas stations and drug stores were temporarily closed. People were strongly advised to stay at home as much as possible. The strict lockdown lasted for 77 days.

\subsubsection{Method applied}

As most of the existing studies investigating the impacts of the Covid-19 pandemic published so far (till September 2020) focus on employing quantitative approaches such as questionnaires and surveys to measure consumers' attitudes, awareness and preferences of food consumption. However, when it comes to 
investigating people's household food consumption doings, knowledge generated from the quantitative approach is likely to be insufficient. An in-depth and descriptive account of how individual consumers cope with the current situation in their actual food consumption contextual settings is needed. Therefore, an ethnography-informed qualitative research approach was chosen in this project.

The study started in the first month of the lockdown. The participants of the project are recruited based on my personal networks in Wuhan. All participants were informed about the overall purpose of the project. The participation is voluntarily. 7 participants joined the study. Diary probe, letters to food and semistructured interview were applied in the data collection process. An overview of the data collection timeline is illustrated in Figure 25.

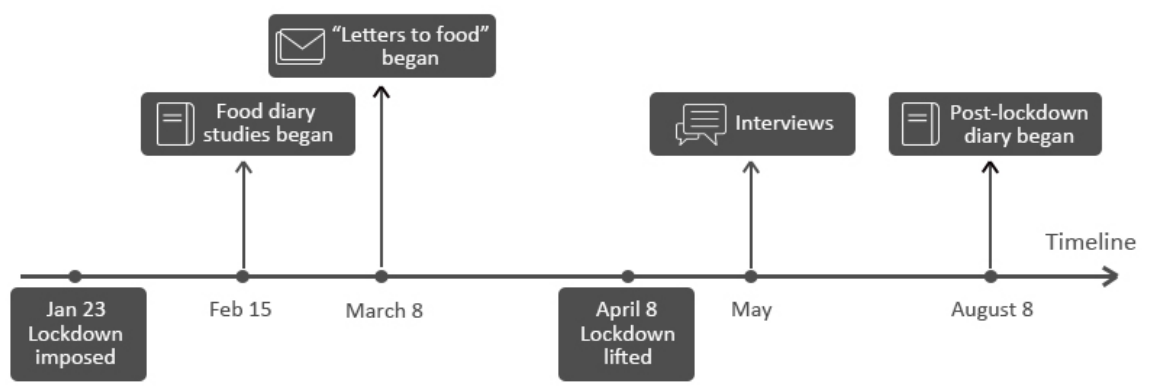

Figure 25. The timeline of diary studies, letters to food and semistructured interviews conducted in this study.

First, a seven-times digital diary probe was sent to the participants. Participants were asked to document their food consumption patterns and send the diary back to the researcher on a daily basis. The diary probes used in this study were first evaluated in pilot studies. Two workshops were conducted to collect design researchers' feedback about the diary probes.

Each diary comprises three parts:

- The first part is an instruction on the daily theme of the diary. Each diary has a particular theme, such as food acquiring, cooking, and food storage.

- In the second part, participants were encouraged to document anything related to food consumption that was impressive, fun, or even depressing. This is referred to as "casual talks". 
- The third part is a set of questions proposed by the researcher. The questions were formulated after reading through participants' diary of the previous day. Therefore, the questions included in each diary can be tailored designed for each participant based on their previous recordings.

Following the diary probes, "letters to food" was sent to the participants. This method is inspired by the "love letter and breaking up letter" method created in product and service design (Hanington \& Martin, 2012). In the context of this study, the goal of "letters to food" is to encourage participants to write down their feelings, thoughts, experiences and reflections generated in their food consumption during the lockdown situation. Participants can select any food items (e.g., eggs, yogurt, milk, cheese, bread, meat and vegetables) that they have/had at home as the receiver of the letter, and then write a confession letter to the selected food item, describing how they got the food item, why they chose to purchase this particular item, the original plan of consumption, where they stored it, how they cooked it, what happened to the waste or left-overs, and so on. This method was previously tested and improved in a pilot study. Four participants accepted this task and each of these participants wrote two letters individually. In total, 8 letters were collected.

All the diaries were summarized into 'diary graphs' and sent back to the participants for review (see Figure 26). After that, semi-structured interviews were conducted with all the participants. Each interview lasted approximately 30 minutes. An interview protocol was tailored developed for each participant based on the collected data from diary probes. The interview serves two purposes: First, information that was not fully elaborated in the diaries was asked in the interview. In this respect, the interview can provide a complementary view of the diaries. Second, as the food diaries revealed participants' concrete doings, the interview was focused on uncovering why participants performed the particular doings, what participants think and feel about their food consumption activities in that particular context.

Moreover, three months after the lockdown was lifted, post-lockdown diaries were sent to the same group of participants. The purpose is to investigate how participants perform their food consumption doings after the lockdown in the context where the pandemic has already been ended in the city. The post-lockdown diary probes were made and used in the same way as the lockdown diary probes. 5 of the 7 participants joined the post-lockdown diary study. 
In line with the other studies included in the thesis, an abductive data analysis approach was applied. Two rounds of data analysis were conducted. The first round was focused on categorizing the raw data into different themes. A particular focus was put on two types of data: one summarizes the concrete doings that participants performed, such as food acquisition, cooking, and food management; the other summarizes how participants feel about their doings, such as their subjective experiences and reflections. The second round was focused on using the previously proposed AT-based theoretical framework to categorize the identified themes.

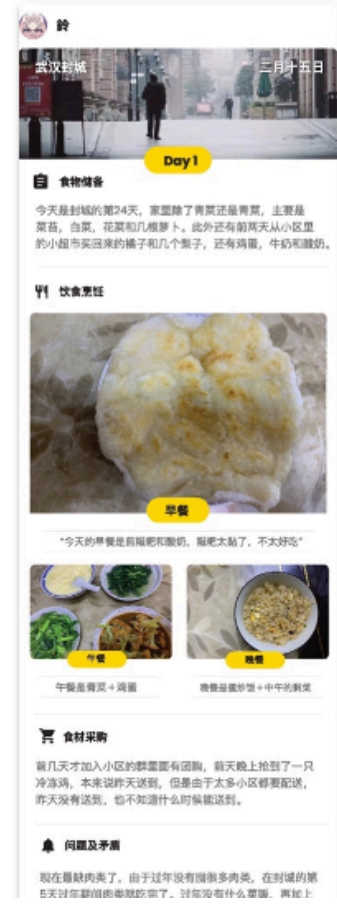

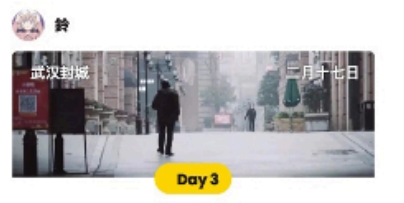

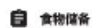

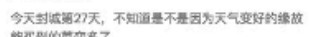

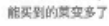
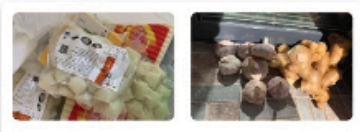

Y1

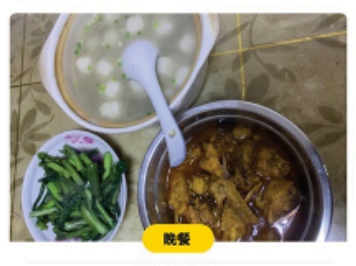

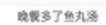
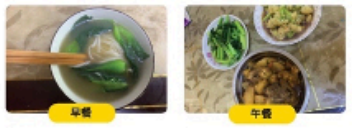

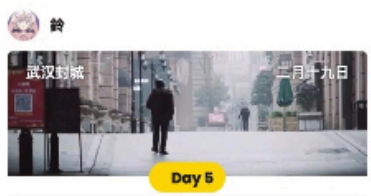

W1 the the

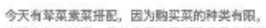

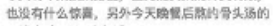

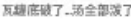

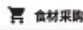

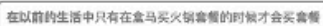

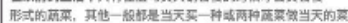

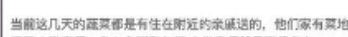

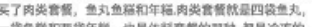

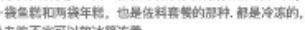

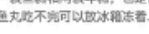

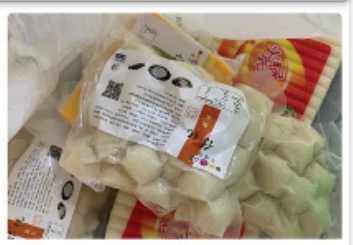

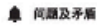

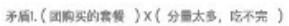

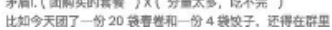

Figure 26. An example of the digital diary graphs summarized from participants' daily diary documentation. 


\subsubsection{Results}

Based on the AT-theoretical lens, seven themes emerged from the data analysis: 1). Awareness of food waste; 2). Food consumption routines; 3). Food acquisition; 4). Food storage management; 5). Food edibility assessment; 6). In-home meal preparation and planning; and 7). Leftover management.

In summary, all the participants reported that their attitudes towards food waste have changed when entering the lockdown. Unlike the pre-pandemic time when food is easily accessible, participants were especially concerned about the potential risk associated with food supply shortage due to the strict lockdown. As a result, participants were more aware of the importance of better utilizing food resources at home and avoiding food waste. This shift of attitudes is also in line with the results from the survey-based quantitative studies reported in some of the other lockdown situations around world. Instead of being driven by socio-ecological concerns, most of the food waste prevention measures that consumers undertook during the pandemic were triggered by socio-economic considerations such as fear of infection (Aldaco et al., 2020; Jung, Park, Hong, \& Hyun, 2016), food shortage (Sharma et al., 2020) and income shocks (Niles et al., 2020).

Furthermore, during the lockdown, participants became more aware of what to eat and what to purchase. Their shopping frequency has dropped down significantly due to the strict lockdown policy. Moreover, since they had restricted access to supermarkets or grocery stores, they had to purchase food items online. In some cases, participants purchased much more food than they usually need, this was due to: 1). Some food was pre-packed in food bags and can only be delivered to customers in a large quantity during the lockdown. 2). Participants were worried about the risk associated with food scarcity caused by the lockdown. However, according to participants' reflections, the increased amount of food stored at home didn't lead to the increasement of household food waste. Instead, most of the food items were consumed before they went spoiled, and food was only discarded if participants think it would cause health issues. Almost all the participants reported that they learned new food handling techniques to extend food shelf-life and make the best of the food at hand. Moreover, participants noted that they developed a better estimation of how much to eat in each meal. They were able to make a weeklybased food consumption plan and pay more attention to food shelf-life and freshens status. A summary of the detailed measures in relation to food waste prevention that participants developed during the pandemic is presented in Table 10. 
Table 10. A summary of the food waste prevention-related measures that participants developed during the strict lockdown.

\begin{tabular}{|c|c|}
\hline $\begin{array}{l}\text { Measures developed } \\
\text { during the lockdown }\end{array}$ & Examples and quotations \\
\hline $\begin{array}{l}\text { Same food items } \\
\text { came in a large } \\
\text { quantity }\end{array}$ & $\begin{array}{l}\text { "15 kg of garlic sprout came at once today. To better preserve them, I spent half of } \\
\text { the day. I peeled off the skin, put some in the fridge while pickled the rest." (P5) }\end{array}$ \\
\hline $\begin{array}{l}\text { Develop new food } \\
\text { handling skills }\end{array}$ & $\begin{array}{l}\text { "Some tomatoes left unnoticed in the fridge looked bad. I don't want to waste } \\
\text { precious vegetables in this hard time, so I will turn them into home-made ketchup } \\
\text { which is easy to preserve.... Before the pandemic, I don't need to waste time in } \\
\text { these common food items. But now, it offers more tastes to many different foods } \\
\text { such as noodles, bread, and fries." (P7) }\end{array}$ \\
\hline $\begin{array}{l}\text { Attitudes towards } \\
\text { food }\end{array}$ & $\begin{array}{l}\text { "During the lockdown, we make different dishes by using flour and we use flour to } \\
\text { compensate the rice. I used to take flour for granted, but after this, I will value it } \\
\text { more." (P6) }\end{array}$ \\
\hline $\begin{array}{l}\text { Decide what to buy } \\
\text { and eat based on } \\
\text { food storage at home } \\
\text { and food sold online. }\end{array}$ & $\begin{array}{l}\text { "Now, based on that I have at home and ordered online, I need to roughly divide } \\
\text { them into } 7 \text { days portion. Before the pandemic, I didn't pay particular attention to } \\
\text { how much to cook for each meal." (P2) } \\
\text { "I usually buy what I want to eat. But now I buy fresh vegetables when I spot them } \\
\text { online, and then decide how I should make them into a meal." (P3) }\end{array}$ \\
\hline $\begin{array}{l}\text { Make weekly-based } \\
\text { meal plans }\end{array}$ & $\begin{array}{l}\text { "Before the pandemic, we visit grocery stores when needed. Food sometimes was } \\
\text { discarded if we forgot it is there at home. In the lockdown, we buy the food for the } \\
\text { whole week at once. In order to avoid unnecessary waste, we often make a weekly } \\
\text { consumption plan" (P1) }\end{array}$ \\
\hline $\begin{array}{l}\text { Frequently check } \\
\text { shelf-life and } \\
\text { freshness status of } \\
\text { food stored at home }\end{array}$ & $\begin{array}{l}\text { "During the lockdown, my grandmother moved in with us. When she cooks, she } \\
\text { would first check the shelf-life and quality of food in the fridge, then decide what to } \\
\text { cook. Before the pandemic, my parents and I didn't do this." (P1) } \\
\text { "I found a bag of sun-dried mushroom which has been long forgotten in the shelf } \\
\text { before. It would go expired if we didn't check the shelf due to the pandemic. We will } \\
\text { use it in some dishes in the coming days." (P1) }\end{array}$ \\
\hline $\begin{array}{l}\text { More tolerant for } \\
\text { food edibility and } \\
\text { taste }\end{array}$ & $\begin{array}{l}\text { "Before the pandemic, I would just discard the whole vegetable if it looks not fresh } \\
\text { anymore. Now I cut off the bad part and cook the rest." (P4) } \\
\text { "One day I found the vegetables in my fridge looked bad. But I didn't just throw } \\
\text { them away. I searched through the Internet and then ate it as it wouldn't harm } \\
\text { health." (P6) }\end{array}$ \\
\hline
\end{tabular}


"I have bought too many potatoes, although they have longer shelf-life, I used different ways to cook them in one meal. My family liked it a lot." (P6)

Make the best use of the food at hand

5.5.2 Reflections on the use of the AT-based theoretical framework Version_3.0

In Study D, by adopting the AT-based theoretical framework and analytical approach proposed in the previous section, how people transit their household food consumption activity systems during the lockdown and after a strict lockdown can be clearly illustrated. With a particular focus on the household food reduction measures, insights extracted from the AT-based theoretical lens indicate that the participants tend to reconsider their pre-existing food waste behavior and continuously adjust their food consumption activities to cope with the dynamic situation during a lockdown, especially in the action layer. In addition, the framework also highlights that, as the onset of the pandemic has already opened up a window of opportunity that transformed people's food waste behavior, then ending the pandemic would constitute another window of opportunity, which can be used to support a continued reduction and prevention in household food waste in the post-pandemic era. By comparing participants' food consumption activity systems during and after the lockdown through the AT-based framework, we found that without any design interventions taken at the individual level, the desired food waste reduction measures that participants developed during the pandemic, such as in-home cooking skills, leftovers management, pre-shop planning, checking food storage conditions, would likely to fade away in the post-pandemic time. 


\section{6}

Development and evaluation of an ATinformed sustainable design toolkit

This chapter presents how the proposed theoretical framework is developed into an AT-informed ideation toolkit prototype and AT-informed sustainable design implications for design practitioners to use in their early-stage design ideation. The development process is illustrated in Figure 27. Table 11 clarifies the input and outcome of each research step conducted in this stage. 
Development of AT-informed design ideation toolkit \& sustainable design implications

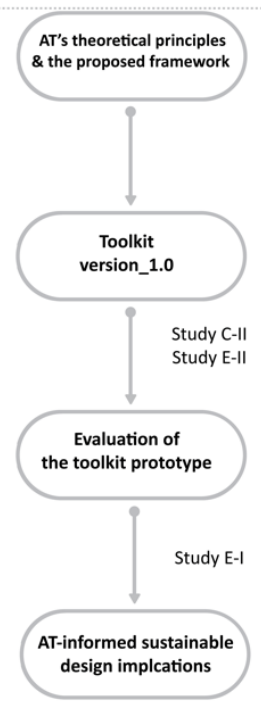

Figure 27. The iteration process of the AT-informed design ideation toolkit and the development process of the sustainable design implications.

Table 11. The input and outcome of each research step conducted in this stage.

\begin{tabular}{c|c|c}
\hline Inputs and corresponding studies & Main outcomes & Sections \\
\hline $\begin{array}{c}\text { AT's theoretical principles in } \\
\text { (as presented in Section 2.4) }\end{array}$ & $\begin{array}{c}\text { AT-informed design ideation toolkit } \\
\text { prototype }\end{array}$ & Section 6.1 \\
\hline $\begin{array}{c}\text { Date labelling project } \\
\text { (Study C-II and Study E-II) }\end{array}$ & Evaluation results & Section 6.2 \\
\hline $\begin{array}{c}\text { Meta-synthesis findings part 1 } \\
\text { (Study E-I) }\end{array}$ & $\begin{array}{c}\text { Extracting AT-based theoretical } \\
\text { understandings }\end{array}$ & Section 6.3 \\
\hline $\begin{array}{c}\text { Meta-synthesis findings part 2 } \\
\text { (Study E-I) }\end{array}$ & $\begin{array}{c}\text { Translating theoretical } \\
\text { understandings into sustainable } \\
\text { design implications }\end{array}$ & Section 6.4 \\
\hline
\end{tabular}

\subsection{AT-informed design ideation toolkit prototype}

The AT-informed ideation toolkit prototype is in the form of a cube named "Activity Cube" and a deck of ideation cards named "Activity Design Cards". The Activity Cube is bounded by six facets that match the six key theoretical principles of AT: 1). Motivations, goals, and outcome, 2). Sociocultural contexts, 3). Mediating 
artefact, 4). Tensions and contradictions, 5). Internalization and externalization, and 6). History and development. The intention is to provide design researchers and practitioners with a physical object to interact with while enabling them to learn about the different aspects of human activity.

In line with the Activity Cube, the Activity Design Cards also comprise six categories, each category matches with one facet of the Activity Cube. As shown in Figure 28, each card consists of two parts: a design ideation question and a corresponding design example. For example, in the category of hierarchical structure, one of the cards asks the question: "Can you enable users to attain a series of different goals in a row within the targeted activity?" In the category of history and development, one of the cards asks the question: "Can you adopt some design features from the old tools that users previously used in the targeted activity to your current design?" A list of design ideation questions formulated based on AT's theoretical principles is shown in Table 12. These questions were formulated based on the author's interpretation of AT's key theoretical principles (see Section 2.4). The corresponding design examples illustrated in the cards are extracted from the common products and services people use in everyday life contexts. For instance, Airbnb's accommodation and sightseeing service is used to provide a clue to the question: "Can you enable users to attain a series of different goals in a row within the targeted activity?". Similarly, keyboard layout of mechanical typewriters and modern computers is used to provide an example for the question: "Can you adopt some design features from the old tools that users previously used in the targeted activity to your current design?". A total number of 24 Activity Design Card were developed in this version of the toolkit (see Appendix 1). 


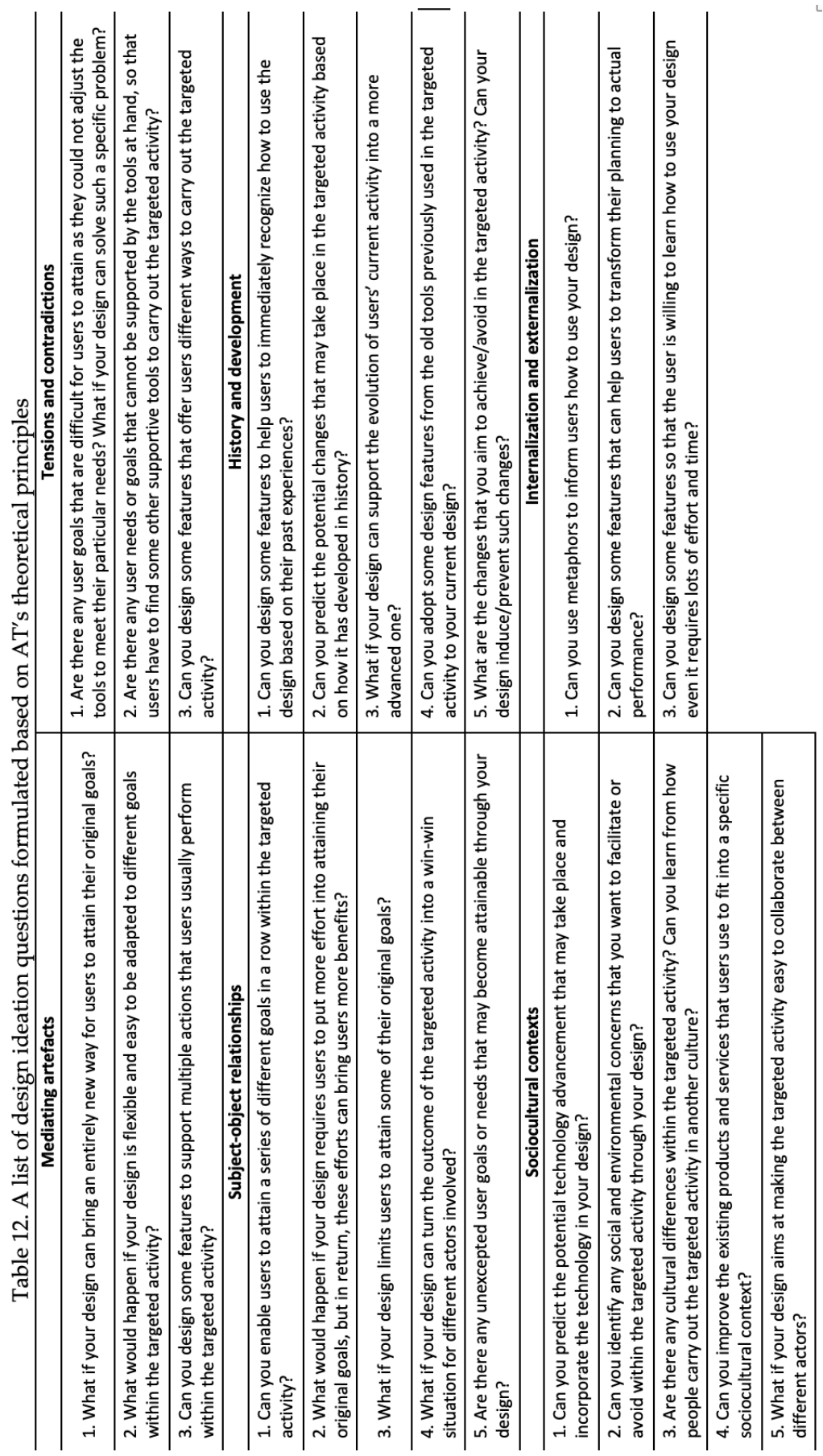


Besides the Activity Design Cards, two types of Activity Cube were developed: the dice and the Rubik's cube (as shown in Figure 29). Both of the cubes are based on the concept of randomness and play used in design ideation. The content of these two cubes is the same. The only difference lies in the play mechanism. For the dice, users are supposed to first roll the dice and then pick up a card from the corresponding card category. For the 4 X4 Rubik's cube, each color of the cube refers to one card category, users are supposed to rotate the Rubik's cube and then draw four cards separately from the corresponding card categories.

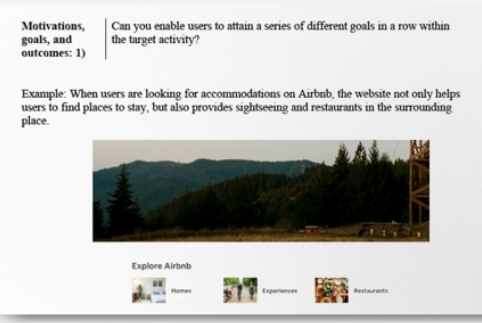

\begin{tabular}{l|l} 
History and \\
developinent: 4)
\end{tabular} \mid $\begin{aligned} & \text { Can you adopt some design features from the old tools which were } \\
& \text { previously used in the user target activities to your current design? }\end{aligned}$ Example: In order to not interupt users' typing flow, the modern computer keyboand follows
the same layout of the old typewriter

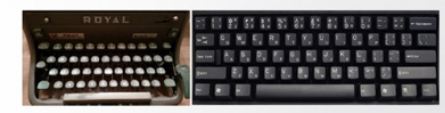

Figure 28. Examples of the Activity Design Cards used in this version of the toolkit.

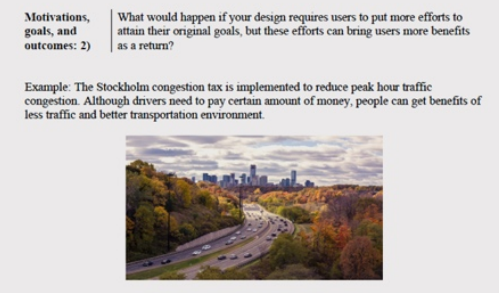

\begin{tabular}{l|l}
$\begin{array}{c}\text { Contradictions } \\
\text { and tensions: 1) }\end{array}$ & $\begin{array}{l}\text { Are there any user goals that are hard for users to attain because they } \\
\text { couldn't adjust the tools to their own preferences? What if your design }\end{array}$
\end{tabular} can solve that specific problem?

Example when using this dish washer, there is no way to designante a specific area in the dish
washer to be cleaned

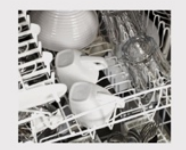
the toolkit. 

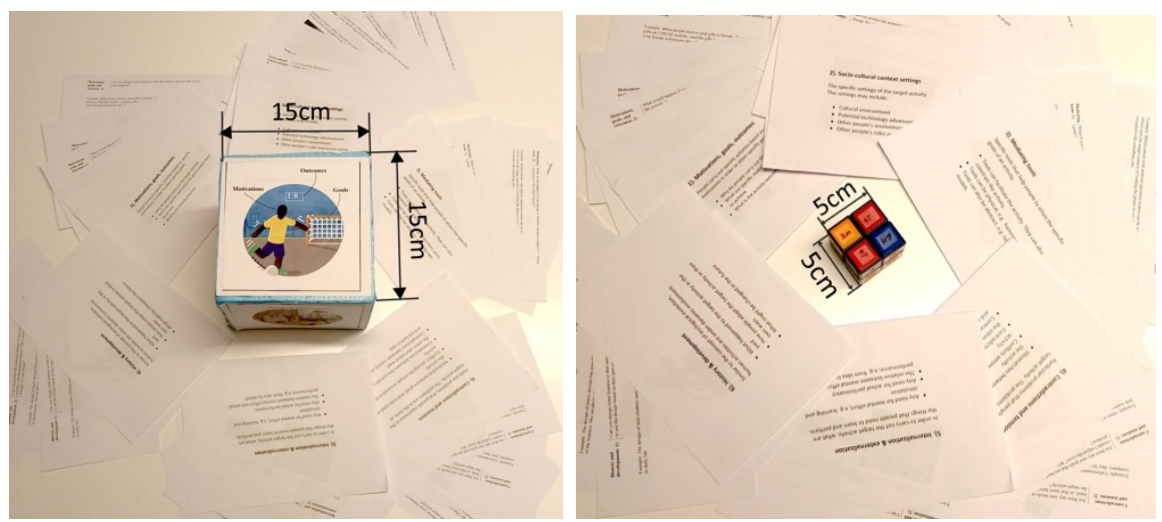

Figure 29. The AT-informed toolkit prototype. Left: toolkit in the form of a dice; Right: toolkit in the form of a Rubik's cube.

\subsection{Evaluation of the AT-onformed toolkit prototype}

\subsubsection{Methods applied}

The first version of the toolkit was evaluated in the date labelling project (for the background of the project see Section 5.4). Two rounds of co-creation sessions were conducted to evaluate how the toolkit can be used in designers' early-stage ideation process. The first round of co-creation sessions was conducted in collaborative design workshops where design experts were involved. The second round of co-creation sessions involved participants without prior design background in individual brainstorming settings. Table 12 shows the specific set-up of the evaluation. The design brief that participants received in these two sessions was the same, that is, to design products or services to promote consumers' correct usage of date and storage labelling information in household environments. The two types of the cube were evaluated separately. The dice form of the toolkit was evaluated in the collaborative design workshops as it can be shared and played by multiple participants at the same time, while the Rubik's cube was evaluated in the individual brainstorming sessions as it has the potential to bring randomness to the idea generation process performed by the individual. 
Table 12. The set-up of the AT-informed toolkit prototype evaluation sessions.

\begin{tabular}{c|c|c}
\hline & Collaborative workshop & Individual brainstorming \\
\hline Participants & $\begin{array}{c}\text { Group 1 \& 2: } \\
\text { Each with 1-2 design experts and 3-4 } \\
\text { general consumers }\end{array}$ & $\begin{array}{c}\text { 4 food and packaging industry } \\
\text { practitioners }\end{array}$ \\
\hline $\begin{array}{c}\text { Tested } \\
\text { toolkit }\end{array}$ & \multicolumn{2}{|c|}{ Dice form } \\
\hline Design brief & $\begin{array}{r}\text { To design products or services that promote consumers' correct usage of date and } \\
\text { storage labelling information in household environments }\end{array}$ \\
\hline
\end{tabular}

In terms of collaborative design workshops, two workshop sessions were organized, each with 5-6 participants (1-2 design experts and 3-4 general consumers). Each workshop session lasted for approximately 75-90 minutes. In terms of individual brainstorming, 4 industry practitioners participated in the session separately. Each session lasted around 45 to 65 minutes. In both sessions, the AT-informed toolkit prototype was used to facilitate participants' design idea generation (the evaluation process is illustrated in Figure 30). A detailed description of the design workshops and brainstorming sessions can be found in Paper III and Paper VI.
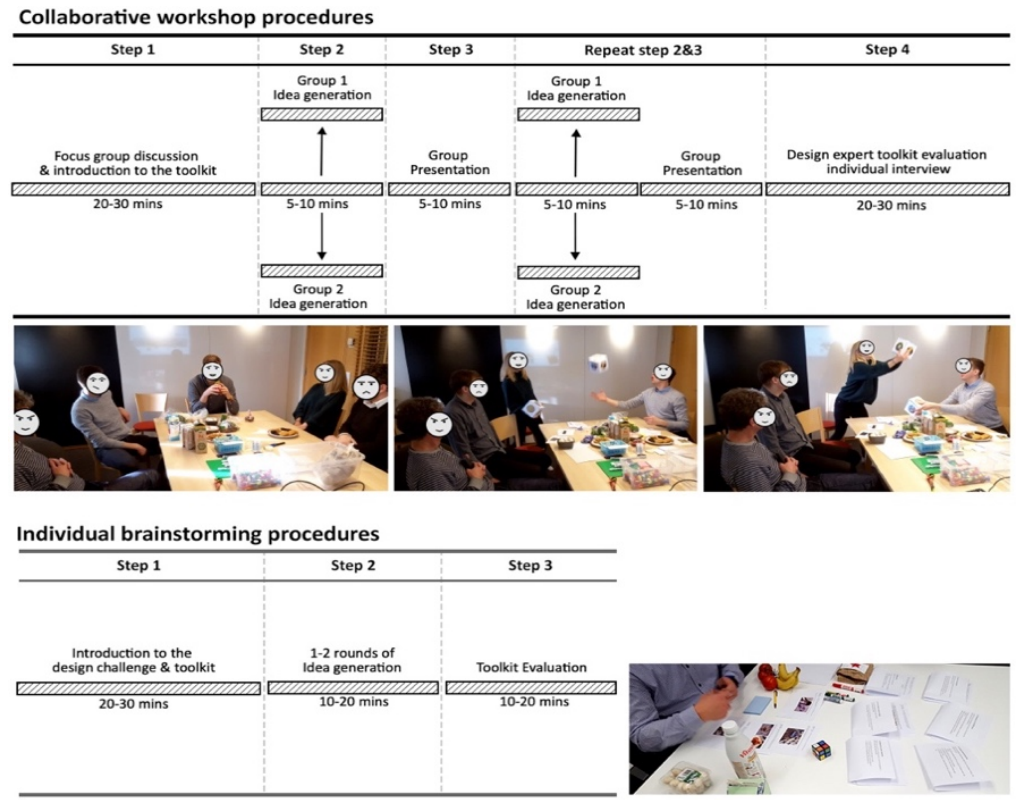

Figure 30. Evaluation of the AT-informed toolkit prototype. Up: collaborative design workshop evaluation procedures; Down: individual brainstorming evaluation procedures. 


\subsubsection{Evaluation results and reflections of the first version toolkit}

The design ideas generated through the use of the toolkit is presented in Table 13. In general, the design ideas can be categorized into three categories: 1). ideas revolving around improving date and storage information presentation, 2). ideas revolving around improving consumers' sensory assessment of food edibility, and ideas about employing technological innovations to help consumers to make better judgments.

Table 13. A list of design ideas generated through using the toolkit.

\begin{tabular}{|c|c|}
\hline Category & Early-stage design Ideas for interventions \\
\hline $\begin{array}{l}\text { Improve date and storage } \\
\text { information presentation }\end{array}$ & $\begin{array}{l}\text { - A graphic presentation of product shelf life instead of only presenting } \\
\text { date (e.g., timetable, visualization of the probability for bacteria to } \\
\text { grow). } \\
\text { - A visual aid of how the food item would look like if it is gone bad (e.g., } \\
\text { a visual comparison between edible and spoiled food). } \\
\text { - A description of how the food item would smell if it is gone bad. } \\
\text { - "Use within X days after opening" label with a sticker to show when the } \\
\text { product was first opened. }\end{array}$ \\
\hline Improve sensory assessment & $\begin{array}{l}\text { - Tips of which sensory perceptions are recommended to assess the } \\
\text { edibility of a certain food product. } \\
\text { - Packaging designed to encourage people to squeeze, smell and look } \\
\text { inside. }\end{array}$ \\
\hline $\begin{array}{l}\text { Incorporate technological } \\
\text { innovations }\end{array}$ & $\begin{array}{l}\text { - Smart labels that can detect food status in real-time and change colors } \\
\text { accordingly. } \\
\text { - Intelligent fridge to help consumers to better manage food items in the } \\
\text { fridge. } \\
\text { - QR codes on packaging to inform consumers about product relevant } \\
\text { information such as detailed date and storage guidance, production, } \\
\text { transportation and brand identity. } \\
\text { - Provide digitalized and tailored recipes for consumers to deal with food } \\
\text { items close to the expiration date. }\end{array}$ \\
\hline
\end{tabular}

Based on the design ideas shown in Table 14, an AR-based mobile digital prototype that aims to support consumers in making better food edibility assessment was developed (see Paper IV). To be more specific, the AR prototype can transform the date labelling and storage-related information presented on the packaging to consumers' mobile devices. This feature can be used to solve the limitation of on-pack labelling space issue that food industry practitioners are concerned about. It can also provide consumers with a way to interact with the information in real-time. In other words, instead of purely being an information receiver, consumers can actively find knowledge and information such as product storage methods, shelf-life and recipes. Furthermore, as consumers noted that visual 
representation of how the food item would look like if it is gone bad is especially helpful, the augmented 3D presentation of food items thus are able to offer such visual aid to help consumers make edibility judgement based on their sensory prescriptions (see Figure 31).
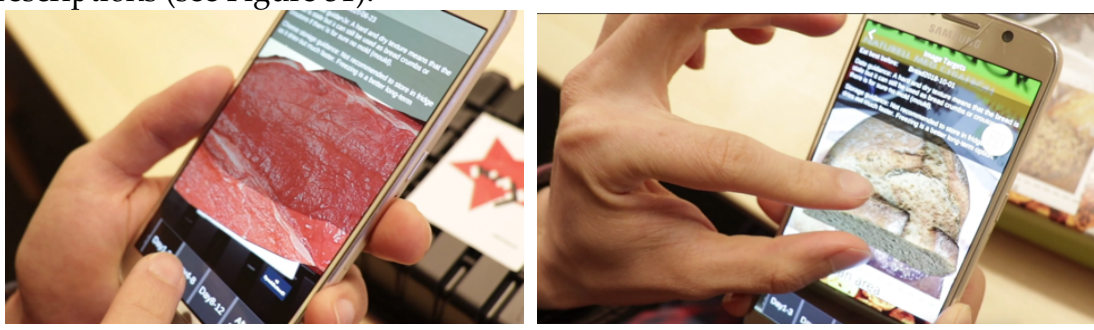

Figure 31. The Augmented Reality digital prototype developed to support consumers' food edibility assessment activities.

Furthermore, as shown in Table 13, although the theme of this design project is focused on the perspective of on-pack date labelling communication, the design ideas that participants generated not only center around date labelling design itself, they also covered different aspects of people's food edibility assessment activity system, ranging from improvements on visual presentation to technological supports. This finding sheds some light on the effects of the toolkit in terms of its usefulness to systemically inform activity-based design interventions to address sustainability challenges. Therefore, the toolkit has the potential to work as an entry point for designers to take activity as the unit of design and thus engage with complex sustainability issues in users' activity system. Besides that, the variety of the generated design ideas also indicates that the toolkit is applicable when it comes to supporting designers in developing early-stage design ideas.

Furthermore, the Activity Cube (both the dice and Rubik's Cube) was reported by participants as interactive and fun. However, the form of the Activity Design Cards was criticized by the participants. Three main limitations regarding the Activity Design Cards can be summarized:

- The text descriptions on Activity Design Cards were redundant.

- The layout of Activity Design Cards needed to be adjusted.

- Some of the design examples illustrated on the Activity Design Cards help to understand the question, while some brought extra difficulties for understanding the question. 


\subsection{Extracting AT-informed design implications}

\subsubsection{Study set-up and goals}

Study E-I is conducted to explore 1). how have AT and its theoretical principles been applied in existing studies which focus on addressing design and sustainability challenges? And 2). what are the design implications that AT can offer for design researchers in the field of DfSB?

6.3.2 Methods applied: narrative literature review and theory-generating qualitative meta-synthesis

As illustrated in Figure 32, a narrative literature review was first conducted to gain an overview of the literature search scope and determine the literature search strategy. The results of the narrative literature review can be found in Paper VI.

Building upon the results of the narrative literature review, a systematic literature search and meta-synthesis was then carried out to analyze and synthesize the existing studies that applied an AT theoretical perspective for investigating design for sustainability issues. The meta-synthesis performed in this study was comprised of 4 steps: 1) develop workable definitions of key concepts and search scope, 2) identification of research, 3) study selection and quality assessment, 4) data extraction and synthesis.

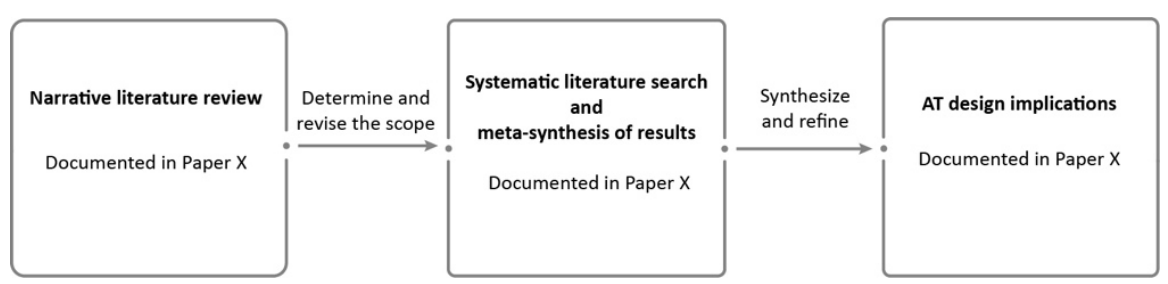

Figure 32. An overview of the research process applied in this stage.

As shown in Table 14, peer-reviewed conference papers, journal articles and book chapters published until April 2020 were included in the literature search. After removing duplicated search records, 621 articles were identified. After the study selection and assessment process, 18 articles remained in the final selection stage. 
Table 14. Search scope, search string and the corresponding search records in the meta-synthesis study.

\begin{tabular}{c|c|c}
\hline Databases and search criteria & Scopus & Web of Science Core Collection \\
\hline Document type & $\begin{array}{c}\text { Article, conference paper, book } \\
\text { chapter }\end{array}$ & $\begin{array}{c}\text { Article, conference paper, book } \\
\text { chapter }\end{array}$ \\
\hline Language & English & English \\
\hline Publication year & From 1990 to April 2020 & From 1975 to April 2020 \\
\hline Search strings applied to & TITLE-ABS-KEY & TITLE-ABS-KEY \\
\hline $\begin{array}{c}\text { "activity theory" AND } \\
\text { "sustainab*" }\end{array}$ & 98 records & 67 records \\
\hline $\begin{array}{c}\text { "activity theory" AND } \\
\text { "behavior* change" }\end{array}$ & 8 records & 3 records \\
\hline $\begin{array}{c}\text { "activity theory" AND } \\
\text { "environment*" AND "design" }\end{array}$ & 243 records & 156 records \\
\hline $\begin{array}{c}\text { "activity theory" AND "social*" } \\
\text { AND "design" }\end{array}$ & 294 records & \\
\hline
\end{tabular}

Regarding the data extraction and synthesis, data from the included primary studies were first extracted into two categories: basic study characteristics and the specific use of AT. Then, the memoing method was adopted to analyze and synthesize the extracted codes. An overview of the data analysis and synthesis process is presented in Figure 33.

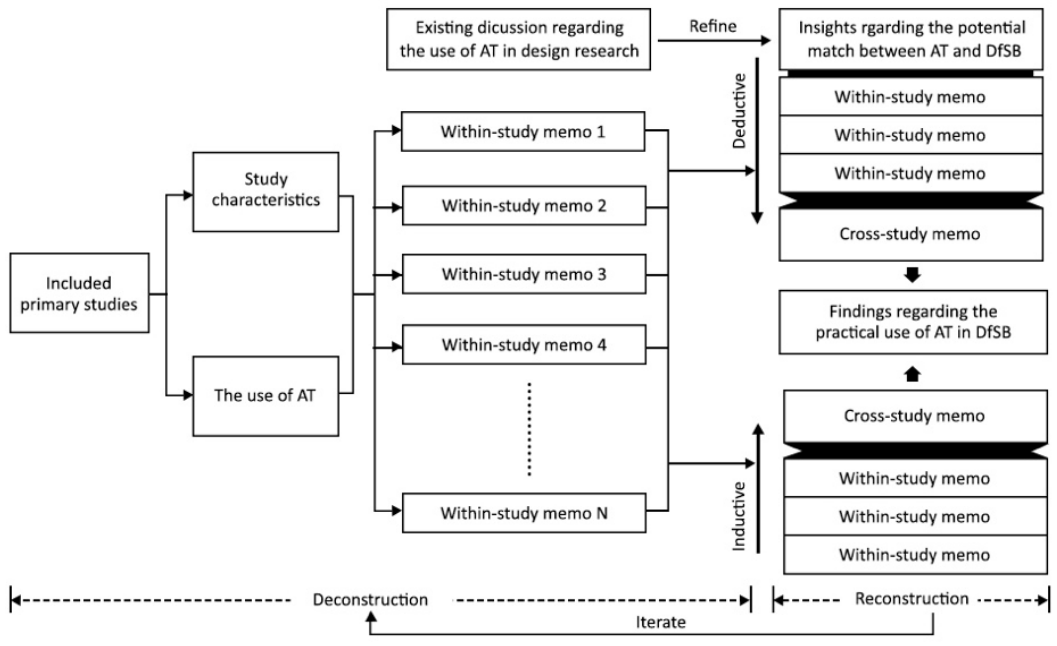

Figure 33. The analysis and synthesis process of qualitative findings extracted from the primary studies. 


\subsubsection{Results}

In total, 18 articles are included in the final review. Table 15 shows a summary of the included primary studies. The general topics of the included articles cover five areas: 1). the design, development and evaluation of Information and communication technology (ICT) platform to solve social and ecological sustainability issues (see Aguoyo, 2016; Aguoyo \& Emaes, 2017; Smith \& Turpin, 2017; Ssozi, 2016; Sclater, 2016; Lally \& Sclater, 2012 Hnasan \& Meloche, 2013), 2). information system (IS) to tackle challenges associated with climate change (see Hansan et al. 2017; Hansan \& Lonescu, 2017; Chen et al., 2009), 3). sustainable eHealth services (Svensson, 2020; Bai\&Guo, 2011; Lin \& Hsieh, 2014; Lin et al., 2012), 4). energy conservation artefacts and monitoring systems (Svelvefors et al, 2015, viktorelius \& Lundh, 2019), and 5). design related to sustainable consumption in general (Perold et al., 2019; Chu et al., 2020; Khan et al., 2015). It has to be noted that the design interventions that most of the included studies developed and evaluated were in digital form. This is not surprising given that AT has already been widely applied in the research field of ICT and HCI.

Table 15. A summary of the included articles' research area, topic, relation to sustainability and design, and engagement with AT.

\begin{tabular}{|c|c|c|c|}
\hline $\begin{array}{l}\text { Types of design } \\
\text { intervention and } \\
\text { fields of } \\
\text { implementation }\end{array}$ & $\begin{array}{l}\text { Included } \\
\text { articles }\end{array}$ & Sustainability and design goal(s) & Overall engagement with AT \\
\hline \multirow{5}{*}{$\begin{array}{l}\text { Information and } \\
\text { communication } \\
\text { technology (ICT) }\end{array}$} & $\begin{array}{l}\text { Aguoyo, 2016; } \\
\text { Aguoyo \& } \\
\text { Emaes, 2017; }\end{array}$ & $\begin{array}{l}\text { Design and evaluate an ICT platform to } \\
\text { promote local residents' understanding of } \\
\text { the socio-ecological sustainability of a lake } \\
\text { in southern Chile. }\end{array}$ & $\begin{array}{l}\text { To analyze and guide the design, } \\
\text { implementation and evaluation } \\
\text { phase of the platform }\end{array}$ \\
\hline & $\begin{array}{l}\text { Smith \& } \\
\text { Turpin, 2017; }\end{array}$ & $\begin{array}{l}\text { Design and evaluate an ICT platform to } \\
\text { empower elderly women in a rural } \\
\text { community in South Africa. }\end{array}$ & $\begin{array}{l}\text { To describe the social and } \\
\text { political dynamics in the } \\
\text { community }\end{array}$ \\
\hline & $\begin{array}{l}\text { Ssozi- } \\
\text { Mugarura et } \\
\text { al., } 2016\end{array}$ & $\begin{array}{l}\text { Evaluate an ICT intervention for sustainable } \\
\text { water management in rural communities in } \\
\text { Uganda. }\end{array}$ & $\begin{array}{l}\text { To analyze the contextual factors } \\
\text { that influence the mediation } \\
\text { capacity of the intervention }\end{array}$ \\
\hline & $\begin{array}{l}\text { Sclater, 2016; } \\
\text { Lally \& Sclater, } \\
\quad 2012\end{array}$ & $\begin{array}{l}\text { Evaluate the effects of a Technology } \\
\text { Enhanced Learning platform on supporting } \\
\text { pedagogies of socio-ecological sustainability } \\
\text { in Art and Design education. }\end{array}$ & $\begin{array}{l}\text { To understand how participants } \\
\text { acted and developed when } \\
\text { engaged in co-designed creative } \\
\text { activities on the platform }\end{array}$ \\
\hline & $\begin{array}{l}\text { Hnasan \& } \\
\text { Meloche, } \\
2013\end{array}$ & $\begin{array}{l}\text { Identify ICT-mediated opportunities in } \\
\text { solving environmental challenges. }\end{array}$ & $\begin{array}{l}\text { To interpret the key factors } \\
\text { emerged from the collected } \\
\text { empirical data }\end{array}$ \\
\hline \multirow{2}{*}{$\begin{array}{l}\text { Information } \\
\text { system (IS) }\end{array}$} & $\begin{array}{l}\text { Hansan et al, } \\
\text { 2017; }\end{array}$ & $\begin{array}{l}\text { Explore the potential of using IS to support } \\
\text { the planning and execution of design } \\
\text { interventions for climate change } \\
\text { adaptation. }\end{array}$ & $\begin{array}{l}\text { To develop and analyze design } \\
\text { interventions for solving complex } \\
\text { climate change problems }\end{array}$ \\
\hline & $\begin{array}{l}\text { Hansan \& } \\
\text { Lonescu, } \\
\text { 2017; }\end{array}$ & $\begin{array}{l}\text { Design an online system to enable small } \\
\text { businesses to track and reduce the } \\
\text { environmental footprint of their business } \\
\text { activities. }\end{array}$ & $\begin{array}{l}\text { To identify business activities } \\
\text { that have a significant } \\
\text { environmental footprint }\end{array}$ \\
\hline
\end{tabular}


Development and evaluation of an AT-informed sustainable design toolkit

\begin{tabular}{|c|c|c|c|}
\hline & $\begin{array}{c}\text { Chen et al., } \\
2009\end{array}$ & $\begin{array}{l}\text { Explore the design of information } \\
\text { technologies to address socio-economic } \\
\text { emergency communication challenges. }\end{array}$ & $\begin{array}{l}\text { To analyze the key issues in and } \\
\text { understand the requirements for } \\
\text { emergency communication } \\
\text { system design. }\end{array}$ \\
\hline \multirow{3}{*}{ eHealth services } & $\begin{array}{l}\text { Svensson, } \\
\text { 2020; }\end{array}$ & $\begin{array}{l}\text { Introduce innovative eHealth services at a } \\
\text { municipal level to obtain a sustainable } \\
\text { society. }\end{array}$ & $\begin{array}{l}\text { To understand the voices of } \\
\text { different actors and analyze their } \\
\text { contradictive motives in eHealth } \\
\text { work practice }\end{array}$ \\
\hline & $\begin{array}{l}\text { Bai\&Guo, } \\
\text { 2011; }\end{array}$ & $\begin{array}{l}\text { Develop eHealth services for elderly care } \\
\text { with an emphasis on sustainability } \\
\text { properties. }\end{array}$ & $\begin{array}{l}\text { To design the architecture of the } \\
\text { system and identify the } \\
\text { relationships between different } \\
\text { components of the healthcare } \\
\text { system }\end{array}$ \\
\hline & $\begin{array}{l}\text { Lin et al., } \\
\text { 2012; } \\
\text { Lin \& Hsieh, } \\
2014 \\
\end{array}$ & $\begin{array}{l}\text { Evaluate and investigate what design factors } \\
\text { affect the sustainability of telehealth } \\
\text { services. }\end{array}$ & $\begin{array}{l}\text { To identify the contradictions } \\
\text { among the key actors of the } \\
\text { telehealth system }\end{array}$ \\
\hline \multirow{2}{*}{$\begin{array}{c}\text { Energy } \\
\text { consumption } \\
\text { and conservation }\end{array}$} & $\begin{array}{l}\text { Svelvefors et } \\
\text { al, } 2015\end{array}$ & $\begin{array}{l}\text { Explore design implications and } \\
\text { opportunities for supporting people's } \\
\text { everyday energy conservation. }\end{array}$ & $\begin{array}{l}\text { To understand how people } \\
\text { perceive the possibilities to } \\
\text { engage in energy conservation } \\
\text { from a goal-oriented perspective }\end{array}$ \\
\hline & $\begin{array}{l}\text { Viktorelius \& } \\
\text { Lundh, } 2019\end{array}$ & $\begin{array}{l}\text { Evaluate the design of an energy monitoring } \\
\text { system and energy saving policy for } \\
\text { improving energy efficiency in shipping. }\end{array}$ & $\begin{array}{l}\text { To analyze and understand } \\
\text { energy conservation and } \\
\text { efficiency in the complex } \\
\text { sociotechnical setting }\end{array}$ \\
\hline \multirow{3}{*}{$\begin{array}{l}\text { Sustainable } \\
\text { consumption in } \\
\text { general }\end{array}$} & $\begin{array}{l}\text { Perold et al., } \\
\quad 2019\end{array}$ & $\begin{array}{l}\text { Design to support informal settlement } \\
\text { residents' transitions toward sustainable } \\
\text { urbanism in Southern African. }\end{array}$ & $\begin{array}{l}\text { To analyze and identify } \\
\text { contradictions between two co- } \\
\text { existing design activity systems in } \\
\text { architectural practice. }\end{array}$ \\
\hline & $\begin{array}{c}\text { Chu et al., } \\
2020\end{array}$ & $\begin{array}{l}\text { Explore design opportunities to reduce date } \\
\text { and storage labelling related household } \\
\text { food waste. }\end{array}$ & $\begin{array}{l}\text { To conceptualize subjects' } \\
\text { interaction with mediating } \\
\text { artefacts and the corresponding } \\
\text { tensions and contractions }\end{array}$ \\
\hline & $\begin{array}{c}\text { Khan et al., } \\
2015\end{array}$ & $\begin{array}{l}\text { Solve environmental management issues of } \\
\text { electric and electronic waste by redesigning } \\
\text { human interaction in socio-cultural } \\
\text { perspectives. }\end{array}$ & $\begin{array}{l}\text { To develop a framework to } \\
\text { systemically solve electric and } \\
\text { electronic waste issues. }\end{array}$ \\
\hline
\end{tabular}

As shown in Table 16, the key theoretical principles of AT were used either for analyzing the causes of sustainability-related issues and inform sustainable design implications (as presented in theme 1) or evaluating the effects of the proposed design interventions on solving the targeted sustainability challenges (as presented in theme 2).

Table 16. An overview of the AT theoretical principles used in each primary study.

\begin{tabular}{|c|c|c|c|c|c|c|}
\hline Themes & Articles & $\begin{array}{c}\text { Mediating } \\
\text { artefacts }\end{array}$ & $\begin{array}{c}\text { History } \\
\& \\
\text { development }\end{array}$ & $\begin{array}{l}\text { Sociocultural } \\
\text { contexts }\end{array}$ & $\begin{array}{c}\text { Tensions } \\
\& \\
\text { contradictions }\end{array}$ & $\begin{array}{c}\begin{array}{c}\text { Subject- } \\
\text { object } \\
\text { relationships }\end{array} \\
\end{array}$ \\
\hline \multirow{5}{*}{$\begin{array}{l}\text { Theme 1: Analyze the } \\
\text { causes of } \\
\text { sustainability issues } \\
\text { and inform } \\
\text { sustainable design } \\
\text { interventions }\end{array}$} & $\begin{array}{c}\text { Hasan \& Meloche, } \\
2013\end{array}$ & $\sqrt{ }$ & & & & \\
\hline & Hasan et al., 2017 & $\sqrt{ }$ & & $\sqrt{ }$ & $\sqrt{ }$ & $\sqrt{ }$ \\
\hline & Perold et al., 2019 & $\sqrt{ }$ & & & $\sqrt{ }$ & \\
\hline & $\begin{array}{c}\text { Selvefors et al., } \\
2015\end{array}$ & $\sqrt{ }$ & $\sqrt{ }$ & & $\sqrt{ }$ & $\sqrt{ }$ \\
\hline & Bai \& Guo, 2011 & $\sqrt{ }$ & & & & $\sqrt{ }$ \\
\hline
\end{tabular}




\begin{tabular}{|c|c|c|c|c|c|c|}
\hline & Chu et al., 2020 & $\sqrt{ }$ & & & $\sqrt{ }$ & $\sqrt{ }$ \\
\hline & Khan et al., 2015 & $\sqrt{ }$ & & $\sqrt{ }$ & & \\
\hline & Chen et al., 2009 & $\sqrt{ }$ & & $\sqrt{ }$ & & \\
\hline \multirow{8}{*}{$\begin{array}{l}\text { Theme 2: Evaluate } \\
\text { the effects of design } \\
\text { interventions on } \\
\text { solving the targeted } \\
\text { sustainability } \\
\text { challenges }\end{array}$} & $\begin{array}{c}\text { Hasan \& Ionescu, } \\
2017\end{array}$ & $\sqrt{ }$ & & & & \\
\hline & Lin \& Hsieh, 2014 & $\sqrt{ }$ & & $\sqrt{ }$ & $\sqrt{ }$ & \\
\hline & $\begin{array}{l}\text { Sclater, 2016; } \\
\text { Lally \& Sclater, } \\
2012\end{array}$ & $\sqrt{ }$ & $\sqrt{ }$ & & & \\
\hline & $\begin{array}{c}\text { Ssozi-Mugarura et } \\
\text { al., } 2016\end{array}$ & $\sqrt{ }$ & $\sqrt{ }$ & $\sqrt{ }$ & & $\sqrt{ }$ \\
\hline & Svensson, 2020 & $\sqrt{ }$ & & & $\sqrt{ }$ & $\sqrt{ }$ \\
\hline & $\begin{array}{l}\text { Viktorelius \& } \\
\text { Lundh, } 2019\end{array}$ & $\sqrt{ }$ & $\sqrt{ }$ & & $\sqrt{ }$ & \\
\hline & $\begin{array}{c}\text { Aguayo, 2016; } \\
\text { Aguayo \& Eames, } \\
2017\end{array}$ & $\sqrt{ }$ & $\sqrt{ }$ & $\sqrt{ }$ & & $\sqrt{ }$ \\
\hline & $\begin{array}{l}\text { Smith \& Turpin, } \\
2017\end{array}$ & $\sqrt{ }$ & & $\sqrt{ }$ & $\sqrt{ }$ & \\
\hline
\end{tabular}

\subsection{Translating the extracted design implications}

Two steps were taken to translate the above design implications for designers with no prior theoretical knowledge of AT to apply.

In the first step, the AT-informed design implications were justified through the case studies (see Study A-I, A-II, B-I, B-II, C-I, D) included in the dissertation. Most of the implications extracted from the findings of meta-synthesis are already covered and supported in the case studies. For instance, the design implication under the sociocultural context category: "Investigate the effects of the proposed sustainable design interventions at an individual level, while informing opportunities of how the interventions might be incorporated into the targeted activity system on a broader scale" is used in Study C-I, B-I and B-II. Results from these studies also support that this particular design implication is useful when it comes to sustainable design explorations. Table 18 shows the connection between the design implications and the case studies included in the dissertation. In the second step, the abstract design implications were translated into more practical design questions. This is done by integrating the design implications with the results and reflections regarding the use of AT in each corresponding case study included in this dissertation.

1. Sustainable mediating effects of artefacts: As presented in Section 2.4.1, the theoretical principle of the mediating effects of artefacts may enable design researchers to find design interventions that facilitate the transformation of the 
whole activity systems towards sustainability. Findings of the meta-synthesis specified this presumption by indicating that it can:

- Inform sustainable design interventions that take both the internal and external mediating effects of artefacts into considerations.

- Envisage whether and how might subjects incorporate the proposed sustainable design interventions into their existing activity systems.

2. Directing sustainable subject-object relationships: As presented in Section 2.4.2, the theoretical principle of subject-object relationships is assumed to have the potential to expand the scope of analysis from users' interaction with a specific artefact to how subjects carry out meaningful motive-oriented activities. Findings of the meta-synthesis confirmed this presumption and further revealed that the theoretical principle can help design researchers to:

- Uncover the relations between the subject's primary motives in an activity system and the corresponding sustainable or unsustainable actions and operations that the subject performs.

- Assess how the proposed sustainable design interventions might be compatible with subjects' existing motives and goals embedded in the target activity system.

3. Incorporating sociocultural contexts into sustainable design considerations: As presented in Section 2.4.5, the theoretical principle of sociocultural contexts may help design researchers to analyze or envisage the potential impacts of sustainable design intervention at different levels. Moreover, it suggests that empirical phenomenon related to sustainable behavior needs to be investigated in real-life contextual settings rather than task-based laboratory settings. Findings from the meta-synthesis confirmed the above presumptions and highlighted the importance to:

- Interpret individuals' needs in relation to the social, cultural and historical context of the targeted activity system.

- $\quad$ Find an analytical balance between individual behavior and the sociocultural context to investigate the cause of sustainability issues.

- Investigate the effects of the proposed sustainable design interventions at the individual level, while informing how the interventions might be incorporated into the targeted activity system on a broader scale.

4. Uncovering tensions and contradictions within and between the target activity systems: As presented in Section 2.4.3, when used in the context of 
design for sustainable behavior, AT's theoretical principle of tensions and contradictions may provide design researchers with a holistic view to understand how tensions and contradictions within and between activity systems can cause sustainability problems. The findings of meta-synthesis explicated this statement by suggesting that it can enable design researchers to:

- Reveal tensions and contradictions within and between different constituents of the target activity system, and how these tensions and contradictions may affect the sustainability outcome of the activity.

- Investigate why interventions particularly designed to promote people's sustainable behavior failed to achieve the intended outcomes.

- Identify the contradictive motives and needs of different actors involved in the target activity system and the influences on the sustainability outcome of the activity.

- Identify the potential conflicts between subjects' existing forms of activity and the preferred sustainable forms of activity intended by the design interventions.

5. Understanding the dynamism of activities: As presented in Section 2.4.4, activities are under a constant development and evolution process as the subject attempting to find temporary solutions to cope with the tensions and contradictions that took place in people's activity system. Therefore, the way how we carry out a specific activity at a specific point of time is influenced by the evolution of the targeted activity in the past, and it will also influence the future development of the activity. The findings from the meta-synthesis supported this argument, they also indicated that AT's theoretical principle of history and development can allow design researchers to:

- Analyze how subjects cope with existing tensions and contradictions in the target activity system and how this can lead to potential opportunities for sustainable design interventions.

- Illustrate how the target activity system develops over time and what sustainability challenges, along with design opportunities, may emerge in this development process.

- Envisage whether and how the proposed design interventions may lead to desired or undesired changes in the activity system. 


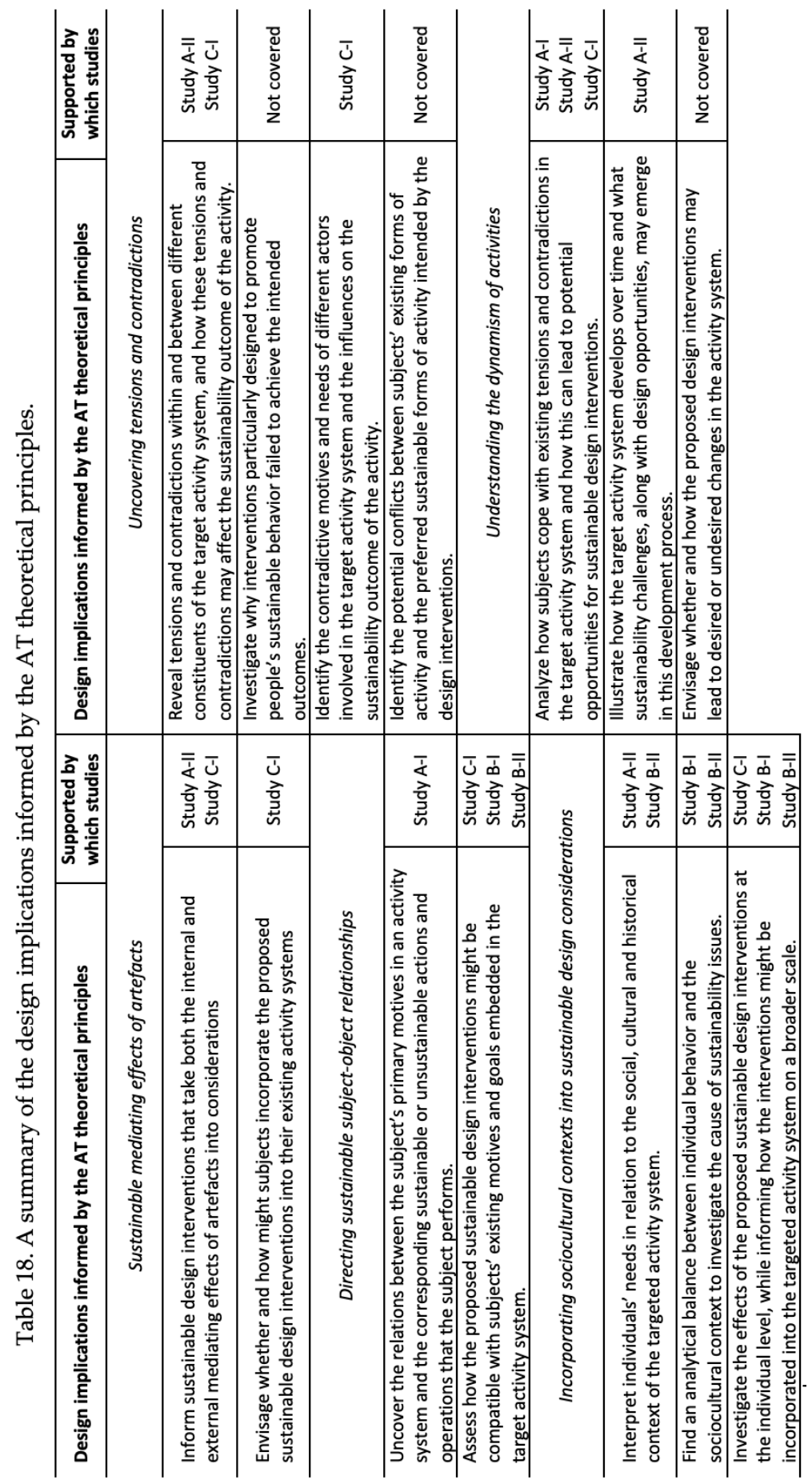




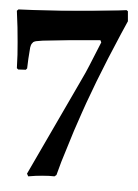

\section{Discussion}

This chapter discusses the design opportunity and implications that a context change transition and behavior retention perspective can provide for the field of Design for sustainable Everyday Life. Furthermore, the research approach and knowledge generation process applied in this PhD study are also reflected in this chapter.

\subsection{Revisit the concept of design for sustainable behaviour retention}

Given the understanding of design for sustainable behavior retention through context change disruptions, the questions then come to what are the overlaps and differences between design for sustainable behavior retention and design for sustainable behavior change at a conceptual level? and how the behavior retention perspective and the behavior change perspective might complement each other in terms of facilitating people's behavior transition towards a sustainable lifestyle? These two questions will be discussed in the following section.

\section{Overlaps and differences between change and retention}

As shown in Table 19, both the behavior change perspective and the behavior retention perspective aim at introducing design interventions to facilitate a transition towards a sustainable lifestyle. However, a design for sustainable behavior change perspective explicitly aims at reducing the negative impacts of people's wrongdoings. In contrast, the sustainable behavior retention perspective aims at supporting people in maintaining and adapting the positive effects of their existing doings. The difference in overarching goal also determines that the focus of analysis between the two concepts varies from each other. A design for behavior change perspective focuses on identifying and analyzing what and how unsustainable doings are carried out by users. In contrast, a design for sustainable 
behavior retention perspective emphasizes the importance of learning from the existing desired and sustainable doings that people have been performing.

\section{Change and retention: complementarity to achieve sustainable behavior transition}

The fundamental reason that causes the differences in these two perspectives may be ascribed to the different interventional approaches used to achieve sustainability. According to Faber et al. (2016), two approaches exist when designing sustainability-oriented innovations: an absolute approach and a relative approach. An absolute approach suggests that a set of selected criteria or objectives can be used to determine an idealized state of sustainability. For example, reducing energy consumption of the appliance by $20 \%$, cutting down the CO2 emission by $10 \%$. Interventions that facilitate the transition towards sustainability thereby need to explicitly aim at fulfilling these pre-set objectives. On the contrary, a relative approach suggests that an idealized sustainability state does not exist because the context in which people situate keeps changing. Therefore, achieving sustainability should be regarded as a dynamic and ongoing process in which constant improvements and adjustments should be made.

The absolute approach is, to some extent, in line with the concept behind design for sustainable behavior change. More precisely, as described previously, a design for sustainable behavior change perspective tends to treat sustainability dichotomously. There seems to be a clear distinction between what is perceived as sustainable and what is perceived as unsustainable. A behavior change perspective thus implies that there is a desired or undesired sustainable state, and design is used as a means to achieve the desired state (Adams et al., 2016).

A design for sustainable behavior retention perspective aligns with the relative approach mentioned above. In contrast to design for sustainable behavior change, where a definite line can be drawn based on the selected criteria to assess sustainability, in retention, a grey area exists between what is perceived as sustainable and unsustainable. In other words, depending on the specific spatial (sociocultural) and temporal (development) contexts where a particular doing is performed, it can carry both sustainable and unsustainable features with it. Moreover, a particular doing which is regarded as undesired in a specific spatiotemporal context may turn out to be desired in another. 
For example, buying excessive amount of food more than normally needed in one purchase is often regarded as unsustainable behavior as it is likely lead to household food waste. However, in the context of Study D where people underwent the special time of the Covid-19 pandemic, this particular food purchasing behavior complies with the social distancing measures. Moreover, findings from Study D showed that, participants became more aware of the potential food waste issues in their food consumption activities. In order to better cope with the excessive amount food stored at home, participants also developed innovative solutions in their meal planning, food storage and food handling activities to avoid unnecessary food waste. From a development perspective, if the awareness of food waste, together with the innovative solutions in relation to more organized meal planning and food handling, can outlast the pandemic and become habitual doings embedded in people' everyday life, it would still contribute to the transition towards sustainable lifestyle.

Consequently, a design for sustainable behavior retention perspective highlights that, as people's doings, along with the spatial and temporal context in which these doings situate are dynamically evolving, the line that distinguishs what is desired and undesired, what is sustainable doings and wrongdoings, is constantly moving as well. Designers thus need to perform contextual dependent in-depth analysis to break down and analyze people's doings while keeping a holistic view on the spatio-temporal context. The bottom-up context-focused analysis that underlies the behavior retention perspective can thus complement the top-down objective-oriented behavior change perspective.

Table 19. Comparison between design for sustainable behavior change and retention

\begin{tabular}{c|c|c}
\hline & Design for behavior change & Design for behavior retention \\
\hline Overarching goals & Reduce negative impacts & Facilitate positive effects \\
\hline Focus of analysis & $\begin{array}{c}\text { Identifying undesired/unsustainable } \\
\text { wrongdoings }\end{array}$ & $\begin{array}{c}\text { Identifying existing desired/sustainable } \\
\text { doings }\end{array}$ \\
\hline $\begin{array}{c}\text { Approaches to achieve } \\
\text { sustainability }\end{array}$ & Absolute approach \\
\hline $\begin{array}{c}\text { Analysis and design } \\
\text { explorations }\end{array}$ & Top-down sustainability objectives & Bottom-up spatial and temporal contexts \\
\hline
\end{tabular}


7.2 Peeking into the differences between the Activity-based, Behavior-based and Practice-based theoretical approach

Three dominant theories can be identified in the field of Design for Sustainable Everyday Life: behavior model-based theoretical lens from a social-psychology perspective (hereinafter referred to as Behavior-based lens), a practice-based theoretical lens from a social-practice theory perspective (hereinafter referred to as SPT-based lens), and activity-based theoretical lens from an activity theory perspective (hereinafter referred to as AT-based lens). A comprehensive comparison of the strengthens and limitations between the Behavior-based lens and SPT-based lens can be found in previously published $\mathrm{PhD}$ dissertations in the field (see, e.g., Daae, 2014; Pettersen, 2013; Piscicelli, 2016; Tromp, 2013). Furthermore, in her dissertation, Selvefors (2017) compared the AT-based lens with the other two lenses. Building upon their insights, as this PhD study takes AT as the guiding theoretical framework, in this dissertation, the comparison is specifically focused on the strengths and limitations that an AT-based theoretical lens may bring to Design for Sustainable Everyday Life.

According to Wever (2012), at least two clusters can be distinguished among the wide range of research questions proposed in sustainable behavior design. The first cluster aims at developing theoretical understanding about factors that may potentially influence users' sustainable or unsustainable doings. Specifically, it involves questions including how to frame and understand users' doings, and what factors may influence users' response to the designs (see e.g., Kuijer, 2014; Lockton, 2013). The second cluster aims at providing design practitioners with approaches and tools to support their sustainable products and services design process. Questions related to this cluster revolve around determining what and where sustainable design interventions should be introduced (see, e.g., Daae, Chamberlin, \& Boks, 2018; Lockton, 2017). Although being applied for different goals, theoretical lenses play a central role in the research conducted in both clusters. In the first cluster, it often serves as a framework to guide empirical analysis, while in the second cluster, it is widely used as a tool to inform sustainable design explorations. Based on the above understanding, five perspectives are extracted and applied here for the comparison (as shown in Table 20):

- With regard to empirical analysis: 1). unit of analysis, 2). analytical approach, and 3). users' roles.

- With regard to design exploration: 4). primary goals of design intervention, 5). Primary levels of design intervention 
First, in terms of empirical analysis, both the AT-based lens and Behaviorbased lens focus on understanding the role that artefacts can play in influencing people's doings. The Behavior-based lens explicitly focuses on analyzing the interaction between users and artefacts and the corresponding sustainable or unsustainable behavior generated as the result of the interaction (Kuijer, 2014; Tromp, 2013). The analysis is often conducted by first deconstructing a system into different elements (e.g., user behavior and attributes of designed artefact) and then making inferences about the relations between specific user behavior and specific attributes of the designed artefact (Jackson et al., 2005).

In contrast to the Behavior-based lens, AT aims to understand the interaction between users and artefacts in a broader context: people's activity systems. According to Kaptelinin \& Nardi (2006), AT suggests that "the attributes of individual components are of little consequence when the components are integrated within a higher-level unit" ( $p$ 40). In other words, it implies that the socioecological impacts of an artefact on people's doings should not be oversimplified to a sum of users' behavior. Rather, the activity system, that is, the purposeful needbased artefact-mediated interaction of users (subjects) with the world (objects), should be taken as the fundamental unit of analysis. Consequently, although users' interaction with specific artefact inevitably influences the sustainable or unsustainable behavior of individual users, from the perspective of AT, such interaction is not the root cause of sustainability issues. Instead, the way how the subjects use different artefacts as mediating tools to fulfill certain objects/goals is what lies behind the sustainability issues. Therefore, compared with the Behaviorbased lens, the AT-based lens treats sustainability as a system property embedded in the complex sociocultural context rather than an individual element added onto the designed artefact. Taking activity as the basic unit of analysis thus might enable designers to expand the analysis scope from users' behavior to meaningful motiveoriented activities.

Therefore, compared with the Behavior-based lens, the spatial (sociocultural contexts) and temporal (development) perspectives are the strengths that the ATbased lens brings. Whereas the limitation of the AT-based lens is that it does not deconstruct doings into different behavior determinants. Instead, it interprets doings from different theoretical principles. As a consequence, it may not be applicable when it comes to predicting the likelihood of a certain behavior or providing models for identifying relevant factors that affect a certain behavior. 
While the AT-based lens can be distinguished from the Behavior-based lens, it is relatively hard to distinguish the concept behind the AT-based lens from the SPTbased lens. The SPT-based lens takes practices as the unity of analysis. It focuses on investigating how people perform their routinized practices and why they perform them (Reckwitz, 2002; Shove, Pantzar, \& Watson, 2012; Warde, 2005). Daily doings such as shopping, cooking, commuting can be regarded as practices. At the same time, they can also be called activities. Both lenses emphasize the importance of understanding the context of people's everyday life doings, and they acknowledge that people's daily doings can undergo constant change triggered by the dynamics of social contexts (Scott, Bakker, \& Quist, 2012). Therefore, they argue that a systemic analytical approach is needed to understand how contextual factors can influence people's doings. Moreover, both lenses argue that people's daily doings (either activities or practices) cannot be studied in isolation from each other as they are often interwoven in complex networks. Furthermore, the concept of artefacts is highlighted in the theoretical models of both lenses. In SPT, artefact is referred to as "Stuff", while in PT, artefact is often referred to as meditating tools.

Although distinguishing AT and SPT from a broader Design for Sustainable Everyday Life perspective might be difficult, efforts can still be made by focusing on the particular set-up of this dissertation. As the dissertation is focused on understanding how people transit their doings when people undergo context change disruptions, AT's emphasis on the hierarchical structure of the human activity system is one of the strengths compared with the SPT-based lens. It allows designers to break down and categorize activities into the ones that are unconsciously performed by the users (operation layer) and the ones that are consciously intended by the users (action layer). Furthermore, as AT acknowledges the dynamic transition between the operation layer and the action layer, it can also be used to identify design opportunities that may be neglected in a SPT-based lens.

Second, in terms of design exploration. Design interventions introduced from a Behavior-based lens aim to either promote specific desired user behavior or change undesired and unsustainable behavior (Niedderer et al., 2014). The functioning level of design intervention is targeted at the product innovation level. The SPT-based lens takes a more synthetic approach and aims to influence the practices that people perform towards a less resource intensive direction. Compared with the Behaviorbased lens, the design interventions introduced from the SPT-based lens tend to be more disruptive as they often aim at redesigning and reconfiguring people's current practices. For example, reconfiguring the mobility practices (Hasselqvist \& 
Hesselgren, 2019) and bathing practices (Kuijer, Jong, \& Eijk, 2013). The functioning level of design intervention thus can be categorized into a socio-technical system innovation level, where a 'cluster of aligned elements, including artefacts, technology, knowledge, user practices and markets, regulation, cultural meaning, infrastructure, maintenance networks and supply networks, together fulfill a specific societal function' (Geels, 2005).

From an AT-based lens, how the subjects (users) use different artefacts as mediating tools to fulfill certain objects/goals is what lies behind the sustainability issues. To put it plainly, if an artefact, designed with the intention to promote users' sustainable behavior, does not fit into the context of the user's activity systems, it would only lead to limited desired sustainability effects. On the contrary, if an artefact, designed without any particular considerations related to promoting sustainable behavior, is used in an activity system that is already sustainably constructed, the potential negative impacts brought by the artefact are likely to be minimal. However, taking activity as the basic unit of analysis does not mean that individual users should be de-centralized in the design process. As Don Norman noted, "a deep understanding of people is still a part of activity-centered design. But activity-centered design is more: It also requires a deep understanding of the technology, of the tools, and of the reasons for the activities" (Norman, 2005 p: 16). In other words, the AT-based lens suggests that users are more than individuals who use the designed artefacts, they are participants in activities, each with their own socially constructed activity systems which evolves over time (Williams, 2009). Therefore, the AT-based lens can be positioned at the intermediate level between sustainable product innovation and sustainable socio-technical system innovation level. 


\begin{tabular}{|c|c|c|c|}
\hline & AT-based lens & Behavior-based lens & SPT-based lens \\
\hline Unit of analysis & $\begin{array}{l}\text { Purposeful need-based interaction of users } \\
\text { (subjects) with the world (objects) } \\
\text { mediated by artefacts }\end{array}$ & Interaction between users and artefacts & Rountinzed practices \\
\hline $\begin{array}{l}\text { Analytical } \\
\text { Approach }\end{array}$ & $\begin{array}{l}\text { Understand why and how sustainability } \\
\text { problems take place in complex activity } \\
\text { systems }\end{array}$ & $\begin{array}{l}\text { Deconstruct a system into different } \\
\text { elements and make inferences between } \\
\text { the elements }\end{array}$ & $\begin{array}{l}\text { How people perform rountinzed practices and hwy } \\
\text { they perform them }\end{array}$ \\
\hline Users' roles & Participants in activities & Users of artefacts & Carriers of practices \\
\hline $\begin{array}{l}\text { Aim of sustainable } \\
\text { design interventions }\end{array}$ & Mediating subject-object relationships & Influence user behavior & Disruptive resource reconfigureation of a practice \\
\hline $\begin{array}{l}\text { Levels of } \\
\text { interventions }\end{array}$ & Product-service system innovation level & Product-innovation level & Socio-Technical System innovation level \\
\hline
\end{tabular}

\subsection{Reflections about the research approach and the knowledge generation process}

7.3.1 Reflections about the research approach and limitations

Multiple choices of research methodology exist when it comes to developing frameworks and toolkits for supporting sustainable design practices. As described in Section 3.2, DRM is chosen as the guiding methodology in this study. If another methodological approach were chosen, the research process would have differed from what it looks like now. Discussions around which methodology is best suited for similar studies are out of the scope of the thesis. However, reflecting on the use of DRM in the context of this study, it brings three strengths to the development of the AT-based framework and AT-informed toolkit:

- First, DRM divides design research into two interrelated objectives: the formulation of frameworks/models to understand a phenomenon of design interests and the development of tools to support design practices. The Understand and Support component of the DRM matches the overarching aim of this study, which is about understanding phenomena concerning how people transit their everyday life doings when they undergo context change disruptions. Based on the generated knowledge, developing design support for retaining people's existing sustainable doings.

- Second, DRM provides systematic guidance on transforming theoretical knowledge into concrete design practices by dividing the research into descriptive studies and prescriptive studies. The descriptive study focuses on developing understanding, while the prescriptive study focuses on developing support. This feature also aligns with the understand and support goal of the study. 
- Third, DRM illustrates a clear relation between the descriptive study and the prescriptive study; it also emphasizes the importance of iteration both within and between different research stages. This methodological feature was applied in this study to guide the development and validation process of the proposed framework and toolkit. Multiple descriptive and prescriptive studies were performed and iterated.

However, the strengths of DRM co-exist with its limitations. Given that DRM is heuristic rather than algorithmic in its methodological nature, DRM could have been applied with more flexibilities in this study. Relatively more focuses can be put on Stage 4 - Descriptive Study II, which evaluates the effects of AT-informed toolkit prototype in real design practices. However, due to the time and scope constraints of the PhD study, only one iteration has been conducted in Stage 4. Further iteration, evaluation and validation of the AT-informed toolkit would be carried out as future work.

Moreover, given the methodological discussion presented above, the study did not evaluate any design interventions for retaining people's existing sustainable behavior. This is mainly due to the explorative nature of this study. As the study aims to 1). develop a theoretical framework to help designers better understand how people transit behavior when they undergo context change disruptions, and 2). explore what design implications can be informed by focusing on the design for sustainable behavior retention aspect of the transition process. Based on this study set-up, the study focuses on the design analytical level rather than the practical design implementation level. As a consequence, the study leans towards conducting conceptual exploration and generating theoretical understanding of a phenomenon rather than developing and evaluating a particular design solution to address a specific problem.

\subsubsection{Reflections about research credibility and transferability}

According to Creswell (2003), credibility refers to the internal validity, that is, to what extent is the result trustworthy based on the particular research set-up and methods applied. Transferability refers to the external validity, that is, to what extent is the finding generalizable to other research contexts. In this study, both credibility and transferability are examined along the way as the study proceeds. Table 21 summarizes the potential risks of bias concerning credibly and transferability and how they were mitigated by the measures taken in this study. 
Table 17. The potential risks of bias concerning credibility and transferability and the measures undertaken to avoid the identified risks.

\begin{tabular}{lll}
\hline Criteria & \multicolumn{1}{c}{ Potential risks of bias } & \multicolumn{1}{c}{ Measures taken to avoid the bias } \\
\hline \multirow{3}{*}{$\begin{array}{l}\text { Credibility } \\
\text { Data were collected and analyzed } \\
\text { only with the intention to support } \\
\text { the preconception that the } \\
\text { framework is valid and useful. }\end{array}$} & $\begin{array}{l}\text { - Abductive analytical approach. } \\
\text { - Data triangulation. }\end{array}$ \\
\hline & $\begin{array}{l}\text { Limited generalizability of the AT- } \\
\text { based theoretical framework }\end{array}$ & $\begin{array}{l}\text { - Use multiple methods and resources to } \\
\text { uncover evidence and build connections } \\
\text { between insights generated in each research } \\
\end{array}$ \\
\hline
\end{tabular}

In terms of research credibility, although the AT-based framework developed in this study has gone through three rounds of iterations and one round of validation, these iterations and validation are all based on the research projects that I am involved in. In most of the case studies, I play two major roles. On the one hand, I am the one who conceives the project and collects and analyzes data, and on the other hand, I also test and evaluate the framework based on the collected data. This mix of roles may bring a potential risk that data collection and analysis of each case study were subjective to the evaluation and validation purpose that I set for the framework. In other words, only the data that support the preconception that the framework is valid and useful were collected and analyzed. Data that did not match this preconception could run into the risk that they were somehow ignored.

To avoid this potential risk, I applied an abductive analytical approach in all the descriptive studies included in this dissertation. The collected data were first analyzed deductively from a bottom-up direction, allowing themes to emerge and consolidate. Following that, an AT-theoretical lens was used deductively to analyze the identified themes from a top-down direction, deconstructing and reconstructing the empirical data according to AT-based theoretical framework and principles. Furthermore, data triangulation was employed to avoid bias in the data collection process. For example, in Study C-I (see Paper III), a systematic literature review, cocreation workshops, and individual interviews were carried out to collect relevant data. Similarly, in Study A-II (see Paper I), diary probes and in-practice studies were used to gain an in-depth view of participants' food consumption doings.

In terms of research transferability, as the AT-based framework is developed based on the studies presented in this dissertation, one could argue that the 
generalizability of the framework is limited to the pre-defined scope of this $\mathrm{PhD}$ research. However, in qualitative research, findings are often context-independent. The case studies included in the dissertation, no matter if it has an explorative or descriptive nature, or directly conducted by me or facilitated by me, all share two commonalities. First, they all focus on the area of people's daily food consumption. Second, they are all explicitly targeted at understanding how people transit their doings when they undergo context change disruptions. Consequently, the overall context of the research is consistent, which allows the research findings (e.g., the proposed AT-based framework) to be applied to other similar research contexts.

Moreover, to avoid the potential bias regarding the research transferability, multiple methods and resources were used to gather insights and build connections between insights generated in each research stage. I reported the results from the multiple case studies conducted within the scope of this $\mathrm{PhD}$ study, and integrated the results and reflections with the findings from the narrative literature review, the systematic literature review, and the meta-synthesis of existing relevant studies. However, one weakness of the study remains unsolved, that is, the AT-based framework and the AT-informed toolkit are, to a large extent, built upon my understandings, explorations and reflections as an independent researcher. A perfect case-scenario would be to evaluate the applicability and the usefulness of the framework and toolkit in studies other than those in which I am involved. For example, let other design researchers who work with sustainable behavior design topics to apply the AT-based framework in their projects with their data, and then get their first-hand feedback about the effects of the AT-based framework. However, the limited time, scope and resources of this PhD study did not allow this to happen.

7.3.3 Reflections about the methods used in relation to an activity theoretical lens

AT does not prescribe to a particular research method. It allows methods to be chosen depending on the specific research focuses and questions (Kaptelinin \& Nardi, 2006). As this study focuses on developing understandings of how people transit their doings when they undergo context change disruptions, it requires researchers to go into the field, gain direct interaction with participants, and coconstruct knowledge with the participants. Therefore, a set of empirical data collection methods, including diary probes, in-practice studies and co-creations, were employed in the study. Although the use of these methods has already been widely discussed in the existing design research studies, how they can be used under the guidance of an activity theoretical perspective and what knowledge can be generated to help design researchers understand people's activity system has not 
been thoroughly discussed. Therefore, in this section, I aim to provide some reflections about the strengths and limitations of the data collection methods mentioned above in relation to an activity theoretical lens (see Table 22).

Table 22. Reflections about the strengths and limitations of the data collection methods used in relation to an activity theoretical lens.

\begin{tabular}{|c|c|c|c|}
\hline $\begin{array}{c}\text { Data } \\
\text { collection } \\
\text { methods }\end{array}$ & $\begin{array}{l}\text { Activity layer } \\
\text { "Why people do } \\
\text { what they do" }\end{array}$ & $\begin{array}{l}\text { Action layer } \\
\text { "What people } \\
\text { actually do" }\end{array}$ & $\begin{array}{l}\text { Operation layer } \\
\text { "How people do } \\
\text { what they do" }\end{array}$ \\
\hline Diary probes & $\begin{array}{l}\text { Lack of direct } \\
\text { communication and } \\
\text { interaction between } \\
\text { researchers and } \\
\text { participants. }\end{array}$ & $\begin{array}{l}\text { Data can be collected over a } \\
\text { mid/long-term time span } \\
\text { without researchers' physical } \\
\text { presence. }\end{array}$ & $\begin{array}{l}\text { Lack of direct observations. } \\
\text { Need to encourage } \\
\text { participants to document } \\
\text { and reflect on their doings } \\
\text { and experiences in detail. }\end{array}$ \\
\hline $\begin{array}{l}\text { In-practices } \\
\text { studies }\end{array}$ & $\begin{array}{l}\text { Encounters in everyday life } \\
\text { contextual settings. }\end{array}$ & $\begin{array}{l}\text { Participants may perform } \\
\text { their actions differently when } \\
\text { encountering researchers. }\end{array}$ & $\begin{array}{l}\text { In-filed interviews and } \\
\text { observations can help to gain } \\
\text { a detailed view. }\end{array}$ \\
\hline Co-creations & $\begin{array}{l}\text { Establish direct } \\
\text { communication and } \\
\text { interaction settings } \\
\text { between researchers and } \\
\text { participants. }\end{array}$ & $\begin{array}{l}\text { Participants may report what } \\
\text { they would do rather than } \\
\text { what they actually have done. }\end{array}$ & $\begin{array}{l}\text { Insufficient to collect data in } \\
\text { real contextual settings. }\end{array}$ \\
\hline
\end{tabular}

According to the hierarchical structure of the activity system, the activity layer refers to why people do what they do, the action layer refers to what people actually do, while the operation layer refers to how people do what they do. Reflections from the study demonstrated that the diary probes method is useful for collecting data in the action layer. In other words, what the goals are and how people use specific artefacts to fulfill these goals. Another potential strength of the diary probes is that it allows a mid or even long-term research encounter with participants. For example, in Study D, diary probes were used to collect data related to participants' food consumption doings during and after the lock-down. By comparing the data from the two sets of the diaries, differences between what people actually do in their food consumption during lock-down and post-lockdown can be identified. However, as there is no direct interaction between researchers and participants in the data collection process, the data collected from the diary probes can sometimes become over tacit. As a consequence, the rationales behind why people do what they do in 
the activity layer and the detailed operations of how people do what they do may be hard to grasp only by using diary probes.

On the contrary, the in-practices studies method requires researchers to visit and directly interact with participants in their everyday contextual settings. Compared with diary studies, which is specialized in helping researchers gain an overview of what participants have done in the action layer, the in-practice studies can enable researchers to obtain an in-depth understanding of why and how participants perform a specific doing in a specific context in the activity layer and the operation layer. Therefore, when used in combination in the specific context of this study to understand people's behavior transition when they undergo context change disruptions, the limitation of the diary probes can be complemented by inpractices studies.

The co-creation method used in the study is in the form of collaborative design workshops. Reflections from the use of co-creation show that direct communication and interaction with participants in workshop settings allow researchers to gain understandings of the activity layer. However, when it comes to asking participants questions such as what you usually did or how you usually coped with a particular situation, participants often need to recall what they have done in their food consumption activities. The reason is that the co-creation sessions are not conducted at the moment when and in the real contextual settings where participants carry out their activities. Therefore, it might lead to a particular data collection concern that participants may report what they would do rather than what they actually have done. 


\section{8 \\ Conclusion}

This chapter presents answers to each research question and the potential contributions of the dissertation.

\subsection{Fulfilling research aims and objectives}

Based on findings from existing studies, context change disruptions (in the form of individual life-course events and socio-economical transitions) can bring a window of opportunity where people might become more likely to reconsider and unfreeze their habitual doings. Looking at this phenomenon from the theoretical stance of Design for Sustainable Everyday Life, in order to better utilize this window of opportunity to transit people's behavior in a more sustainable direction, retaining people's existing desired and sustainable doings may be as same crucial as changing the undesired and unsustainable ones. However, compared with design for behavior change, the opportunities and implications that design can bring in retaining individuals' existing sustainable doings through context change disruptions have been relatively seldom explored.

Therefore, I began this PhD study by asking whether there are any needs for design to take the responsibility to retain people's existing desired and sustainable doings when they are undergoing context change transitions? Correspondingly, the dissertation also departures from this initial research inquiry on design for sustainable behavior retention and moves on to explore an AT-based theoretical approach to generate a more systemic understanding of design's role in facilitating transitions to sustainable everyday life.

In order to better structure the research process, following a Design Research Methodology (DRM) approach, this PhD study is divided into two parts. The objective of the first part of the research focuses on the development of a theoretical 
framework to systematically describe and analyze the influences that context change disruptions have on people's existing daily doings. To fulfill this objective, six smallscale explorative case studies: Study A-I (see Paper II), Study A-II (see Paper I), Study B-I (see Section 5.3.2), Study B-II (see Section 5.3.3), Study C-I (see Paper III) and Study D (see Section 5.5.1), were conducted to investigate the applicability of adopting AT as the theoretical lens for understanding the context change-induced behavior transition phenomenon. As a result, an AT-based theoretical framework was developed, iterated and validated. The objective of the second part of the research focuses on the development of an ideation toolkit prototype for design practitioners to take into account the design for sustainable behavior retention perspective in people's dynamic and complex activity systems. To fulfill this objective, the toolkit prototype is developed by incorporating the proposed ATtheoretical framework with the insights generated from a meta-synthesis study.

\subsection{Answering the research questions}

As presented in Section 1.6, the nature of each research question proposed in this PhD study disrupted across three levels of inquiry: RQ 1 is oriented towards the exploration at a conceptual level, RQ 2 fits into the design analytical level, while RQ 3.1 and 3.2 focus on the design synthesis level. Given the variety of the nature of the research questions, they are addressed with different approaches and with different emphases.

$R Q 1$ : What is the status of current knowledge of sustainable behavior retention in the existing body of literature in the field of design for sustainable everyday life?

In order to develop an overview of to what extent is the topic of design for sustainable behavior retention explored in the current body of research on DfSB, a narrative literature review was conducted. The results showed that, compared with design for behavior change, the behavior retention perspective remains barely covered in the existing body of DfSB studies. Furthermore, the review results also indicated that, when used in DfSB, a behavior retention perspective is often associated with maintaining the positive effects of behavior change over the longterm. However, the specific topic of how to retain people's existing desired and sustainable doings when they undergo context change disruptions has not been explored in DfSB studies both from theoretical and practical aspects. 
$R Q$ 2: From the perspective of design for sustainable everyday life, how to systematically describe and analyze behavior transition induced by context change disruptions?

Following the spatio-temporal lens that Design for Sustainable Everyday Life provides, activity theory (AT) is chosen in this PhD study as the theoretical lens to systematically frame how people transit their everyday life activities when they undergo context change disruptions. Specifically, three theoretical dimensions of AT: 1). the hierarchical structure of an activity system, 2). long-term development and evolution perspective of an activity system, and 3). reality-based contextual scales of analysis were used to formulate an AT-based theoretical framework (see Figure 34). Furthermore, a five-step analytical guide is developed to support the use of the AT-based theoretical framework:

- Step 1: Identify the three key components which constitute the activity system: subjects (users), objects (motivations and goals) and mediating artefacts (tools).

- $\quad$ Step 2: Break down the activity system into three hierarchical layers: activity layer, action layer and operation layer.

- $\quad$ Step 3: Distribute the activity system and its related effects across different contextual levels of analysis: independent activity level, neighboring or supporting activities, and implications at the societal level.

- $\quad$ Step 4: Illustrate how the target activity system develops over time: the preexisting activity, existing activity under the influence of context change disruptions, and anticipated forms of activity shaped by design interventions.

- $\quad$ Step 5: Identify tensions and contradictions that take place within the different hierarchical structure and contextual levels of analysis, along with how the tensions and contradictions are resolved and how they may lead the future evolution of the activity system towards a more sustainable direction. 


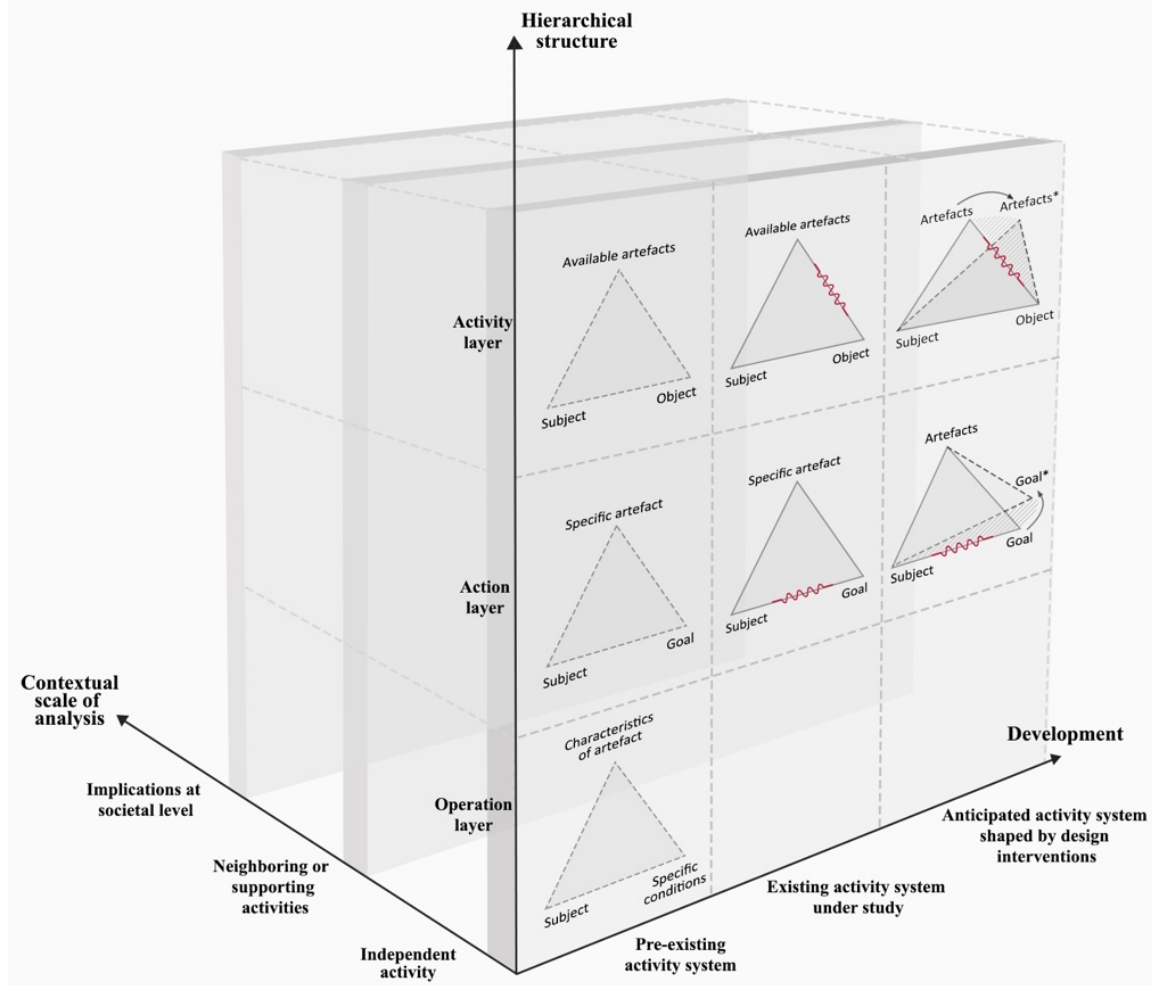

Figure 34.The AT-based theoretical framework developed to systematically describe and analyze behavior transition induced by context change disruptions.

$R Q$ 3.1: How might the proposed AT theoretical lens be incorporated into a toolkit to highlight the behavior retention perspective in sustainable design explorations?

Based on the results of the case studies included in this dissertation, a theoretical framework based on Activity theory (AT) is developed, iterated and validated. By incorporating the proposed framework with theoretical understanding generated from a prescriptive meta-synthesis study, an AT-informed toolkit prototype was developed and evaluated. The toolkit focuses on informing early-stage design ideas for design practitioners to take into account the design for sustainable behavior retention perspective in people's dynamic and complex activity systems. 
$R Q$ 3.2: Building upon the AT theoretical lens, what design implications can a sustainable behavior retention perspective bring to the field of design for sustainable everyday life?

To highlight the implications that a design for sustainable behavior retention can inform to the field of design for sustainable everyday life, the concept of the retention perspectives is compared with the concept of the design for sustainable behavior change. Insights generated from the comparison indicated three design implications.

- First, in terms of sustainable behavior transition, the outcome resulting from the behavior retention perspective may not always necessarily be in contradiction with the outcome of behavior change. Instead, design for sustainable behavior retention may complement design for behavior change by providing a bottom-up and context-focused relative approach to achieve sustainability.

- $\quad$ Secondly, within the scope of Design for Sustainable Everyday Life, creating behavior change is not the only path to achieve sustainable behavior transition. Retaining people's existing sustainable behavior can also open up windows of opportunity to embed sustainable design interventions in people's daily doings.

- Thirdly, by taking activity as the unit of analysis, the effects of change and the effects of retention should not be viewed as two sides of a paper, each covers the existence of the other. Instead, they are compatible entities that can mutually affect the transition of existing doings and the formation of new doings when people undergo context change disruptions. Therefore, from a research perspective, solely focusing on triggering behavior change may let design researchers and practitioners neglect the potential effects of retention, which is of equal importance when it comes to fostering a transition towards a sustainable lifestyle.

Consequently, the dissertation concludes with a call for design researchers in the field of Design for Sustainable Everyday Life to investigate the role that design can play in retaining people's existing sustainable doings, to explore what would happen on the other side of change. 


\subsection{Contributions}

\subsubsection{Theoretical contributions}

1). The AT-based theoretical framework and AT-informed toolkit

Looking at the study from a theoretical perspective, AT has been widely applied as a theoretical lens to investigate complex environmental and social sustainability problems in various studies both within and outside the design discipline. However, the rich theoretical concepts of AT are still waiting to be translated into the language that design researchers and practitioners can easily understand. The AT theoretical lens adopted in this study contributes to filling this knowledge gap by providing a framework to enable design practitioners and researchers to identify which target activity should be the focus of change and which should be retained and developed further.

Furthermore, when it comes to supporting the DfSB practices, different design guidelines have been proposed to help design researchers better identify and cope with sustainable behavior design challenges. For example, (see, e.g., Bhamra, Lilley, \& Tang, 2011; J. Daae, Chamberlin, \& Boks, 2018; Tromp, Hekkert, \& Verbeek, 2011) and Design with Intent Method developed by Lockton, Harrison, \& Stanton (2010), Behavior Change Design Sprints developed by Colusso, Do, \& Hsieh (2018) Dimensions of behavior change developed by Daae \& Boks (2014), Change Points developed by Hoolohan \& Browne (2020). However, these toolkits are, to a large extent, developed to provide designers with strategies and techniques to trigger behavior changes, more precisely, to change people's undesired and unsustainable behavior through design. There lacks the exploration on the opportunities and implications that design can play in retaining people's existing desired and sustainable doings. As the AT-informed design toolkit is developed with an explicit aim to highlight the importance of a sustainable behavior retention aspect in the design ideation process, it can provide a basis for and raise awareness of a more systemic picture that takes both sustainable behavior change and retention perspectives into early-stage design ideation.

\subsubsection{Potential societal values}

Looking at Design for Sustainable Everyday Life from a broader socioeconomic perspective, we may find that the nature of sustainability challenges that design deals with in developed and developing regions seems to be different. In developed countries, given the fact that most people live an unsustainable 
lifestyle. Therefore, the challenge lies in how to change the existing unsustainable lifestyle towards a sustainable direction and how to foster a long-lasting effect brought by the change.

Whereas people in developing countries and emerging economics may have been performing socio-ecologically desired doings over the years. As a result, most people there have already developed habitual doings, along with necessary knowledge and past experience that meet the standard and concept of sustainable lifestyles. However, as people there have been undergoing a significant socioeconomic transition towards growing prosperities, it may also bring a potential risk for unsustainable doings to take place, resulting in undesired behavior changes in every aspect of individuals' life, such as from public transportation to overreliance on private automobiles, from food conservation to waste (Jackson et al., 2005). Facing these context change disruptions caused by socio-economic and individual life-course event transitions, the challenges faced by Design for Sustainable Everyday Life is how to better retain people's existing desired and sustainable lifestyle. Consequently, exploring the design for sustainable behavior retention perspective may potentially support people in pursuing higher standard of living comforts without the need to walk into the Western-liked consumerism lifestyles.

\subsection{Opportunities outlook}

This dissertation is written in the course of the Covid-19 pandemic. Facing the unprecedented impacts of the pandemic on people's everyday lives, I kept asking myself: could the knowledge generated from this research concerning how people transform their doings when undergoing context change disruptions be used to cope with the future sustainability-oriented societal changes.

Comparing the global sustainability issues with the ongoing Covid-19 pandemic, at first glance, they might seem to be two completely different crises with different causes and impacts. For example, the real impacts of sustainability issues such as climate change are often manifested through the collateral damages brought by a chain of events. By contrast, the Covid-19 pandemic brought sudden changes to society, causing disruptions to individual life-course. However, they share some similarities in terms of the effects on people's everyday life. Both crises can, to some extent, disrupt people's existing everyday life rhythms. Consequently, people have to dynamically adapt and continuously adjust their everyday doings to keep up with the changes brought by the crisis. 
The crisis thus constitutes a moment of change where people become more likely to rethink their pre-existing doings. From a Design for Sustainable Everyday Life perspective, it naturally opens up a unique window of opportunity for design to transform some of people's existing unsustainable behavioral patterns. Therefore, in the future, the AT-based framework may be potentially applied to provide an analytical tool for design researchers and practitioners to understand how societal changes may influence the way people carry out their everyday activities, and to identify potential opportunities for design to intervene and transform the targeted activity towards a more sustainable direction. 


\section{9}

\section{References}

Adams, R., Jeanrenaud, S., Bessant, J., Denyer, D., \& Overy, P. (2016). Sustainabilityoriented Innovation: A Systematic Review. International Journal of Management Reviews, 18(2), 180-205. https://doi.org/10.1111/ijmr.12068

Aguayo, C. (2016). Activity Theory and Online Community Education for Sustainability. In Activity Theory in Education (pp. 139-151). https://doi.org/10.1007/978-94-6300-387-2_9

Aguayo, C., \& Eames, C. (2017). Promoting community socio-ecological sustainability through technology: A case study from Chile. International Review of Education, 63(6), 871-895. https://doi.org/10.1007/s11159-017-9685-7

Aldaco, R., Hoehn, D., Laso, J., Margallo, M., Ruiz-Salmón, J., Cristobal, J., ... Vazquez-Rowe, I. (2020). Food waste management during the COVID-19 outbreak: a holistic climate, economic and nutritional approach. Science of The Total Environment, 742, 140524. https://doi.org/10.1016/j.scitotenv.2020.140524

Allen, M. (2017). Narrative Literature Review. In The SAGE Encyclopedia of Communication Research Methods. https://doi.org/10.4135/9781483381411.n370

Bai, G., \& Guo, Y. (2011). A general architecture for developing a sustainable elderly care e-health system. 8th International Conference on Service Systems and Service Management Proceedings

of ICSSSM'11. https://doi.org/10.1109/ICSSSM.2011.5959443

Baker, J. D. (2016). The Purpose, Process, and Methods of Writing a Literature Review. AORN Journal, 103(3), 265-269. 
https://doi.org/10.1016/j.aorn.2016.01.016

Bender, K., Shu, Y., Badiger, A., Heldman, D. R., Qi, D., \& Roe, B. E. (2020). The State of the American Refrigerator. https://doi.org/10.1016/j.resconrec.2019.104440

Bhamra, T., Lilley, D., \& Tang, T. (2011). Design for Sustainable Behaviour: Using Products to Change Consumer Behaviour. The Design Journal, 14(4), 427-445. https://doi.org/10.2752/175630611X13091688930453

Blackler, F., Crump, N., \& McDonald, S. (1999). Managing experts and competing through innovation: An activity theoretical analysis. Organization. https://doi.org/10.1177/135050849961001

Blessing, L. T. M., \& Chakrabarti, A. (2009). DRM, a design research methodology. In DRM, a Design Research Methodology. https://doi.org/10.1007/978-1-84882$587-1$

Bødker, S., \& Andersen, P. B. (2005). Complex mediation. Human-Computer Interaction. https://doi.org/10.1207/s15327051hci2004_1

Bødker, S., \& Klokmose, C. N. (2011). The Human-Artifact Model: An Activity Theoretical Approach to Artifact Ecologies. Human-Computer Interaction, 26(4), 315-371. https://doi.org/10.1080/07370024.2011.626709

Boer, N.-I., van Baalen, P. J., \& Kumar, K. (2002). An activity theory approach for studying the situatedness of knowledge sharing. Proceedings of the 35th Annual Hawaii International Conference on System Sciences, 1483-1492. https://doi.org/10.1109/HICSS.2002.994017

Boon, B., Wever, R., \& Quist, J. (2015). Beyond behaviour change: technological artefacts and characterological development. International Journal of Sustainable Engineering, 8(3), 231-247. https://doi.org/10.1080/19397038.2014.990999

Brynjarsdottir, H., Håkansson, M., Pierce, J., Baumer, E., DiSalvo, C., \& Sengers, P. (2012). Sustainably unpersuaded. Proceedings of the 2012 ACM Annual Conference on Human Factors in Computing Systems - CHI '12, 947. https://doi.org/10.1145/2207676.2208539

Ceschin, F., \& Gaziulusoy, I. (2016). Evolution of design for sustainability: From product design to design for system innovations and transitions. Design 
Studies, 47, 118-163. https://doi.org/10.1016/j.destud.2016.09.002

Chen, R., Coles, J., Lee, J., \& Rao, H. R. (2009). Emergency communication and system design: The case of Indian ocean tsunami. 2009 International Conference on Information and Communication Technologies and Development, ICTD 2009 Proceedings. https://doi.org/10.1109/ICTD.2009.5426699

Chu, W., Williams, H., Verghese, K., Wever, R., \& Glad, W. (2020). Tensions and opportunities: An activity theory perspective on date and storage label design through a literature review and co-creation sessions. Sustainability (Switzerland). https://doi.org/10.3390/su12031162

Colusso, L., Do, T., \& Hsieh, G. (2018). Behavior change design sprints. DIS 2018 Proceedings of the 2018 Designing Interactive Systems Conference. https://doi.org/10.1145/3196709.3196739

Coskun, A., Zimmerman, J., \& Erbug, C. (2015). Promoting sustainability through behavior change: A review. Design Studies, 41, 183-204. https://doi.org/10.1016/j.destud.2015.08.008

Creswell, J. W. (2003). Research design Qualitative quantitative and mixed methods approaches. Research Design Qualitative Quantitative and Mixed Methods Approaches. https://doi.org/10.3109/08941939.2012.723954

Cronin, P., Ryan, F., \& Coughlan, M. (2008). Undertaking a literature review: a stepby-step approach. British Journal of Nursing (Mark Allen Publishing). https://doi.org/10.12968/bjon.2008.17.1.28059

Daae, J. (2014). Informing Design for Sustainable Behaviour. Norwegian University of Science and Technology.

Daae, J., Chamberlin, L., \& Boks, C. (2018). Dimensions of Behaviour Change in the context of Designing for a Circular Economy. Design Journal. https://doi.org/10.1080/14606925.2018.1468003

Daae, J. Z., \& Boks, C. (2014). Dimensions of behaviour change. J. of Design Research, 12(3), 145. https://doi.org/10.1504/JDR.2014.064229

de Koning, Jotte I.J.C., Ta, T. H., Crul, M. R. M., Wever, R., \& Brezet, J. C. (2016). GetGreen Vietnam: towards more sustainable behaviour among the urban 
middle class. Journal of Cleaner Production. https://doi.org/10.1016/j.jclepro.2016.01.063

de Koning, Jotte Ilbine Jozine Charlotte, Crul, M. R. M., Wever, R., \& Brezet, J. C. (2015). Sustainable consumption in Vietnam: An explorative study among the urban middle class. International Journal of Consumer Studies. https://doi.org/10.1111/ijcs.12235

Dou, Z., Stefanovski, D., Galligan, D., Lindem, M., Rozin, P., Chen, T., \& Chao, A. (2020). The COVID-19 Pandemic Impacting Household Food Dynamics: A CrossNational Comparison of China and the U.S. https://doi.org/10.31235/osf.io/64jwy Duignan, M., Noble, J., \& Biddle, R. (2006). Activity theory for design: From checklist to interview. IFIP International Federation for Information Processing. https://doi.org/10.1007/978-0-387-36792-7_1

Engestrom, Y. (1987). Learning by Expanding: An Activity-Theoretical Approach to Developmental Research, Second Edition. Helsinki: Orienta-Konsultit Oy.

Engeström, Y. (1999). Activity theory and individual and social transformation. In Perspectives on Activity Theory (pp. 19-38). https://doi.org/10.1017/CBO9780511812774.003

Faber, N., Jorna, R., \& Van Engelen, J. (2005). The sustainability of "sustainability" A study into the conceptual foundations of the notion of "sustainability." Journal of Environmental Assessment Policy and Management. https://doi.org/10.1142/S1464333205001955

Finfgeld-Connett, D. (2018). A Guide to Qualitative Meta-Synthesis. In A Guide to Qualitative Meta-Synthesis. https://doi.org/10.4324/9781351212793

Finlayson, K. W., \& Dixon, A. (2008). Qualitative meta-synthesis: a guide for the novice. Nurse Researcher, 15(2), 59-71. https://doi.org/10.7748/nr2008.01.15.2.59.c6330

Fleetwood, J. (2020). Social justice, food loss, and the sustainable development goals in the era of COVID-19. Sustainability (Switzerland). https://doi.org/10.3390/su12125027

Garud, R., \& Kumaraswamy, A. (1996). Technological designs for retention and 
reuse. International Journal of Technology Management. https://doi.org/10.1504/IJTM.1996.025476

Gaver, B., Dunne, T., \& Pacenti, E. (1999). Design: Cultural probes. Interactions. https://doi.org/10.1145/291224.291235

Gay, G., \& Hembrooke, H. (2004). Activity-centered design: An ecological approach to designing smart tools and usable systems.

Geels, I. F. W. (2005). The dynamics of transitions in socio-technical systems: A multi-level analysis of the transition pathway from horse-drawn carriages to automobiles (1860-1930). Technology Analysis and Strategic Management. https://doi.org/10.1080/09537320500357319

Guba, E. G., \& Lincoln, Y. S. (1994). Competing paradigms in qualitative research. In Handbook of qualitative research.

Hanington, B., \& Martin, B. (2012). Universal methods of design: 100 ways to research complex problems. In Develop Innovative Ideas.

Hasan, H., \& Ionescu, C. (2017). Co-development of a wiki for tracking the environmental footprint of small business activities. Informing Science. https://doi.org/10.28945/3874

Hasan, H., \& Meloche, J. (2013). Innovative ICT-mediated activities for people, profit and planet. European Journal of Innovation Management. https://doi.org/10.1108/EJIM-08-2011-0063

Hasan, H., Smith, S., \& Finnegan, P. (2017). An activity theoretic analysis of the mediating role of information systems in tackling climate change adaptation. Information Systems Journal. https://doi.org/10.1111/isj.12104

Hasselqvist, H., \& Hesselgren, M. (2019). Bridging citizen and stakeholder perspectives of sustainable mobility through practice-oriented design. Sustainability: Science, Practice, and Policy. https://doi.org/10.1080/15487733.2018.1533781

Hicks, S. (2009). Lectures on Philosophy of Education. Rockford, Illinois: Rockford University.

Hielscher, S., Fisher, T., \& Cooper, T. (2009). The Return of the Beehives, Brylcreem 
and Botanical! An Historical Review of Hair Care Practices with a view to Opportunities for Sustainable Design. Undisciplined! Proceedings of the Design Research Society Conference 2008.

Honold, P. (2000). Culture and context: An empirical study for the development of a framework for the elicitation of cultural influence in product usage. International Journal of Human-Computer Interaction. https://doi.org/10.1207/s15327590ijhc1203\&4_5

Hoolohan, C., \& Browne, A. L. (2020). Design thinking for practice-based intervention: Co-producing the change points toolkit to unlock (un)sustainable practices. Design Studies, 67, 102-132. https://doi.org/10.1016/j.destud.2019.12.002

Jackson, T., Begg, K., Darnton, A., Davey, A., Dobson, A., Ekins, P., ... Uzzell, D. (2005). Motivating Sustainable Consumption . Retrieved from www.surrey.ac.uk/CES

Johnson, R. B., \& Onwuegbuzie, A. J. (2004). Mixed Methods Research: A Research Paradigm Whose Time Has Come. Educational Researcher. https://doi.org/10.3102/0013189X033007014

Joore, P., \& Brezet, H. (2015). A Multilevel Design Model: The mutual relationship between product-service system development and societal change processes. Journal of Cleaner Production. https://doi.org/10.1016/j.jclepro.2014.06.043

Jribi, S., Ben Ismail, H., Doggui, D., \& Debbabi, H. (2020). COVID-19 virus outbreak lockdown: What impacts on household food wastage? Environment, Development and Sustainability, 22(5), 3939-3955. https://doi.org/10.1007/s10668-020-00740-y

Jung, H., Park, M., Hong, K., \& Hyun, E. (2016). The Impact of an epidemic outbreak on consumer expenditures: An empirical assessment for MERS Korea. Sustainability (Switzerland). https://doi.org/10.3390/su8050454

Kaptelinin, V. (2014). Activity Theory. In The encyclopedia of human-computer interaction (2nd Editio). The Interaction Design Foundation.

Kaptelinin, V., \& Nardi, B. (2006). Acting with technology: Activity theory and 
interaction design. MIT press.

Kaptelinin, V., \& Nardi, B. (2012). Activity Theory in HCI: Fundamentals and Reflections. Synthesis Lectures on Human-Centered Informatics. https://doi.org/10.2200/s00413ed1v01y201203hci013

Kaptelinin, V., Nardi, B. A., \& Macaulay, C. (1999). Methods \& tools: The activity checklist: a tool for representing the "space" of context. Interactions. https://doi.org/10.1145/306412.306431

Karanasios, S. (2014). Framing ICT4D Research Using Activity Theory: A Match Between the ICT4D Field and Theory? Information Technologies and International Development.

Karlsson, M. (1996). User Requirements Elicitation-A framework for the study between user and artefact. Chalmers University of Technology.

Khan, S. S., Lodhi, S. A., \& Akhtar, F. (2015). Sustainable WEEE management solution for developing countries applying human activity system modeling. Management of Environmental Quality: An International Journal. https://doi.org/10.1108/MEQ-05-2014-0072

Kitchenham, B. (2004). Procedures for Performing Systematic Literature Reviews. Joint Technical Report, Keele University TR/SE-0401 and NICTA TR-0400011T.1.

Kitchenham, B., \& Brereton, P. (2013). A systematic review of systematic review process research in software engineering. Information and Software Technology, 55(12), 2049-2075. https://doi.org/10.1016/j.infsof.2013.07.010

Kitchenham, B., \& Charters, S. (2007). Guidelines for performing Systematic Literature Reviews in Software Engineering. EBSE Technical Report Nr. EBSE2007-01. In EBSE Technical Report.

Kuijer, L. (2014). Implications of social practice theory for sustainable design. Delft University of Technology.

Kuijer, L., Jong, A. de, \& Eijk, D. van. (2013). Practices as a unit of design. ACM Transactions on Computer-Human Interaction, 20(4), 1-22. https://doi.org/10.1145/2493382

Kuutti, K. (1996). Activity theory as a potential framework for human-computer 
interaction research. Context and Consciousness: Activity Theory and Human- ....

Kuutti, K. (2011). Out of the Shadow of Simon: Artifacts, Practices, and History in Design Research. Proceedings of the Doctoral Education in Design Conference, Hong Kong.

Lally, V., \& Sclater, M. (2012). The inter-life project: Inter-cultural spaces for young people to use creative practices and research to assist with life changes and transition. Research in Comparative and International Education. https://doi.org/10.2304/rcie.2012.7.4.480

Leary, H., \& Walker, A. (2018). Meta-Analysis and Meta-Synthesis Methodologies: Rigorously Piecing Together Research. TechTrends. https://doi.org/10.1007/s11528-018-0312-7

Leont'ev, A. (1974). The Problem of Activity in Psychology. Soviet Psychology, 13(2), 4-33. https://doi.org/10.2753/RPO1061-040513024

Leont'ev, A. N. (1978). Activity, Consciousness, and Personality. Englewood Cliffs: Prentice-Hall.

Li, Y., \& Landay, J. A. (2008). Activity-based prototyping of ubicomp applications for long-lived, everyday human activities. Conference on Human Factors in Computing Systems - Proceedings. https://doi.org/10.1145/1357054.1357259

Lilley, D. (2009). Design for sustainable behaviour: strategies and perceptions. Design Studies, 30(6), 704-720. https://doi.org/10.1016/j.destud.2009.05.001

Lin, F. R., \& Hsieh, P. S. (2014). Analyzing the sustainability of a newly developed service: An activity theory perspective. Technovation. https://doi.org/10.1016/j.technovation.2013.08.004

Lockton, D. (2013). Design with intent: a design pattern toolkit for environmental and social behaviour change. Brunel University.

Lockton, D. (2017). Design, behaviour change and the Design with Intent toolkit. In Design for Behaviour Change: Theories and Practices of Designing for Change. https://doi.org/10.4324/9781315576602

Lockton, D., Harrison, D., \& Stanton, N. (2008). Making the user more efficient: Design for sustainable behaviour. International Journal of Sustainable 
Engineering. https://doi.org/10.1080/19397030802131068

Lockton, D., Harrison, D., \& Stanton, N. A. (2010). The Design with Intent Method: A design tool for influencing user behaviour. Applied Ergonomics, 41(3), 382392. https://doi.org/10.1016/j.apergo.2009.09.001

Machi, L. a., \& McEvoy, B. T. (2012). The Literature Review - Six Steps to Sucess. Corwin.

Mankoff, J. C., Blevis, E., Borning, A., Friedman, B., Fussell, S. R., Hasbrouck, J., ... Sengers, P. (2007). Environmental sustainability and interaction. CHI '07 Extended Abstracts on Human Factors in Computing Systems - CHI '07, 2121. https://doi.org/10.1145/1240866.1240963

Mattelmäki, T. (2005). Applying probes - from inspirational notes to collaborative insights. CoDesign, 1(2), 83-102. https://doi.org/10.1080/15719880500135821

Mitchell, R., Schuster, L., \& Drennan, J. (2017). Understanding how gamification influences behaviour in social marketing. Australasian Marketing Journal. https://doi.org/10.1016/j.ausmj.2016.12.001

Moher, D., Liberati, A., Tetzlaff, J., Altman, D. G., Altman, D., Antes, G., ... Tugwell, P. (2009). Preferred reporting items for systematic reviews and meta-analyses: The PRISMA statement. PLoS Medicine. https://doi.org/10.1371/journal.pmed.1000097

Moher, D., Shamseer, L., Clarke, M., Ghersi, D., Liberati, A., Petticrew, M., ... Whitlock, E. (2016). Preferred reporting items for systematic review and metaanalysis protocols (PRISMA-P) 2015 statement. Revista Espanola de Nutricion Humana y Dietetica. https://doi.org/10.1186/2046-4053-4-1

Mwanza, D. (2001). Where Theory meets Practice: A Case for an Activity Theory based Methodology to guide Computer System Design. Human-Computer Interaction.

Nardi, B. (1996). Context and consciousness: activity theory and human-computer interaction. Retrieved from https://books.google.com/books?hl=en\&lr=\&id=JeqcgP1S2UAC\&oi=fnd\&pg= PR7\&dq=Context+and+consciousness:+activity+theory+and+human- 
computer+interaction\&ots=e-gf-

yu_Es\&sig=ZihubFO8ELVTvEbJDBNkRxnyTBM

Niedderer, K., Cain, R., Clune, S., Lockton, D., Ludden, G., Mackrill, J., \& Morris, A. (2014). Creating sustainable innovation through design for behaviour change: full project report. In Statewide Agricultural Land Use Baseline 2015. https://doi.org/10.1017/CBO9781107415324.004

Niles, M. T., Bertmann, F., Belarmino, E. H., Wentworth, T., Biehl, E., \& Neff, R. (2020). The Early Food Insecurity Impacts of COVID-19. Nutrients, 12(7), 2096. https://doi.org/10.3390/nu12072096

Norman, D. A. (2005). Human-centered design considered harmful. Interactions. https://doi.org/10.1145/1070960.1070976

Paterson, B., Thorne, S., Canam, C., \& Jillings, C. (2001). Meta-study of qualitative health research: A practical guide to meta-analysis and meta-synthesis. SAGE Publications, Inc.

Perold, R., Donaldson, R., \& Devisch, O. (2019). Architecture in Southern African informal settlements: A contextually appropriate intervention. Urbani Izziv, Supplement(30), 96-111. https://doi.org/10.5379/urbani-izziv-en-2019-30supplement-007

Pettersen, I. N. (2013). Changing Practices: The Role of Design in Supporting the Sustainability of Everyday Life. NTNU.

Petticrew, M., \& Roberts, H. (2008). Systematic Reviews in the Social Sciences: A Practical Guide. In Systematic Reviews in the Social Sciences: A Practical Guide. https://doi.org/10.1002/9780470754887

Pink, S. (2017). Making Homes: Ethnography and Design. In Making Homes: Ethnography and Design. https://doi.org/10.5040/9781474239189

Pink, S., \& Mackley, K. L. (2015). Social science, design and everyday life: Refiguring showering through anthropological ethnography. Journal of Design Research. https://doi.org/10.1504/JDR.2015.071454

Piscicelli, L. (2016). Do I share because I care? The role of values in the acceptance, adoption and diffusion of collaborative consumption. Nottingham Trent University. 
Polit, D. F., \& Beck, C. T. (2006). The content validity index: Are you sure you know what's being reported? Critique and recommendations. Research in Nursing and Health. https://doi.org/10.1002/nur.20147

Reckwitz, A. (2002). Toward a Theory of Social Practices. European Journal of Social Theory, 5(2), 243-263. https://doi.org/10.1177/13684310222225432

ReFED. (2020). Food System Review. Retrieved August 30, 2020, from ReFED website: https://covid.refed.com/overview

Renström, S. (2019). Participating in Energy Systems through Everyday DesignsExploring Roles for Households in a More Sustainable Energy Future. Chalmers University of Technology.

Rexfelt, O. (2008). User-centred design and technology-mediated services-identifying and addressing challenges by analysing activities. Chalmers University of Technology.

Roe, B. E., Phinney, D. M., Simons, C. T., Badiger, A. S., Bender, K. E., \& Heldman, D. R. (2018). Discard intentions are lower for milk presented in containers without date labels. Food Quality and Preference, 66, 13-18. https://doi.org/10.1016/j.foodqual.2017.12.016

Sandelowski, M., Docherty, S., \& Emden, C. (1997). Qualitative metasynthesis: Issues and techniques. Research in Nursing $\mathcal{E}$ Health, 20(4), 365-371. https://doi.org/10.1002/(SICI)1098-240X(199708)20:4<365::AIDNUR9>3.3.CO;2-7

Sanders, E. B.-N., \& Stappers, P. J. (2008). Co-creation and the new landscapes of design. CoDesign. https://doi.org/10.1080/15710880701875068

Sclater, M. (2016). Beneath Our Eyes: An Exploration of the Relationship between Technology Enhanced Learning and Socio-Ecological Sustainability in Art and Design Higher Education. International Journal of Art $\mathcal{E}$ Design Education, 35(3), 296-306. https://doi.org/10.1111/jade.12125

Scott, K., Bakker, C., \& Quist, J. (2012). Designing change by living change. Design Studies. https://doi.org/10.1016/j.destud.2011.08.002

Selvefors, A. (2017). Design Beyond Interventions - Supporting Less Energy-reliant Activities in the Everyday. Chalmers University of Technology. 
Selvefors, A., Karlsson, I. C., \& Rahe, U. (2015). Conflicts in everyday life: The influence of competing goals on domestic energy conservation. Sustainability (Switzerland). https://doi.org/10.3390/su7055963

Sharma, H. B., Vanapalli, K. R., Cheela, V. S., Ranjan, V. P., Jaglan, A. K., Dubey, B., ... Bhattacharya, J. (2020). Challenges, opportunities, and innovations for effective solid waste management during and post COVID-19 pandemic. Resources, Conservation and Recycling, 162, 105052. https://doi.org/10.1016/j.resconrec.2020.105052

Shin, H. D., \& Bhamra, T. (2016). Design for sustainable behaviour: A case study of using human-power as an everyday energy source. Journal of Design Research. https://doi.org/10.1504/JDR.2016.079763

Shove, E., Pantzar, M., \& Watson, M. (2012). The Dynamics of Social Practice: Everyday Life and How it Changes. In The Dynamics of Social Practice: Everyday Life and How it Changes. https://doi.org/10.4135/9781446250655

Simon, H. A. (1969). The sciences of the artificial. Cambridge: MA.

Smith, R., \& Turpin, M. (2017). Design science research and activity theory in ICT4D: Developing a socially relevant ICT platform for elderly women in remote rural South Africa. IFIP Advances in Information and Communication Technology. https://doi.org/10.1007/978-3-319-59111-7_29

Ssozi-Mugarura, F., Rivett, U., \& Blake, E. (2016). Using activity theory to understand technology use and perception among rural users in Uganda. ACM International Conference Proceeding Series. https://doi.org/10.1145/2909609.2909650

Stern, P. N., \& Harris, C. C. (1985). Women's health and the self-care paradox. A model to guide self-care readiness. Health Care for Women International. https://doi.org/10.1080/07399338509515689

Stickdorn, M., Hormess, M., Lawrence, A., \& Schneider, J. (Economist). (2017). This is service design doing : applying service design thinking in the real world : a practitioner's handbook. This Is Service Design Doing.

Stuster, J. W. (2000). Bold endeavors: behavioral lessons from polar and space 
exploration. Gravitational and Space Biology Bulletin: Publication of the American Society for Gravitational and Space Biology.

Stuster, J. W. (2010). Behavioral issues associated with long- duration space expeditions: Review and analysis of astronaut journals. In NASA/TM-2010216130.

Stuster, J. W. (2016). Behavioral Issues Associated with Long- Duration Space Expeditions : Review and Analysis of Astronaut Journals Experiment 01-E104 (Journals): Final Report. Nasa/Tm-2016-218603.

Svensson. (2020). Identifying Motives for Implementing eHealth by using Activity Theory. Sustainability, 12(4), 1298. https://doi.org/10.3390/su12041298

Tang, T., \& Bhamra, T. (2012). Putting consumers first in design for sustainable behaviour: a case study of reducing environmental impacts of cold appliance use. International Journal of Sustainable Engineering, 5(4), 288-303. https://doi.org/10.1080/19397038.2012.685900

Thompson, S., Michaelson, J., Abdallah, S., Johnson, V., Morris, D., Riley, K., \& Simms, A. (2011). 'Moments of change' as opportunities for influencing behaviour: A research report completed for the Department for Environment, Food and Rural Affairs. Nef (the New Economics Foundation).

Thorpe, A. (2010). Design's Role in Sustainable Consumption. Design Issues, 26(2), 3-16. https://doi.org/10.1162/DESI_a_00001

Tromp, N. (2013). Social design: How products and services can help us act in ways that benefit society. Delft University of Technology.

Tromp, N., Hekkert, P., \& Verbeek, P.-P. (2011). Design for Socially Responsible Behavior: A Classification of Influence Based on Intended User Experience. Design Issues, 27(3), 3-19. https://doi.org/10.1162/DESI_a_00087

Uden, L. (2007). Activity theory for designing mobile learning. International Journal of Mobile Learning and Organisation. https://doi.org/10.1504/IJMLO.2007.011190 van Dam, S. S., Bakker, C. A., \& van Hal, J. D. M. (2010). Home energy monitors: impact over the medium-term. Building Research \& Information, 38(5), 458-469. https://doi.org/10.1080/09613218.2010.494832 
Verplanken, B., \& Roy, D. (2016). Empowering interventions to promote sustainable lifestyles: Testing the habit discontinuity hypothesis in a field experiment. Journal of Environmental Psychology, 45, 127-134. https://doi.org/10.1016/j.jenvp.2015.11.008

Verplanken, B., Walker, I., Davis, A., \& Jurasek, M. (2008). Context change and travel mode choice: Combining the habit discontinuity and self-activation hypotheses. Journal of Environmental Psychology. https://doi.org/10.1016/j.jenvp.2007.10.005

Verplanken, B., \& Wood, W. (2006). Interventions to Break and Create Consumer Habits. Journal of Public Policy \& Marketing, 25(1), 90-103. https://doi.org/10.1509/jppm.25.1.90

Viktorelius, M., \& Lundh, M. (2019). Energy efficiency at sea: An activity theoretical perspective on operational energy efficiency in maritime transport. Energy Research and Social Science. https://doi.org/10.1016/j.erss.2019.01.021

Vygotsky, L. S. (1978). Mind in Society: The Development of Higher Psychological Processes. In Harvard University Press. https://doi.org/(Original manuscripts [ca. 1930-1934])

Walsh, D., \& Downe, S. (2005). Meta-synthesis method for qualitative research: A literature review. Journal of Advanced Nursing. https://doi.org/10.1111/j.13652648.2005.03380.x

Warde, A. (2005). Consumption and theories of practice. Journal of Consumer Culture. https://doi.org/10.1177/1469540505053090

Wever, R., van Kuijk, J., \& Boks, C. (2008). User-centred design for sustainable behaviour. International Journal of Sustainable Engineering, 1(1), 9-20. https://doi.org/10.1080/19397030802166205

Wever, R., \& Vogtländer, J. (2015). Design for the Value of Sustainability. In Handbook of Ethics, Values, and Technological Design (pp. 513-549). https://doi.org/10.1007/978-94-007-6970-0_20

Williams, A. (2009). User-centered design, activity-centered design, and goal-directed design. https://doi.org/10.1145/1621995.1621997 
Wood, W., Tam, L., \& Witt, M. G. (2005). Changing circumstances, disrupting habits. Journal of Personality and Social Psychology. https://doi.org/10.1037/00223514.88.6.918

WRAP. (2020). The COVID-19 Lockdown - Food Purchasing, Management and Waste. Retrieved from www.wrap.org.uk

Zhang, J., \& Lowry, P. B. (2016). Designing quantified-self 2.0 running platform to ensure physical activity maintenance: The role of achievement goals and achievement motivational affordance. Pacific Asia Conference on Information Systems, PACIS 2016 - Proceedings.

Zhou, M., Mintz, Y., Fukuoka, Y., Goldberg, K., Flowers, E., Kaminsky, P., ... Aswani, A. (2018). Personalizing Mobile Fitness Apps using Reinforcement Learning. CEUR Workshop Proceedings, 2068. Retrieved from http://www.ncbi.nlm.nih.gov/pubmed/32405286

Zimmer, L. (2006). Qualitative meta-synthesis: a question of dialoguing with texts. Journal of Advanced Nursing, 53(3), 311-318. https://doi.org/10.1111/j.13652648.2006.03721.x 


\title{
Appendix 1
}

\section{The AT-informed ideation prototype}

\author{
Motivations, $\quad$ Can you enable users to attain a series of different goals in a row within \\ goals, and \\ outcomes: 1) \\ the target activity?
}

Example: When users are looking for accommodations on Airbnb, the website not only helps users to find places to stay, but also provides sightseeing and restaurants in the surrounding place.

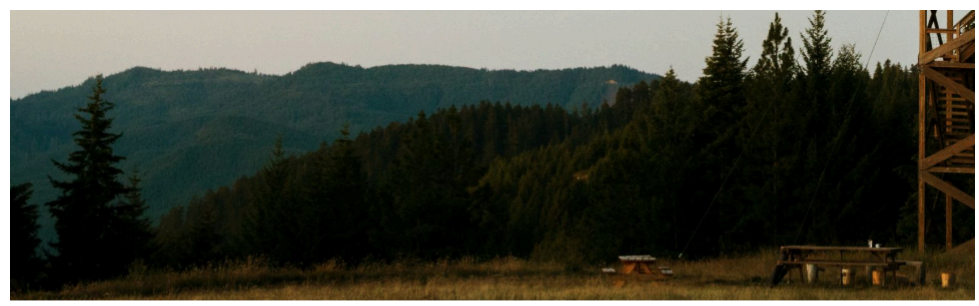

Explore Airbnb

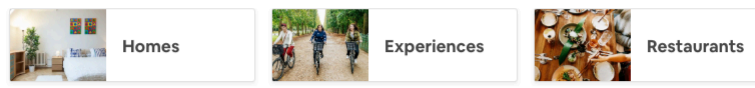


Motivations, goals, and outcomes: 2)
What would happen if your design requires users to put more efforts to attain their original goals, but these efforts can bring users more benefits as a return?

Example: The Stockholm congestion tax is implemented to reduce peak hour traffic congestion. Although drivers need to pay certain amount of money, people can get benefits of less traffic and better transportation environment.

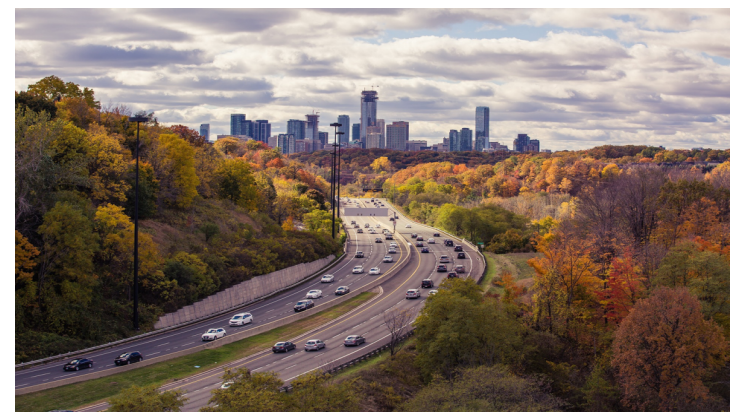

Motivations, $\quad$ What if your design restricts users to attain their original goals? goals, and outcomes: 3)

Example: Some online games restrict players from spending too much time in playing without taking a pause.

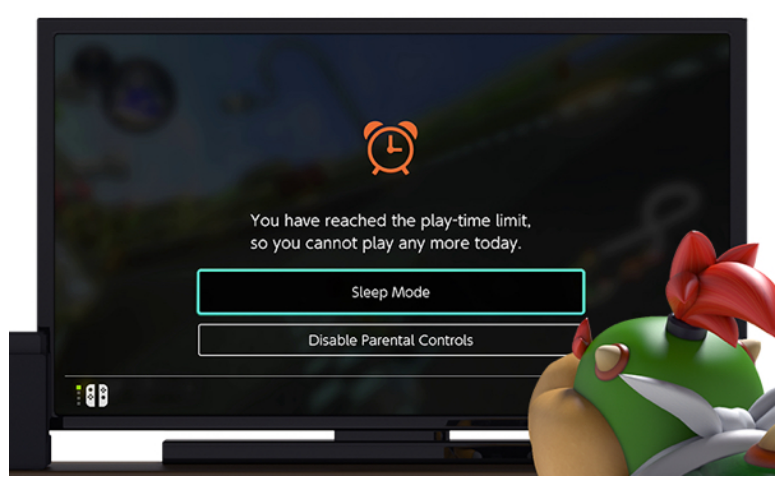


Motivations, goals, and outcome: 4 )
Can you design some features to turn the activity outcome into a winwin situation?

Example: When people need to send gifts to friends, they can choose to purchase charitable gifts on UNICEF website, and then send the gifts to poor children in the name of your friends. Your friends will receive the gift card.

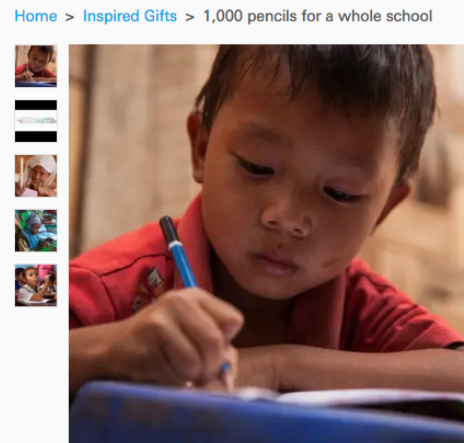

Product ID: S4460701

\section{1,000 pencils for a} whole school

Delivery Details

\section{IN STOCK}

What are inspired gifts?

These are charitable gifts you can give to children in the name of friends or loved ones.

\section{LEARN MORE}

Motivations, goals, and outcome: 5)
Are there any unexcepted user goals or needs that may become attainable through your design?

Example: Users use aluminum food as containers for growing plants.

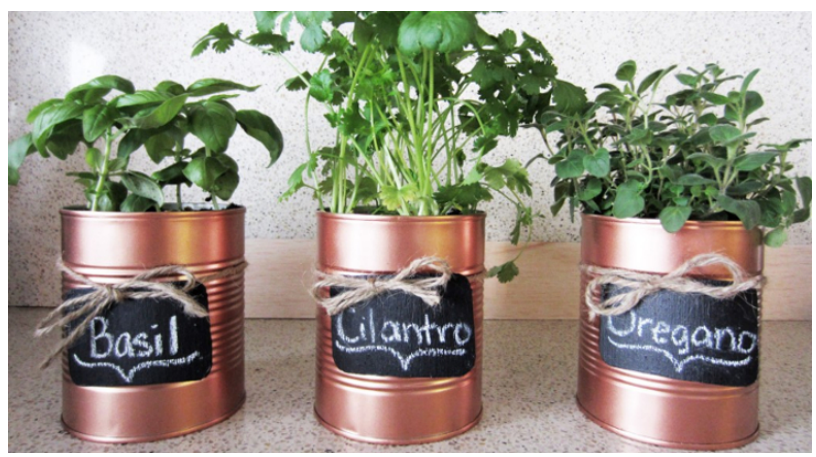


Socio-cultural context settings: 1)
Can you predict the potential technology advancement that would take place in the current society, and then can you incorporate the technology in your design?

Example: More stores started to use automatic self-check-out system. This system brings the customers conveniences and solved check-out time, space, and labor issues.

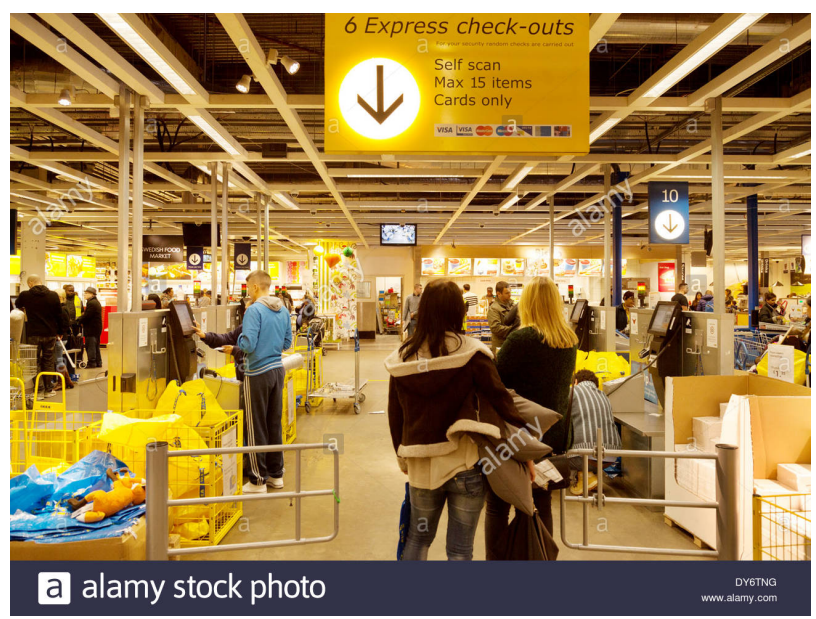

Socio-cultural Can you identify any social and environmental concerns within the context settings: 2) user activity system that you want to facilitate or avoid through your design?

Example: This soymilk packaging presents the benefits of plant power, thus telling consumers how the product can benefit both their own health and the environment.

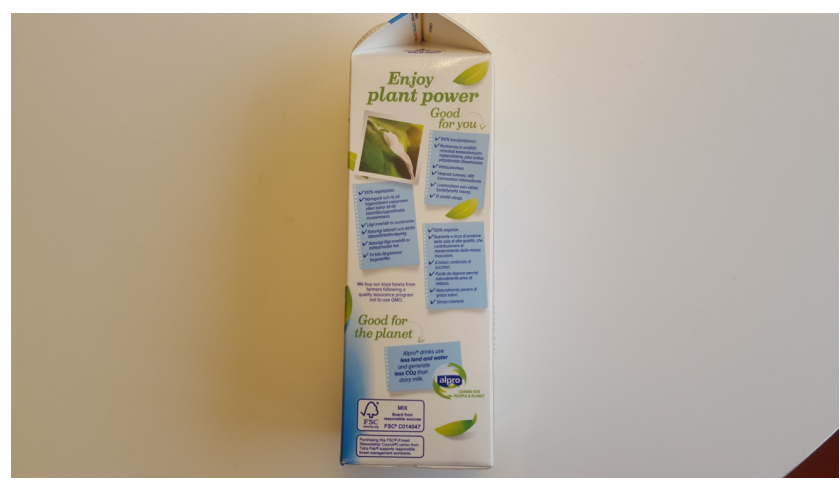


Socio-cultural context settings:

3)

Example: In Eastern culture, chopsticks are commonly used as the tools for eating, while in Western culture, people prefer to use forks and knifes.
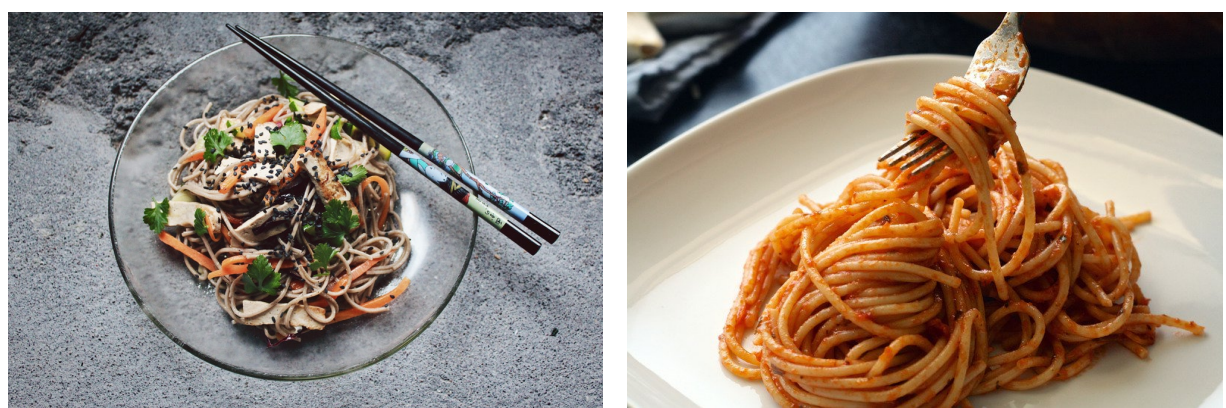

Socio-cultural context settings:

4)

Example: These helmet umbrellas allow users to walk in windy and crowded city area.

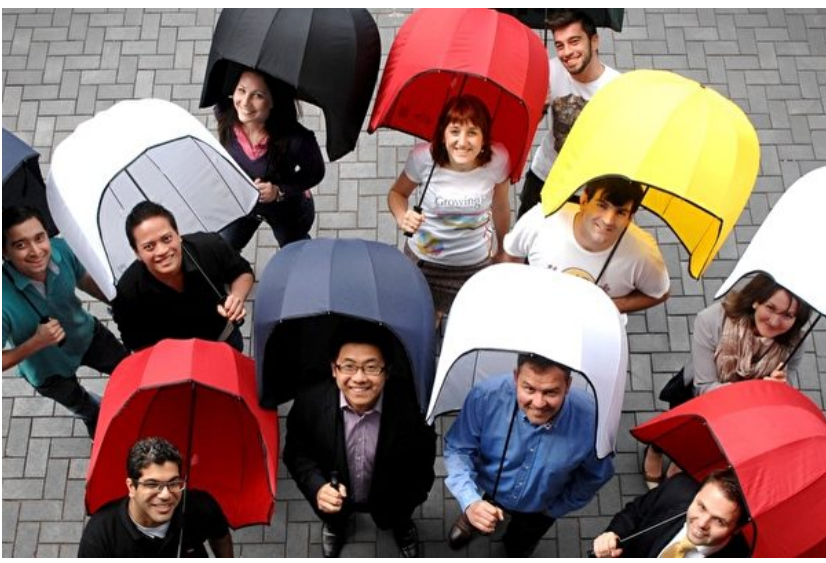




\section{Socio-cultural context settings: \\ 5) \\ What if your design aims at making the target activity easy to collaborate?}

Example: When checking-out, POS system used in supermarkets or restaurants enables customers to collaborate with salesclerks in a more efficient way.

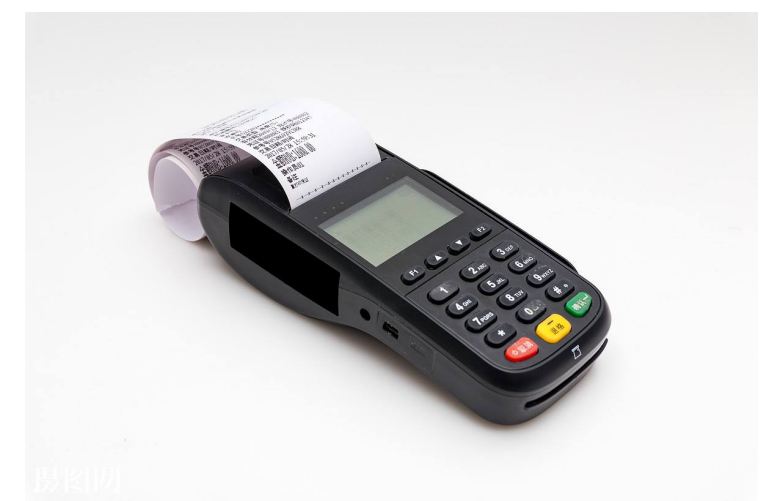

Mediating What if you design a completely new way to help users attain their original tools: 1) goals?

Example: Automatic parking system helps drivers to park their car into a parking spot with enhanced safety and less mental effort.

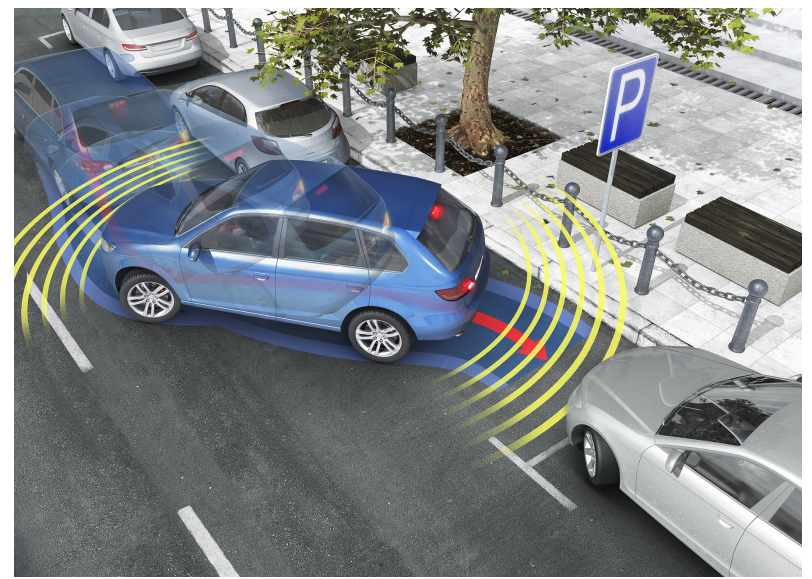


Mediating What would happen if your design is flexible and easy to be adapted to tools: 2) different scenarios of the target activity?

Example: Android phone operation system has a "one-handed" mode, which suits the usage scenario in which users' hands are occupied with something.

ADVANCED FEATURES
Smart stay
Keep the screen on while you're
looking at it.
Games
Manage useful features while you play
games.
One-handed mode
Button
Quick launch Camera
Open Camera by pressing the Home
key twice in quick succession.
Multi window
Show more than one app at the same time.
Smart capture
Include hidden areas of the screen
in your screenshots. You can also
edit or share screenshots after
you take them.

Mediating Can you design some features which support multiple actions which users tools: 3) usually perform within the target activity?

Example: Most of the flight ticket booking systems provide seat selection and food preferences function, so that customers can pre-order relevant services when purchasing the tickets.

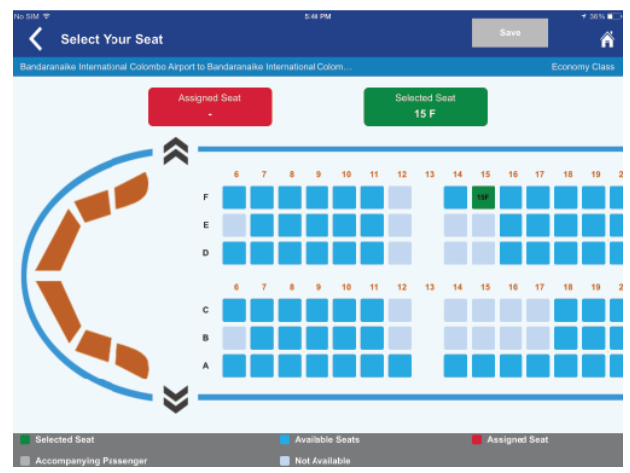


Example: when using this dish washer, there is no way to designate a specific area in the dish washer to be cleaned.

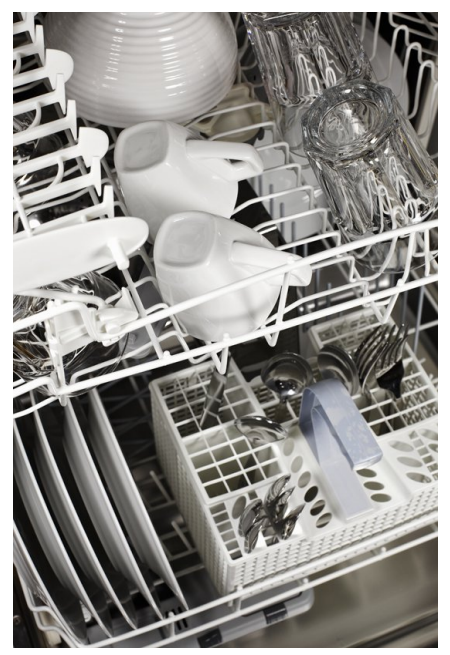

Contradictions and tensions: 2)
Are there any user needs or goals that can not supported by the tools at hand, so that users have to find some other supportive tools to carry out the target activity?

Example: Unfortunately, if users want to connect a USB or HDMI cable to a New MacBook computer, they have to use an adapter.

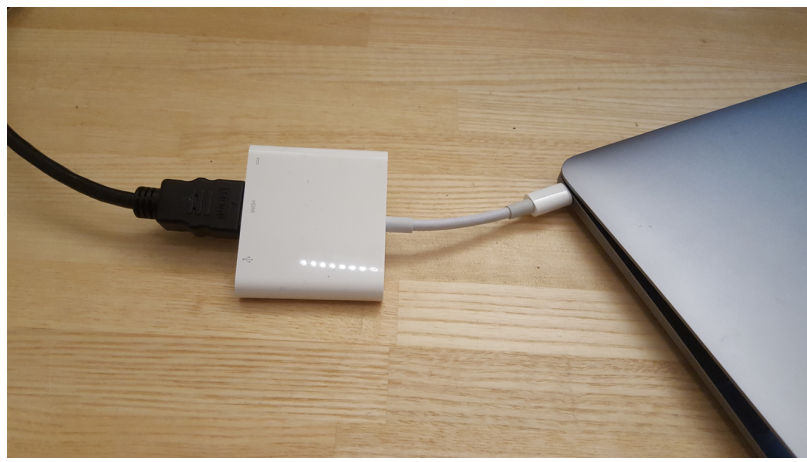


Example: Google Map usually presents several available choices to users, with information of duration, distance, and current traffic condition.

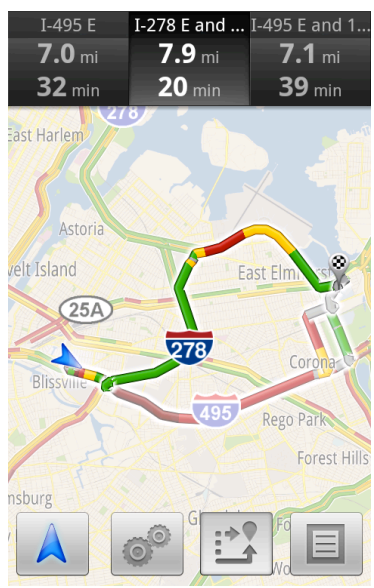

Internalization and Can you use metaphors to guide users' target activity in your design? externalization: 1)

Example: The car fuel gauge uses a gas station sign to indicate when to refuel. Similarly, online stores often use a cart sign to indicate where to check-out.
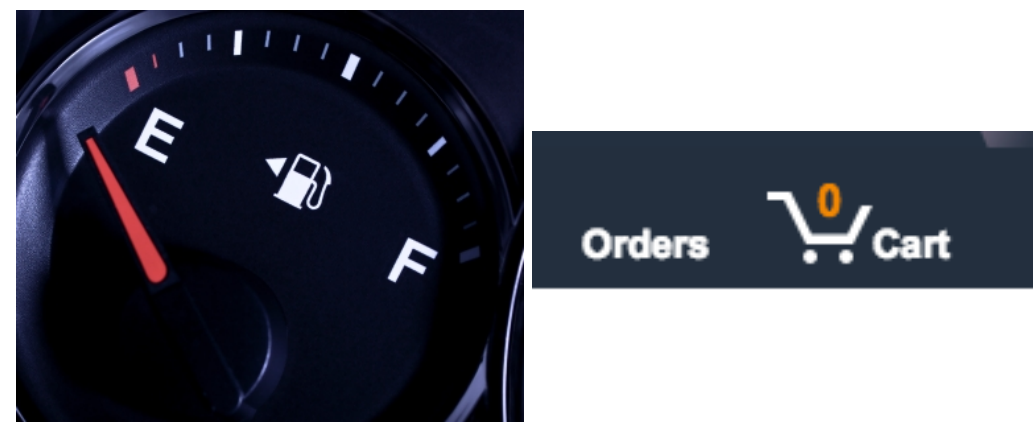
Internalization and $\mid$ Can you design some features which can help users to transit their externalization: 2) planning to actual performance?

Example: Shopping list is commonly used as a planning tool for shopping activities.

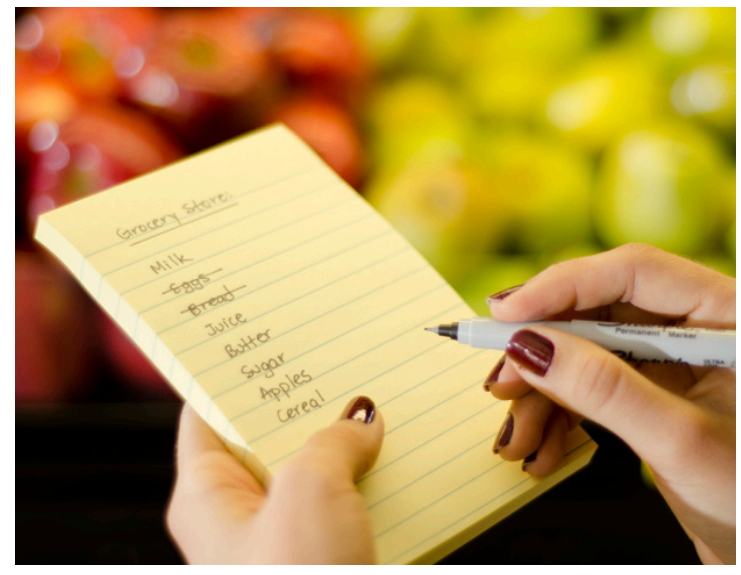

Internalization and Can you design some features so that user is willing to learn how to externalization: 3) use your design even it requires lots of efforts and time?

Example: It takes a lot of efforts to learn how to ride a bike in the beginning, but once you have gained the skills, biking can make your transportation much more convenient and fun.

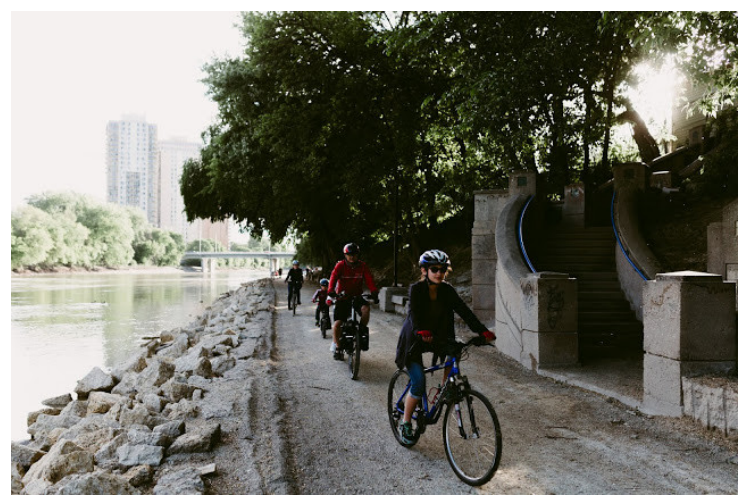


History and Can you design some features so that users can immediately recognize development: 1) how to use the design based on their past experience?

Example: The design of stair climbers and its working mechanisms are inspired by daily life practices.

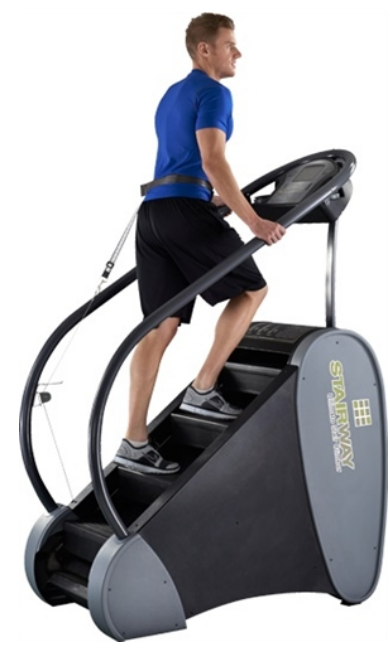

History and

Can you predict the potential changes in the target activity based on how development: 2) it has been developed in the history?

Example: The design of music devices has gone through significant changes, however some of the features, like ear phone plug-in still remains in nowadays' products.
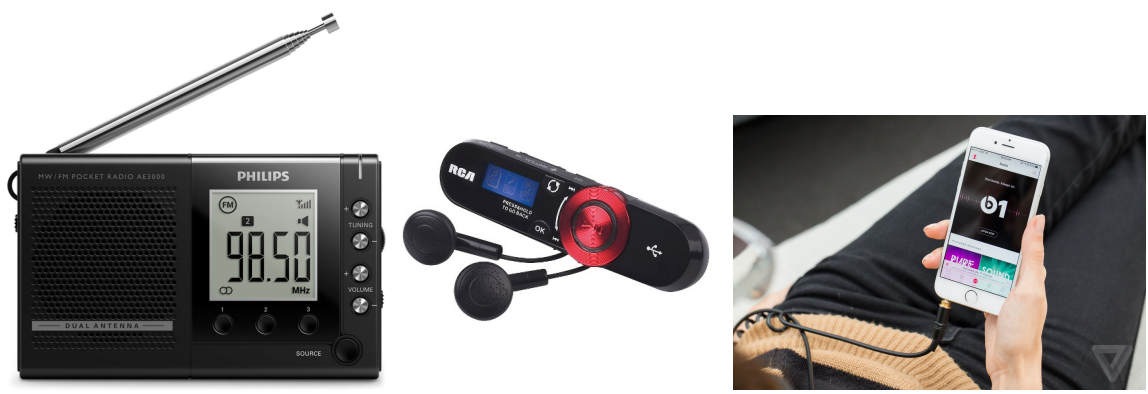
History and development: 3)

What if your design can support the transformation of users' current activity into a future one?

Example: VR toolkits support the transformation of paper sketching into 3D sketching.

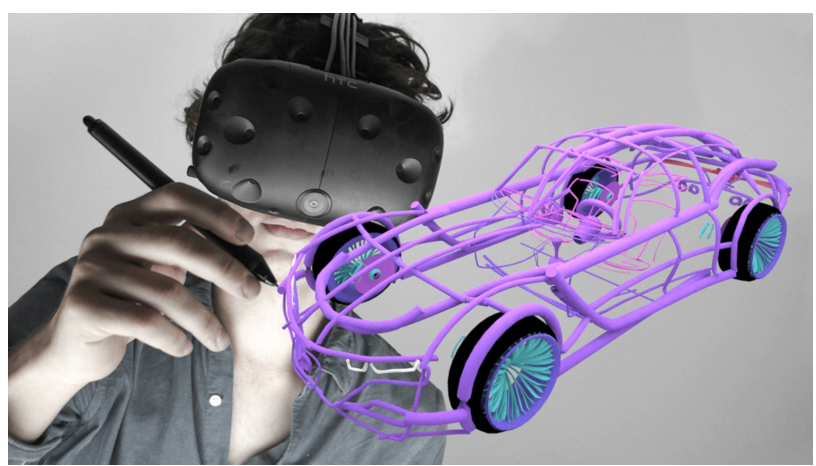

History and $\mid$ Can you adopt some design features from the old tools which were development: 4) previously used in the user target activities to your current design?

Example: In order to not interrupt users' typing flow, the modern computer keyboard follows the same layout of the old typewriter.
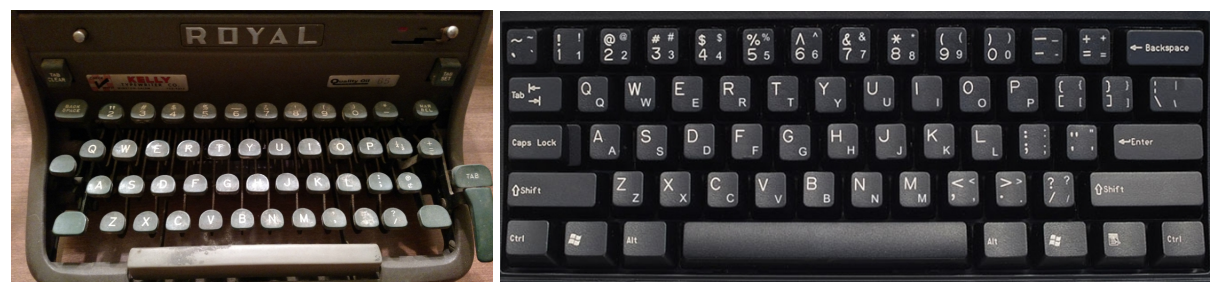

History and development: 5)

What are the potential changes that you aim to achieve/avoid in users' target activity systems? Can your design induce/prevent such changes? 


\section{Papers}

The papers associated with this thesis have been removed for copyright reasons. For more details about these see:

http://urn.kb.se/resolve?urn=urn:nbn:se:liu:diva-172011 


\section{FACULTY OF SCIENCE AND ENGINEERING}

Linköping Studies in Science and Technology, Dissertation No. 2115, 2021

Department of Management and Engineering

Linköping University

SE-581 83 Linköping, Sweden

www.liu.se
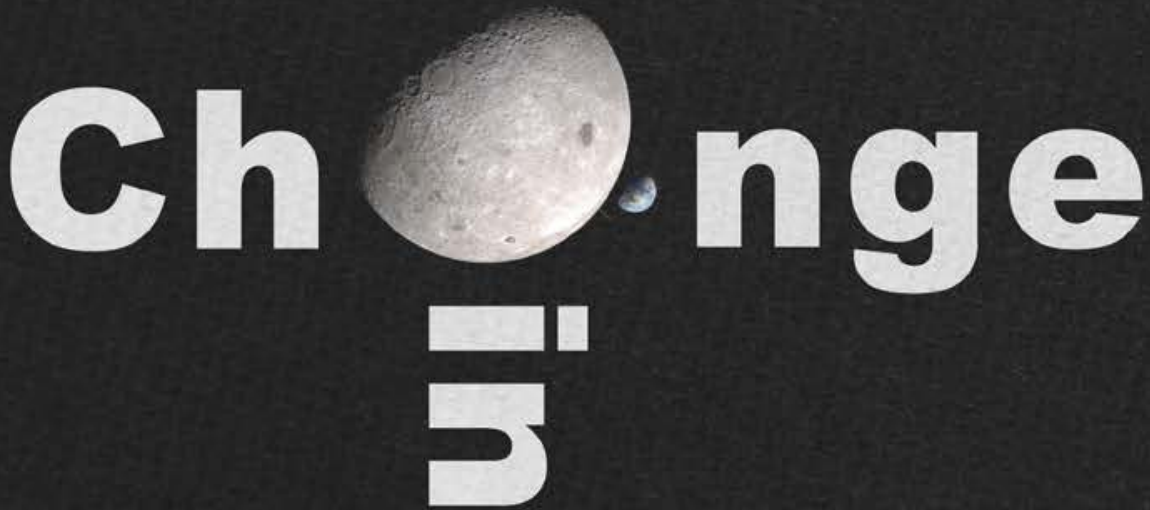

\section{(1)}

